\title{
Freeze-Thaw Durability and Digital Hardened Air Void Analysis of Self Consolidating Concrete
}

\author{
Bryan M. Surface \\ West Virginia University
}

Follow this and additional works at: https://researchrepository.wvu.edu/etd

\section{Recommended Citation}

Surface, Bryan M., "Freeze-Thaw Durability and Digital Hardened Air Void Analysis of Self Consolidating Concrete" (2013). Graduate Theses, Dissertations, and Problem Reports. 5005.

https://researchrepository.wvu.edu/etd/5005

This Thesis is protected by copyright and/or related rights. It has been brought to you by the The Research Repository @ WVU with permission from the rights-holder(s). You are free to use this Thesis in any way that is permitted by the copyright and related rights legislation that applies to your use. For other uses you must obtain permission from the rights-holder(s) directly, unless additional rights are indicated by a Creative Commons license in the record and/ or on the work itself. This Thesis has been accepted for inclusion in WVU Graduate Theses, Dissertations, and Problem Reports collection by an authorized administrator of The Research Repository @ WVU. For more information, please contact researchrepository@mail.wvu.edu. 


\title{
Freeze-Thaw Durability and Digital Hardened Air Void Analysis of Self Consolidating Concrete
}

\author{
Bryan M. Surface
}

Thesis / Dissertation submitted to the College of Human Resources and Education

at West Virginia University in partial fulfillment of the requirements

for the degree of

Master of Science

in

Civil Engineering

\section{Roger Chen Ph. D., Chair}

Felicia Peng, Ph. D.

Fei Dai, Ph. D.

Antarpreet Jutla, Ph. D.

Department of Civil and Environmental Engineering

\author{
Morgantown, West Virginia \\ 2012
}

Keywords: Self-Consolidating Concrete; Air Voids; Air Void Analysis; Durability; Freeze Thaw 


\begin{abstract}
Freeze-Thaw Durability and Digital Hardened Air Void Analysis of Self Consolidating Concrete
\end{abstract}

Bryan M. Surface

The use of Self Consolidated Concrete in West Virginia is very limited. The freeze-thaw durability of Self Consolidated Concrete must be validated to ensure longevity of Self Consolidated Concrete structures used for construction in West Virginia.

Researchers at West Virginia University worked with WVDOH in constructing a bridge using 3 SCC prestressed, precast box beams and 3 traditional concrete prestressed, precast box beams. Upon freeze-thaw testing of concrete prisms, the SCC concrete mix was found to have very low freeze-thaw durability. The mix design for the SCC was replicated twice in the laboratory. For both batches, the effects of steam curing vs. traditional moist curing were observed. Hardened air void analysis was digitally performed using a flat-bed scanner and two programs. The first program used Adobe Photoshop and was developed by Michigan Tech University, and the second program was developed in the WVU laboratory and uses MATLAB. Both batches of laboratory SCC had fresh air contents below the air content of SCC used in the bridge.

Air void analysis showed that none of the specimens had acceptable air void structure. In freeze-thaw testing, almost all of the laboratory SCC specimens failed. The steam-cured specimens from the second batch successfully survived freeze-thaw testing. The failure of the SCC specimens in freeze-thaw testing shows the need for a proper air void structure in SCC as well as traditional concrete. Analysis of the air void structure of concrete can be used to predict freeze-thaw durability without the need for performing the time-consuming and expensive freeze-thaw test. 


\section{ACKNOWLEDGMENTS}

I am grateful for the many people who contributed to the work in this thesis. My advisor, Dr. Roger Chen, is responsible for giving me the basis for my Masters degree and for giving me guidance throughout my research. I would also like to thank the members of my committee, Dr. Felicia Peng, Dr. Fei Dai, and Dr. Antarpreet Jutla for agreeing to review my work and provide constructive criticism.

The West Virginia Division of Highways was directly responsible for the funding of this project. Special thanks to the employees of Greer Limestone, BASF Chemicals, Roanoke Cement, and Eastern Vault for donating the necessary materials for my research.

I am extremely grateful for the assistance and instruction given by my colleagues Joseph Sweet, Alper Yikici, Yun Lin, and Susana Rojas. Their instruction, experience, and guidance were a tremendous help in conducting my research. Finally, I would like to thank my family and friends for their unconditional support during my entire collegiate career. 


\section{TABLE OF CONTENTS}

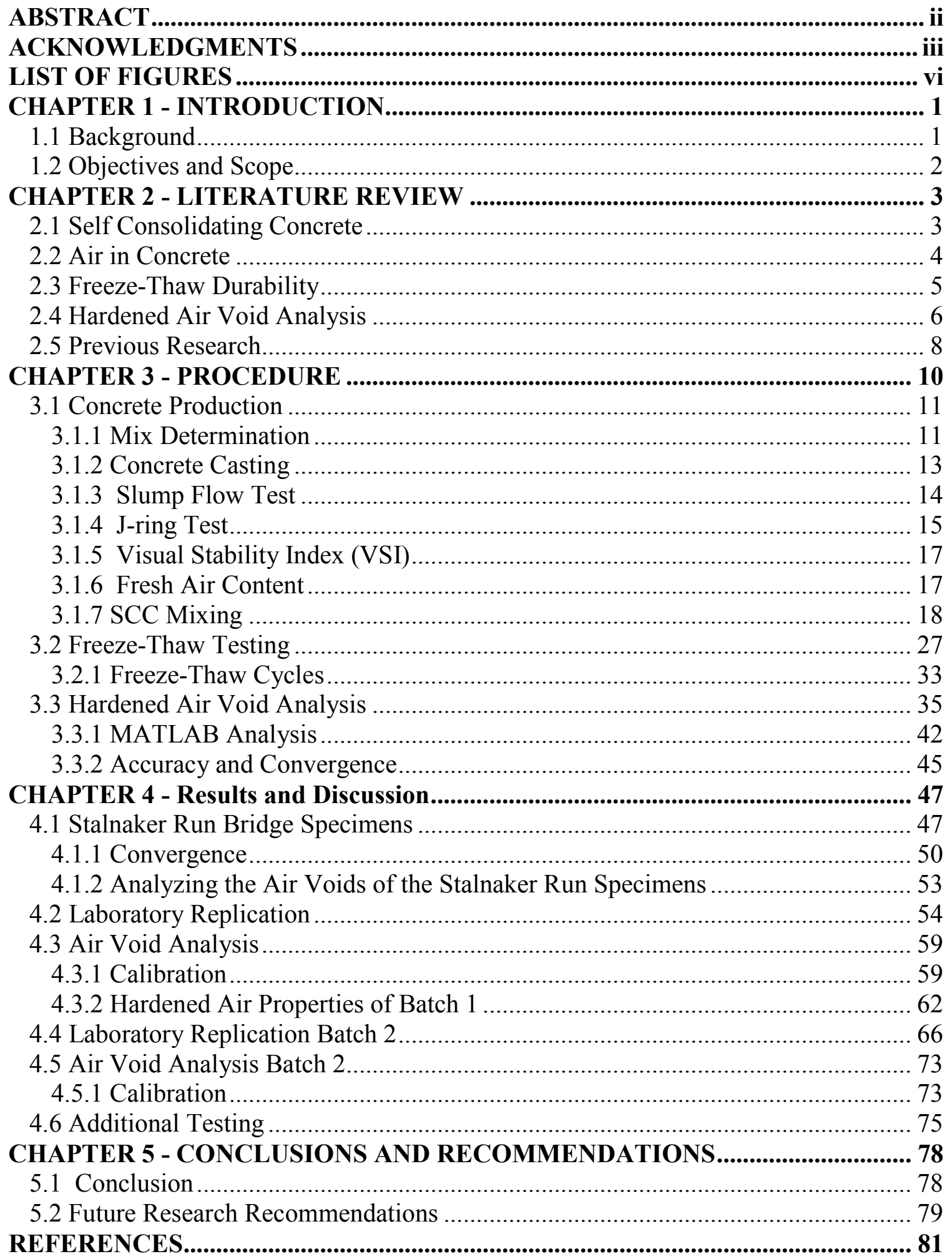




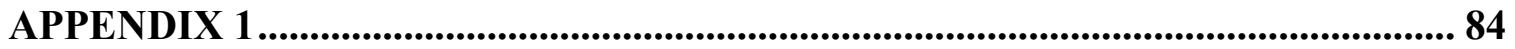

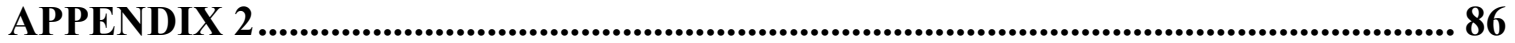

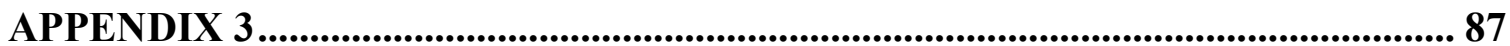




\section{LIST OF FIGURES}

Figure 2.01 - Previous Freeze-thaw Results...............................................................13

Figure 3.01 - J-Ring Schematic (ASTM C1621 - 2009a) …………………………..... 15

Figure 3.02 - Example of J-Ring and Slump Cone (ASTM C1621 - 2009a) .................. 16

Figure 3.03 - Type B Air Meter Schematic (ASTM C231 - 2009b) ............................... 18

Figure 3.04 - SCC in Mixer …………………………................................... 20

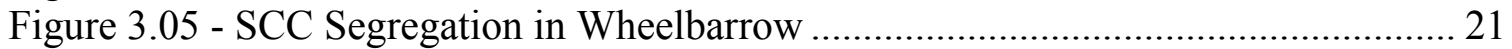

Figure 3.06 - Slump Flow of SCC Batch 1 ............................................................... 21

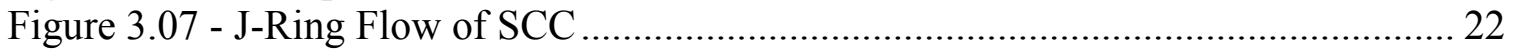

Figure 3.08 - Fresh Freeze-Thaw Prisms ................................................................... 24

Figure 3.09 - Wrapped Specimens for Steam Curing ...................................................... 26

Figure 3.10 - Ideal Cylinder Failures (ASTM C39 - 2012) …………………………..... 27

Figure 3.11 - Transverse Frequency Schematic (ASTM) …………………………….... 29

Figure 3.12 - Impact Resonance Schematic (ASTM) …………………………............. 29

Figure 3.13 - Setup for Transverse Frequency Test.................................................. 30

Figure 3.14 - LabVIEW Frequency Test Outputs........................................................ 31

Figure 3.15 - Longitudinal Resonant Frequency Test Setup …………………………..... 32

Figure 3.16 - Freeze-Thaw Specimens in Test Chamber............................................. 34

Figure 3.17 - Struers Polisher with Specimen ............................................................ 36

Figure 3.18 - Example of Acceptable Polished Concrete Surface.................................... 37

Figure 3.19 - Prepared Specimen for Air Void Analysis................................................ 38

Figure 3.20 - Dialog Box for Bubble Counter ............................................................ 41

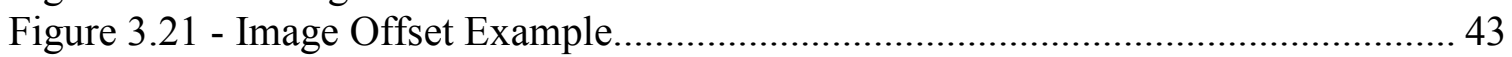

Figure 3.22 - Example of 60 horizontal traverses used in MATLAB ………………..... 44

Figure 3.23 - Example of 60 vertical traverses used in MATLAB.................................. 45

Figure 4.04 - Magnified Sample of Traditional Concrete Image....................................... 49

Figure 4.05 - Percent Difference in Air Content........................................................... 52

Figure 4.06 - Percent Difference in Bubble Distribution Slope........................................ 52

Figure 4.07 - Air Temperature Readings for 30 Cycles of Freeze-Thaw ......................... 58

Figure 4.08 - Dynamic Modulus Using Longitudinal Frequency...................................... 58

Figure 4.09 - Dynamic Modulus Using Transverse Frequency ...................................... 59

Figure 4.10 - Difference in MATLAB and Bubble Counter with Varying Thresholds Trial

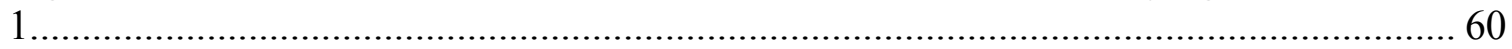

Figure 4.11 - Difference in MATLAB and Bubble Counter with Varying Thresholds Trial

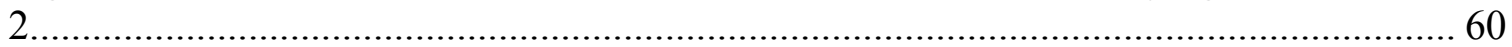

Figure 4.12 - Difference in Spacing Factor of Vertical vs. Horizontal in MATLAB....... 61

Figure 4.13 - Difference in Specific Surface of Vertical vs. Horizontal in MATLAB ... 62

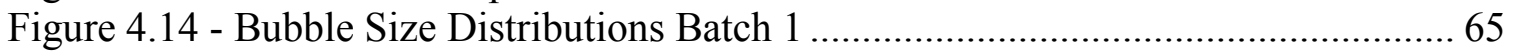

Figure 4.15 - Temperature of Steam Curing Water ....................................................... 68

Figure 4.16 - Air Temperature of Freeze-Thaw Cycles................................................... 69

Figure 4.17 - Dynamic Modulus Using Transverse Frequency ....................................... 70

Figure 4.18 - Dynamic Modulus Using Longitudinal Frequency ...................................... 70

Figure 4.19 - Cracking after 180 cycles on TC1 ……………..................................... 71 
Figure 4.20 - Mass Loss and Cracking after 180 Cycles on TC2 ................................. 71

Figure 4.21 - Major Mass Loss and Cracking after 180 Cycles on TC3 ....................... 72

Figure 4.22 - Effect of Threshold on MATLAB Accuracy Trial 1 ................................. 73

Figure 4.23 - Effect of Threshold on MATLAB Accuracy Trial 2 ................................ 74

Figure 4.24 - Extended Freeze-Thaw Testing for Batch 1........................................... 76

Figure 4.25 - Extended Freeze-Thaw Testing for Batch 2 ....................................... 77 


\section{LIST OF TABLES}

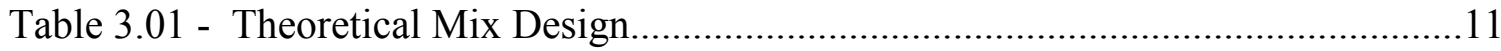

Table 3.02 - Adjusted Weight Values Used................................................................ 19

Table 3.03 - Minimum Total Length of Traverses (ASTM C457) ..................................

Table 4.01 - Horizontal vs. Vertical Traverse Comparisions............................................51

Table 4.02 - Air Void Properties of Stalnaker Run Concrete...........................................53

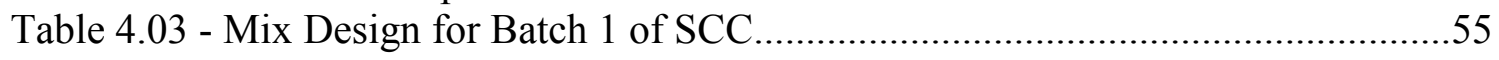

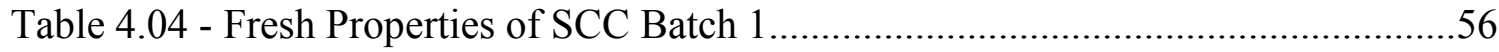

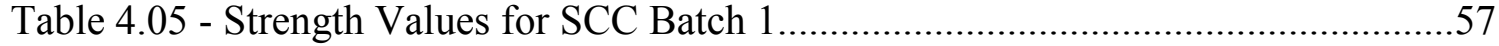

Table 4.06 - Hardened Air Results for Steam Cured Specimen......................................63

Table 4.07 - Hardened Air Void Properties for Most-Cured Specimen...........................63

Table 4.08 - Mix Design Used for Batch 2 ...................................................................66

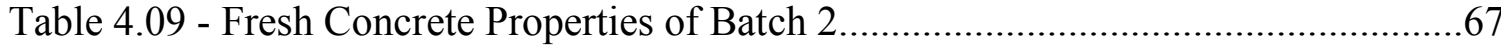

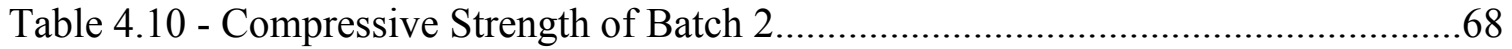

Table 4.11 - Hardened Air Void Properties for Traditionally Cured Specimen................ 74

Table 4.12 - Hardened Air Void Properties for Steam Cured Specimen..........................74 


\section{CHAPTER 1 - INTRODUCTION}

\subsection{Background}

Self Consolidating Concrete (SCC) was developed in the late 1980s for the purpose of simplifying concrete placement and preventing segregation (Ouchi 2003). SCC, unlike conventional concrete, does not need to be vibrated when placed. The lack of vibration eliminates the need for extra workers and reducing the chance of segregation due to improper vibrating techniques.

SCC uses high range water reducers to create a concrete mix with low viscosity. Also, to promote the flowability of the SCC, the coarse aggregate selected for SCC mixes are traditionally smaller than standard concrete. As a result of lower water cementitious materials ratio, $\mathrm{SCC}$ is capable of producing high strength concrete. Even though SCC has been implemented for over twenty years, research on the durability of SCC when exposed to freeze-thaw conditions is limited.

Air entrained in concrete improves the concrete freeze-thaw durability by allowing water in capillary pores to expand into the voids when the water freezes. In concrete with low air content, the water in the pores freezes and expands. This expanding force creates tensile forces within the concrete and breaks it down. ASTM simulates the freezing and thawing of water in concrete in ASTM C666 (2003).

All concrete mixes have some degree of air voids as a result of mixing and placing. Air voids in concrete improve several desirable properties of the concrete. These properties include increased workability, decreased density, improved durability, 
and reduced bleeding and segregation (Nawy 2008). Nawy also states that the optimum air content for concrete mortar is $9 \%$. Air contents this high are achieved by using air entraining admixtures in the concrete mix. The air content of concrete is so important to the freeze-thaw durability of concrete that State Divisions of Highways have requirements for the minimum air content in concrete mixes.

However, the increased air content has certain disadvantages. Increased air content lowers concrete density and, in return, reduces the strength. Hover 2006 states that a $1 \%$ air content increase results in an approximate $3-5 \%$ reduction in compressive strength. Hover also makes the correlation between air-entrained concrete and blistering of concrete slabs finished by a steel trowel. Despite these drawbacks, air entrainment has a significant benefit to concrete exposed to freezing temperatures.

\subsection{Objectives and Scope}

The objectives include the following: establishing a correlation between hardened air void structure and freeze-thaw durability, and testing the effects of steam curing on freeze-thaw durability of SCC. The scope of the research also includes the determination of freeze-thaw durability of some SCC specimens obtained in the field as well as batches cast in a laboratory setting. 


\section{CHAPTER 2 - LITERATURE REVIEW}

\subsection{Self Consolidating Concrete}

Self consolidating concrete was developed in Japan in the 1980s. The goal of SCC development was to create a concrete capable of flowing freely through forms with highly congested reinforcement. Seismically active regions require large amounts of reinforcement, and effectively vibrating conventional concrete into such forms is extremely difficult. Self consolidating concrete solves this problem by freely flowing into concrete forms and around reinforcement without needing any vibration. SCC has additional benefits to contractors, including fewer labor demands and a better work environment. Since SCC does not need vibration, it eliminates the need for extra labor personnel to vibrate the concrete into place, and the lack of vibration makes SCC less labor-intensive and less physically taxing.

Because of the vast difference of SCC from traditional concrete, additional standards must be adopted to ensure quality and consistency. SCC must be capable of moving through reinforcing steel without segregation. SCC must also show no signs of segregation as it passes through concrete forms. SCC must also be nonviscous enough to eliminate the need for vibration. RILEM summarizes these needs with three main requirements: filling ability, passing ability, and resistance to segregation (Skarendahl 2006).

Filling ability refers to the "Complete filling of formwork and encapsulation of reinforcement and inserts." Passing ability is defined as the "Passing of obstacles such as 
narrow sections of the formwork, closely spaced reinforcement etc. without blocking caused by interlocking of aggregate particles." Resistance to segregation is defined as "Maintaining of homogeneity throughout mixing and during transportation and casting" (Skarendahl 2006).

Quality assurance tests that are easily performed in the field are necessary to ensure quality and consistency, and SCC constitutes a need for new, specific tests.

Few studies have been performed concerning the freeze-thaw durability of SCC compared with the durability of standard concrete. A study by Hameed in 2005 concluded that SCC yielded more durable concrete than standard. This study was done in Saudi Arabia with significantly different types of aggregate, which may have a profound effect on the freeze-thaw durability. SCC made from aggregates native to West Virginia would provide more relevant results to the West Virginia Division of Highways (WVDOH) and give a more accurate analysis of the durability of SCC made in West Virginia.

\subsection{Air in Concrete}

Air is present in every concrete mixture. The air bubbles in concrete are a result of air present in and around the dry aggregates, dissolved air in the mix water, air trapped by placing concrete into forms, and air mixing in due to the action of mixing concrete (Hover 2006).

Air entrained in concrete has many beneficial effects to the overall performance of the concrete. Entrained air can act as a lubricant for the aggregates in the concrete, 
increasing workability. The reduction in workability can allow for a lower water/cementitious materials ratio, giving a higher strength mix. Also, Hover states that air-entraining chemical admixtures can reduce segregation, settlement, and bleeding. This increased cohesion is caused by microscopic air bubbles being attracted to grains of Portland cement.

Concrete without any chemical admixtures contains air. However, the percentage by volume of air in concrete without chemical admixtures is relatively low. The percentage by volume of air in a concrete mix, known as air content, can be increased from $1-3 \%$ in non-air entrained concrete to more than $5 \%$ using a chemical admixture. The discovery of air entraining admixtures originated in the 1930's by the Universal Atlas Cement Company. The company experimented with adding grease into the cement during crushing, and the result was a much more durable concrete. After the success, UACC then experimented with multiple additives to increase air content, and one of which was vinsol resin. Vinsol resin is an air entraining admixture that is still used in the concrete industry today (Carlson 2005).

\subsection{Freeze-Thaw Durability}

The durability of concrete in conditions of freezing and thawing is extremely important where concrete in exterior applications is exposed to such cycles. These cycles of freezing and thawing are experienced during the winters in the northern United States and in many other countries that experience freezing temperatures in winter. Damage 
caused by freeze-thaw cycles can lead to reinforcement corrosion and, in severe cases, catastrophic breakdown of the concrete structure.

The air void structure in concrete is the most important factor in freeze-thaw durability. Powers conducted a comprehensive study of concretes containing varying spacing factors. The conclusion of the test was that the spacing factor of the air void structure had a major effect on the freeze thaw durability of the concrete. Powers in 1994 concluded that a spacing factor of $0.01 \mathrm{in} .(0.254 \mathrm{~mm})$ provided the concrete with acceptable freeze thaw durability. ASTM C457 (2011) recommends a maximum spacing factor of 0.008 in. $(0.2 \mathrm{~mm})$.

\subsection{Hardened Air Void Analysis}

Hardened air void analysis following ASTM C457 (2011) has been proven to estimate the freeze thaw durability of a concrete mix. Performing the linear traverse method manually using a microscope is very tedious and subject to human error. Concrete Experts International (CEI) estimates that manually conducting the linear traverse method requires 4-6 hours. Variations of the test using digital methods have been proposed. An apparatus developed by CEI called RapidAir 457 automates the linear traverse method by using a digital camera and a computer to analyze the specimen instead of using a microscope. The digital camera moves across the specimen in parallel lines in the same way the microscope would. RapidAir requires only 12 minutes to conduct the linear traverse method. Jakobsen et al conducted a round robin study of the RapidAir system compared to the manual linear traverse. Seven laboratories conducted 
the manual linear traverse test and the RapidAir test. The conclusion of the round robin study was that RapidAir showed very impressive repeatability and was comparable with the manual method. In fact, the RapidAir system showed smaller variations between the laboratories than the manual method, meaning the RapidAir system is more dependable than using the manual microscope.

The RapidAir apparatus is expensive and can be cost-prohibitive for research. Numerous methods have been developed using a traditional flat-bed scanner readily available in any office. Methods using standard flat-bed scanners take a digital image of the prepared specimen, and use a computer program to digitally perform the linear traverse method on the scanned image. Jana conducted a round robin test of ASTM C457 (2011) comparing RapidAir, the flat-bed scanner method, and other various analysis methods. Jana concluded that every method used, including the flat-bed scanner method, could accurately determine the air void structure of the concrete sample. In fact, the flatbed scanner method had the highest correlation with the RapidAir system of all the other methods tested.

A computer program using a scanned image from a flat-bed scanner was developed for the Wisconsin Department of Transportation by Michigan Tech University. The program, called Bubble Counter, uses a digital TIFF image of 3200 pixels per inch (dpi). In Adobe Photoshop, the program operates as a script, opening a prompt. The program then outputs a csv file with parameters including bubble size distribution, void frequency, spacing factor, specific surface, and air content. 


\subsection{Previous Research}

As part of a comprehensive research project, $\mathrm{SCC}$ was used to construct three prestressed, precast box beams for the Stalnaker Run Bridge in Elkins, West Virginia. The mix design was developed by a combination of WVU researchers and representatives of the BASF chemical company. BASF specializes in admixtures, and because SCC requires careful proportioning of multiple admixtures, BASF's expertise was required. The SCC was then batched by Central Supply Company for use in 3 prestressed, precast box beams. Alongside the 3 SCC beams, 3 beams of the exact same dimensions were cast using traditional concrete.

The beams were steam cured and the internal temperature of the beams was measured. The beams reached a maximum temperature of $150^{\circ} \mathrm{F}$.

Freeze thaw prisms were cast for both the SCC beams and the traditional concrete beams. The prisms were steam cured along with the bridge beams. These beams were tested at private laboratory for freeze thaw durability. The results shown in the graph below indicate that the SCC performed poorly in freeze thaw testing, but traditional concrete performed very well. 


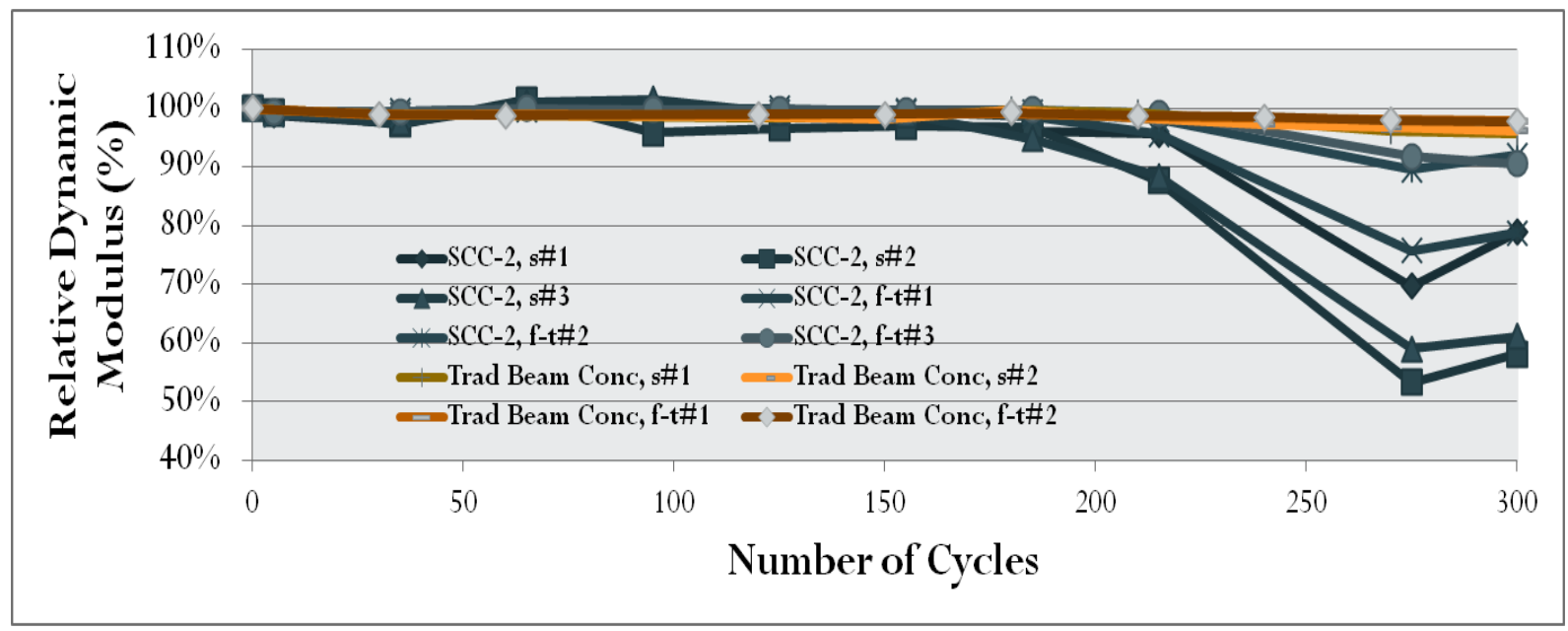

Figure 2.01 - Previous Freeze-thaw Results 


\section{CHAPTER 3 - PROCEDURE}

The concrete mix design used for Self Consolidating Concrete (SCC) in the precast, prestressed concrete beams in the Stalnaker Run Bridge was replicated in the laboratory. The SCC used in the bridge was tested for freeze-thaw durability and underwent hardened air-void analysis. The mix was replicated using the same materials as the field mix. The objective is to compare the lab results of freeze-thaw durability and hardened air-void analysis with the concrete tested from the field.

Concrete was tested for fresh air content, freeze-thaw durability, hardened airvoid analysis, RCPT, compressive strength, shrinkage, and tensile strength. Fresh air content was measured using the pressurized air method. Freeze-thaw durability was tested according to ASTM C666 (2003) using 4 freeze-thaw slabs with dimensions $3 \times 4 \times 16$ in. One of these slabs had a thermocouple at the center to ensure that the temperature of the center of all specimens reached the target ASTM temperature range. Hardened air-void analysis requires 2 6x12 cylinders. RCPT requires $14 \times 8$ cylinder. Compressive strength was measured at 1 day, 2 day, and 28 days. Each compressive strength test requires $24 \times 8$ cylinders, with extras in case the strength difference is over $10 \%$.

The difference between steam curing and standard air curing was also monitored. Every test was done for steam cured specimens as well as normally cured, so the number of required specimens is doubled. 


\subsection{Concrete Production}

\subsubsection{Mix Determination}

The goal of laboratory casting of SCC was to reproduce the SCC that was used in the prestressed, precast bridge beams developed for the Stalnaker Run Bridge. To ensure accuracy, all of the materials used in the laboratory mix were from the same quarries and companies as the concrete used in the field.

Aggregate for the laboratory mix was delivered from the quarries in sealed 5gallon buckets. Therefore, the moisture present in the aggregate was preserved in transit to the laboratory.

For the first casting of SCC concrete in the laboratory, the theoretical mix approved by the WVDOH was closely followed. The mix used in the lab is in the table below.

\section{Table 3.01 - Theoretical Mix Design}

\begin{tabular}{|l|l|}
\hline Material & $\mathrm{lb} / \mathrm{yd}^{3}$ \\
\hline Cement & 735 \\
\hline Silica Fume & 75 \\
\hline \#67 Limestone & 1443 \\
\hline Natural Sand & 1327 \\
\hline Water & 284.0 \\
\hline HRWRA & 14.2 \\
\hline VMA & 1.85 \\
\hline AEA & 2.84 \\
\hline *in oz/CWT & \\
\hline
\end{tabular}

The mix was slightly modified in order to account for the moisture content of the aggregates. Moisture content of aggregates was found by following ASTM C556 Standard Test Method for Total Evaporable Moisture Content of Aggregate by Drying 
(2004). A sample of the natural silica sand was placed in a steel tray with a weight of $9.53 \mathrm{lb}$. The weight of the sand sample placed in the pan was $18.38 \mathrm{lb}$. The sand was evenly spread into the pan, and the pan was placed in an oven for approximately 5 hours, then the sand was mixed within the pan. The pan was placed again in the oven for an additional 15 hours. After the oven heating, the weight of the pan and sand was measured again. When the pan weight is subtracted, the weight of the sand was 18.36. To calculate the total evaporable moisture of the sand, the equation provided by ASTM C566 (2004) is as follows.

$$
p=\frac{100(W-D)}{D}
$$

Where:

$p=$ total evaporable moisture content of sample, as a percent

$W=$ mass of original sample

$D=$ mass of dried sample

Upon calculation, the percent of moisture content in the silica sand is $0.1 \%$. A sample of coarse aggregate was then weighed and tested using ASTM C566 (2004). After drying in the oven for over 18 hours, the coarse aggregate sample experienced no change in mass; the moisture content was $0 \%$.

The moisture content of aggregates used in concrete can have an effect on the water/cementitious materials $(\mathrm{w} / \mathrm{cm})$ ratio. The excess or lack of water present on the aggregates can unintentionally reduce or increase the $\mathrm{w} / \mathrm{cm}$ ratio, causing changes in concrete strength and workability. The amount of aggregate to be used in the mix as well as the amount of water used must be modified in order to produce the desired strength 
and workability. If the aggregate's moisture content is below the Saturated Surface Dry (SSD) condition, the aggregate will absorb water from the concrete into its pores. This absorbed water will take water from the hydration process and lower the $\mathrm{w} / \mathrm{cm}$ ratio. If the aggregate's moisture content is above the SSD condition, excess water is present on the aggregate and this water will increase the $\mathrm{w} / \mathrm{cm}$ ratio.

Both the \#67 limestone and the natural silica sand have SSD moisture content of $0.3 \%$, as provided by the quarries from which the aggregate originated. The coarse limestone aggregate had a moisture content of $0 \%$, therefore the mass of coarse aggregate used in the mix was reduced by $0.3 \%$ and the water needed was increased by $0.3 \%$ of the mass. The silica sand had a moisture content of $0.1 \%$, so the mass of sand was reduced by $0.1 \%$ and the water was increased by $0.2 \%$ of the mass of the sand.

\subsubsection{Concrete Casting}

Concrete in the laboratory was cast according to ASTM C192 (2012). The ASTM procedure mandates that for mixes of volume over $0.25 \mathrm{ft}^{3}$, a machine drum mixer must be used. To begin, coarse aggregate and a small amount of water are to be added into the drum. With the mixer turning, the fine aggregate, cement, and water is to be added to the drum. The mixer is allowed to be stopped in order to add the ingredients to the drum, if necessary. Once every ingredient is in the mixer, the concrete is to be mixed for 3 minutes. The concrete should rest for 2 minutes and mixed for another 2 minutes. After the mixing process, the concrete should be poured into a mixing pan to help prevent segregation. 


\subsubsection{Slump Flow Test}

SCC is inherently different than conventional concrete, so tests for controlling the quality and uniformity of traditional concrete must be modified to test SCC. As stated earlier, SCC should exhibit 3 qualities: filling ability, passing ability, and resistance to segregation. Modified tests for SCC should quantitatively test all 3 of these essential qualities.

Filling ability is measured using a variant of the standard slump test. ASTM C1611 is the Standard Test Method for Slump Flow of Self-Consolidating Concrete (2009b). The slump flow test uses the traditional slump cone and a rigid, non-absorbent base plate. The slump cone is placed in an inverted fashion with the smaller opening at the base plate and the larger opening at the top. Both the mold and the base plate are dampened before inserting the concrete. The inverted slump cone is then filled just over the top of the cone. The SCC should be placed in the slump cone continuously with no rodding or vibration. The concrete at the top of the cone is struck off with a strike-off bar and all concrete is removed from around the bottom of the cone. The cone is to be raised 6-12 inches over 2-4 seconds. Once the concrete stops flowing, two orthogonal diameters must be measured, and one diameter must be the largest observed diameter. The average of the two perpendicular diameters is defined as the slump flow of the SCC. 


\subsubsection{J-ring Test}

Passing ability is measured using the J-ring test, which is also a variant of the slump test. ASTM C1621 is the Standard Test Method for Passing Ability of SelfConsolidating Concrete by J-Ring (2009a). A slump flow cone is placed inverted onto a nonabsorbent base plate in the same fashion as the slump flow test. A steel J-ring is placed around the slump flow cone. The specifications and diagram of the J-ring according to ASTM C1621 are shown in Figure 3.01.
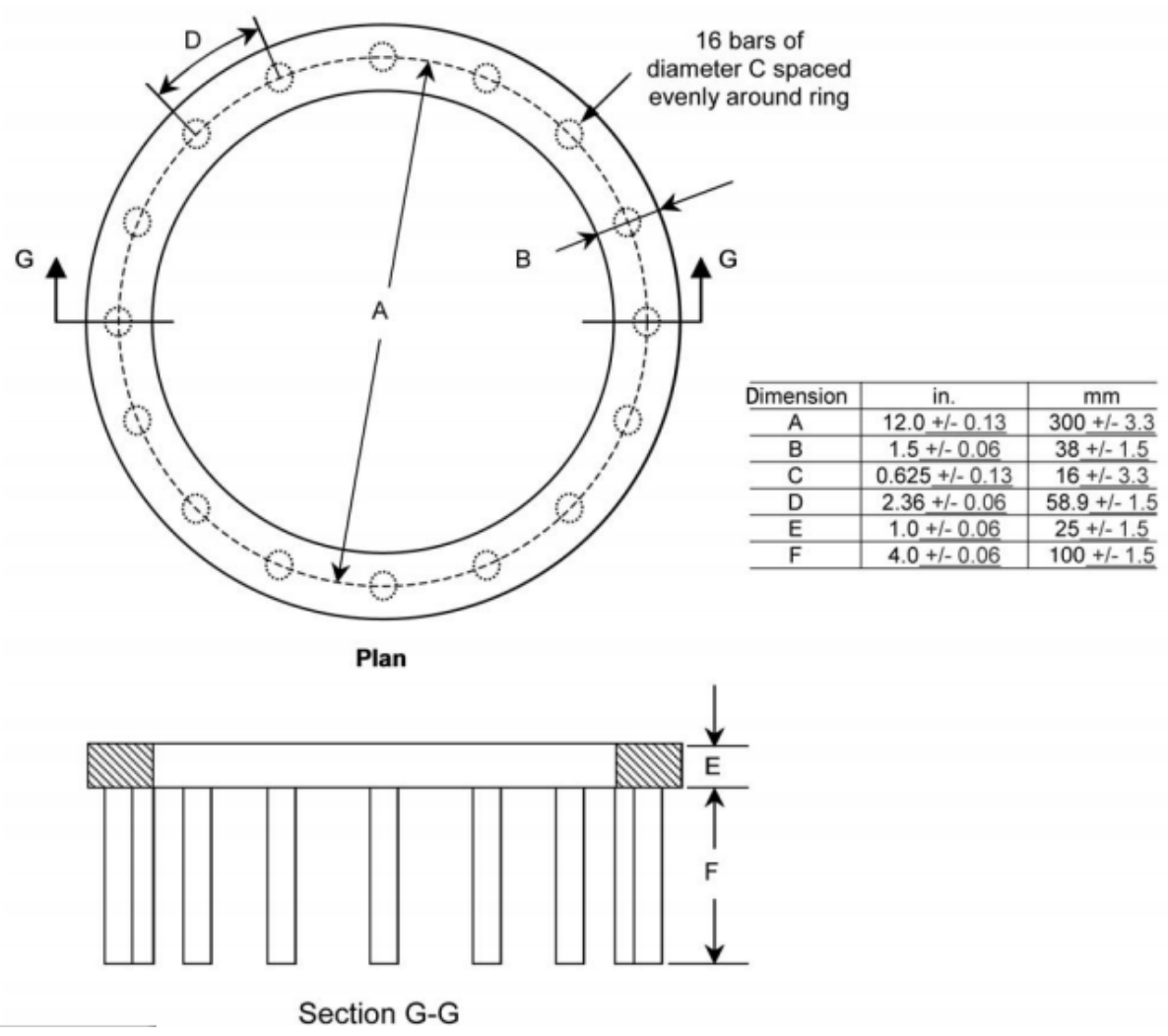

Figure 3.01 - J-Ring Schematic (ASTM C1621 - 2009a)

The slump cone is placed at the center of the J-ring on the base plate as exemplified in Figure 3.02. 


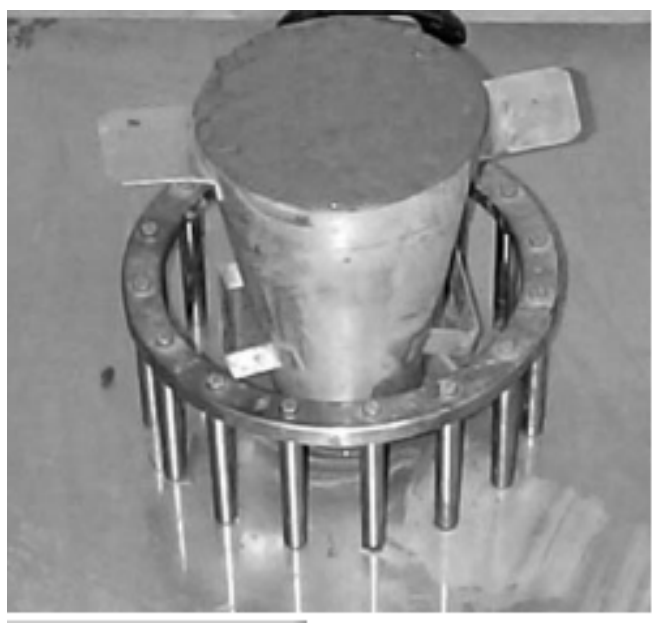

Figure 3.02 - Example of J-Ring and Slump Cone (ASTM C1621 - 2009a)

SCC is then poured continuously into the slump cone without rodding or vibration. Concrete at the top is struck off using a strike bar and the concrete at the base is removed. The cone is then raised a distance of 6-12 inches over a time period of 2-4 seconds steadily upward with no twisting or lateral movement. Once the SCC has stopped flowing, two orthogonal diameters are to be measured. One of the diameters must be the largest observed diameter of the resulting concrete patty. The other diameter is perpendicular to the largest diameter. The average of the two diameters is defined as the J-ring flow. To quantify the passing ability of the SCC, the J-ring flow is compared with the slump flow. The difference in J-ring flow and slump flow is calculated and compared with a table of values given in ASTM C1621 (2009a). If the difference is less than or equal to 1 inch, no visible blocking has occurred. If the difference is greater than one but less than or equal to 2 , minimal blocking to noticeable blocking has occurred. If the difference is greater than 2, noticeable to extreme blocking has occurred. 


\subsubsection{Visual Stability Index (VSI)}

Resistance to segregation is measured immediately after the slump flow test. The stability of the mix is determined by observing the concrete mass for signs of instability, such as a mortar halo, uneven distribution of aggregates, and bleeding. Observations are quantified in an index ranging from values 0-3 called the Visual Stability Index (VSI). Values of 0 and 1 are considered stable and acceptable, while values 2 and 3 are considered unstable. A value of 0 is highly stable and shows no evidence of segregation or bleeding. A value of 1 is stable and shows no segregation, but slight bleeding is observed. A value of 2 shows a mortar halo and a higher concentration of aggregates at the center of the concrete mass. Finally, a value of 3 is highly unstable with a large mortar halo greater than 0.5 in. and a distinct pile of aggregates at the center.

\subsubsection{Fresh Air Content}

Fresh air content in concrete is a commonly used standard for roughly estimating the freeze-thaw durability of concrete. Finding the air content in fresh concrete is a rapid and simple procedure, allowing the procedure to be easily used for quality control of concrete delivered to field operations. The procedure of finding the fresh air content of concrete is dictated by ASTM C231, Standard Test Method for Air Content of Freshly Mixed Concrete by the Pressure Method (2009b). The ASTM guideline describes two proper air meters. For this thesis, a meter of type B is used for this test. A type B meter pressurizes a known volume of air inside the chamber to a calibrated value, which also pressurizes the air inside the concrete. A diagram of a type B meter is shown in Figure 
3.03. When the pressure in the chamber is released, the resulting value on the pressure gauge is the fresh air content.

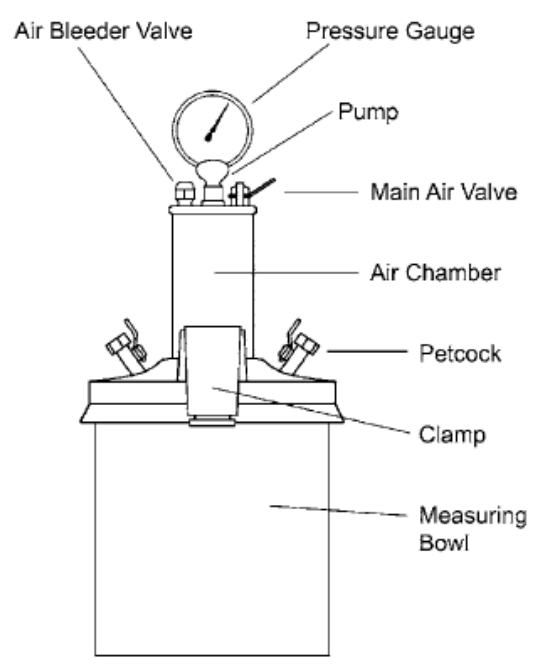

2b. Vertical Air Chamber

Figure 3.03 - Type B Air Meter Schematic (ASTM C231 - 2009b)

\subsubsection{SCC Mixing}

SCC was mixed in the lab using previously mentioned materials. According to the resources available, $2.5 \mathrm{ft}^{3}$ of SCC was to be cast. For $2.5 \mathrm{ft}^{3}$ of concrete, the following table was used for measuring the amount of material needed according to the mix design. 


\section{Table 3.02 - Adjusted Weight Values Used}

\begin{tabular}{|l|l|}
\hline Material & $(\mathrm{lb})$ \\
\hline Cement & 68 \\
\hline Silica Fume & 7 \\
\hline \#67 Stone & 133 \\
\hline Natural Sand & 123 \\
\hline Water & 27 \\
\hline HRWRA* & 315 \\
\hline VMA* & 41 \\
\hline AEA* & 63 \\
\hline *in mL & \\
\hline
\end{tabular}

The mixing process began by first placing the \#67 limestone and the natural silica sand into a concrete mixer. The aggregates were blended thoroughly inside the mixer, and a small amount of water was added to the aggregate mixture to ensure that all of the coarse aggregate was in the SSD condition. An air entraining admixture was measured by syringe and poured onto the aggregate mixture. According to the admixture producer, the air entraining admixure is most effective when placed on damp, fine aggregate before mixing the aggregate with cement.

After the aggregates and the air entraining admixture had been well blended, the Type III cement and silica fume were then added to the aggregate mixture. The dry mixture was then blended well. HRWRA can either be added to the water used for the batch or added after the concrete mix is complete. The producer of the HRWRA states that it is more effective when added to the complete concrete mix. However, for this 
mixture, HRWRA was added to the batch water before the water used in the mix. The batch water with the HRWRA was then added to the dry mix.

VMA is a Viscosity Modifying Admixture that is designed to stabilize concrete mixes that are highly nonviscous such as SCC. The purpose of adding VMA to the concrete is to reduce segregation, improve consolidation, increased viscosity, and enhance finishing. The VMA was added to the mix at the end of the mixing process. After the final mixing according to ASTM C192 (2012), the SCC was placed in a wheelbarrow to help place into forms.

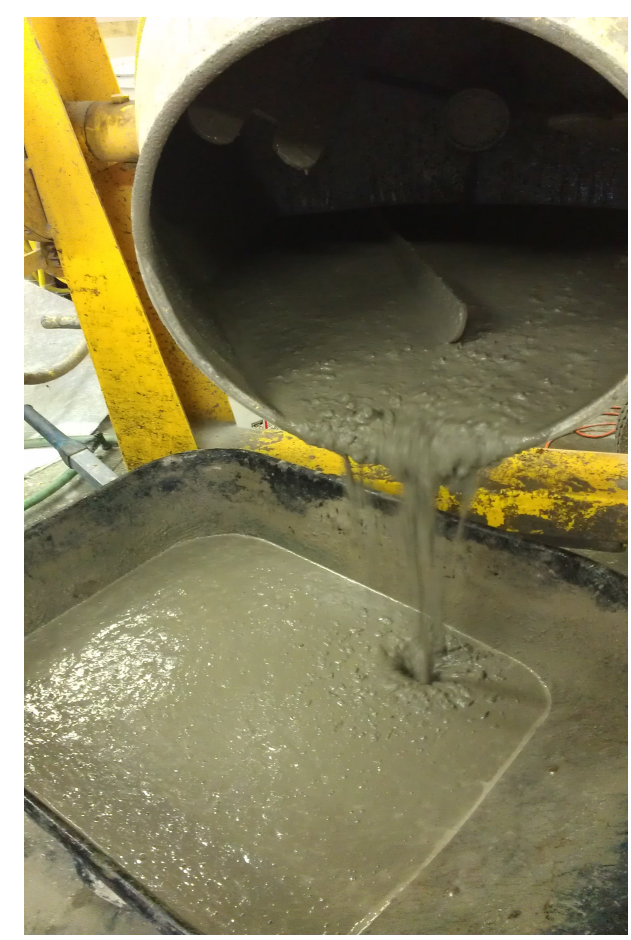

Figure 3.04 - SCC in Mixer

As is apparent from Figure 3.04, the concrete exhibits a low viscosity, which is a main characteristic of SCC. Unfortunately, after mixing, the SCC began to exhibit evidence of segregation seen in Figure 3.05. 


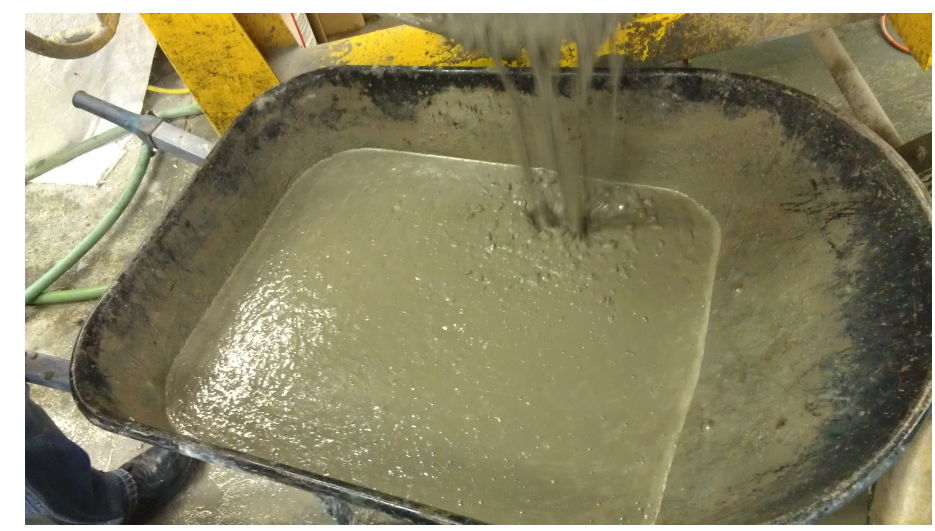

Figure 3.05 - SCC Segregation in Wheelbarrow

The SCC in Figure 3.05 shows that coarse aggregate is not easily visible away from the point at which the SCC is poured into the wheelbarrow. Coarse aggregates near the pouring point are, by contrast, easily visible. A mix exhibiting no segregation should have coarse aggregates evenly distributed throughout the concrete.

After the SCC is placed into the wheelbarrow, the slump flow, J-ring flow, and VSI were measured according to the respective ASTM procedures previously described. Slump flow was measured according to ASTM C1611 (2009b).

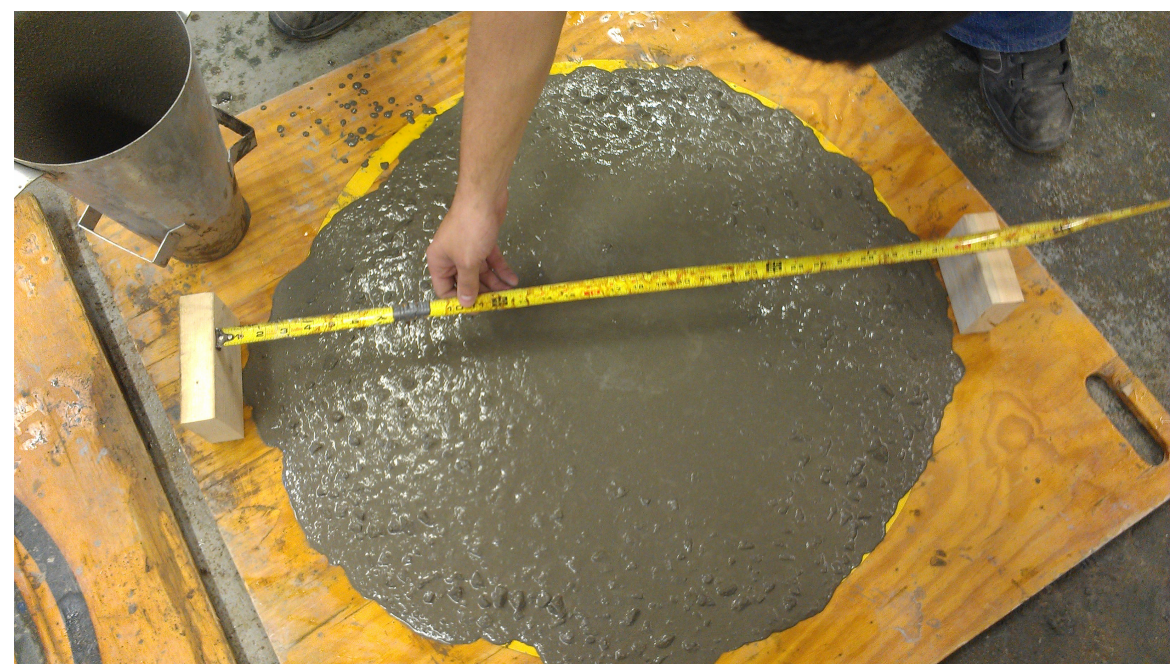

Figure 3.06 - Slump Flow of SCC Batch 1 
The result of the slump flow test is shown in Figure 3.06. The image shows the maximum diameter of the concrete mass. The slump flow of the SCC was calculated to be 29.5 in. After the slump flow was measured, the VSI was determined through observation. The concrete mass did not have a clear mortar halo, but did show a lack of aggregate at the center of the mass. For this reason, the VSI was determined to be 1 for this mix.

Next, the J-ring test was performed according to ASTM C1621 (2009a). The result of the J-ring test is shown in Figure 3.07.

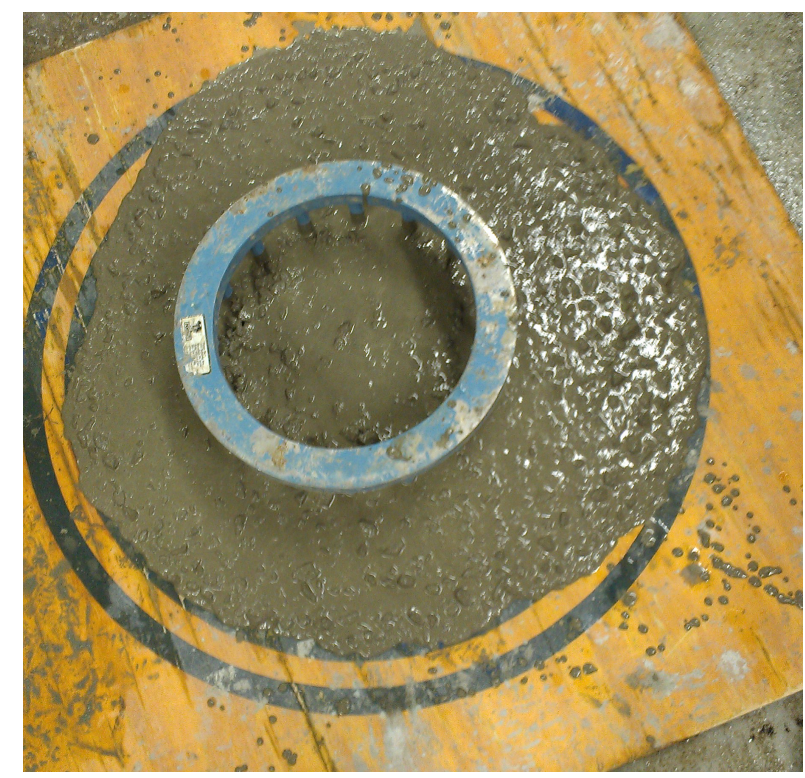

Figure 3.07 - J-Ring Flow of SCC

For the J-ring test, the largest diameter was measured to be $27.25 \mathrm{in}$. and the orthogonal diameter was measured to be 26.75 in., so the J-ring flow was $27 \mathrm{in.}$ The difference between the slump flow and J-ring is 2.5 in. indicating that noticeable blocking had occurred. 
A fresh air content test was performed according to ASTM C231 (2009b). The steel bowl was filled to slightly overflowing. Because the concrete is SCC, the concrete was poured continuously without rodding or any vibration. The top of the concrete was made level with the rim of the bowl using a strike-off plate. The rim of the bowl where the cap makes contact was cleaned with a wet towel to ensure an air tight seal. The cap was placed on the bowl and secured tightly by clamps. After the petcocks were both opened, water was poured into one. When no more air escaped from the open petcock, both were closed. Air was pumped into the air chamber until the pressure gauge reached a specified calibrated value. Pressurized air inside the air chamber was then released through the main valve. The resulting reading on the pressure gauge was read as the fresh air content of the SCC.

Concrete cylinders and freeze-thaw prisms were needed for future testing. For SCC, the standard of fabricating test specimens is ASTM C1758, Standard Practice for Fabricating Test Specimens with Self-Consolidating Concrete (2011). According to the standard, a pouring vessel should be filled with a representative sample of SCC, and then the SCC should be poured into the specimen containers. The standard dictates that the pouring vessel should be no more than 5 in. above the top of the specimen container. SCC in the specimen container should not be rodded, nor should it be tapped or vibrated. Compression strength test specimens were fabricated using plastic $4 \times 8$ in. cylindrical molds. Large 6x12 in. cylinders were fabricated using plastic cylindrical molds for use in hardened air void analysis. Rectangular freeze-thaw prisms with dimensions of $3 \times 4 \times 16$ in. were fabricated using steel molds. None of the specimens were 
tamped with a rod, and no vibration was used. To prevent damage to the specimens upon removal, every cylindrical and steel prism mold was lightly oiled.

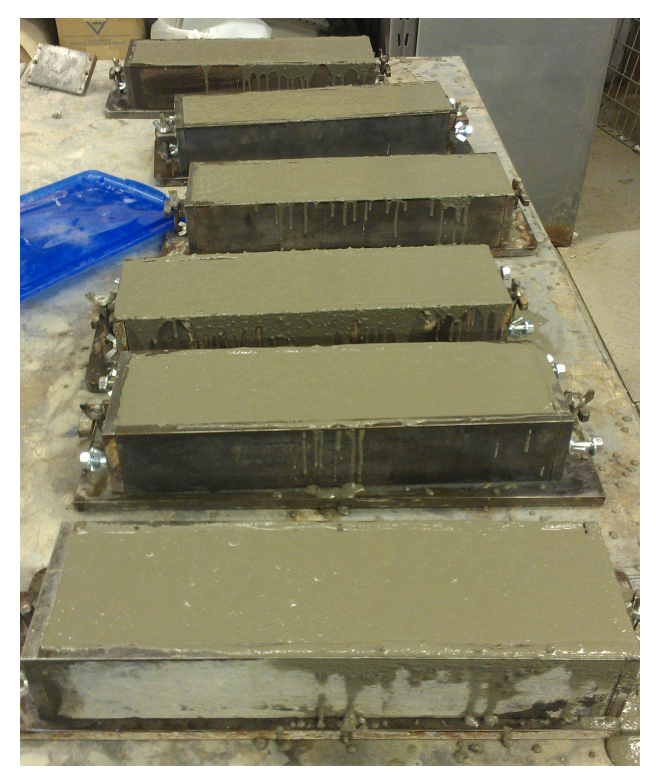

Figure 3.08 - Fresh Freeze-Thaw Prisms

Upon completion of casting the specimens, all the specimens were covered in wet burlap and a tough, durable plastic tarp. Cylindrical specimens were capped with plastic caps to prevent moisture loss. The capped cylinders were used to support the burlap over the rectangular prisms in order to prevent the burlap from contacting the finished surface of the prisms. All the specimens were left to cure under the wet burlap and plastic at room temperature for 6 hours.

After the concrete had set after 6 hours, half of the specimens were placed under the effects of steam curing. To replicate steam curing in the laboratory, a hot water bath was prepared in an insulated tank large enough for every specimen. Water in the tank 
was heated by an electric water heater and an aquarium water mixer was placed in the water to ensure a constant temperature throughout the water.

Temperature in the water was regulated by a Proportional, Integral, and Derivative (PID) controller. The PID controls the power input to the water heater by using three calculations related to the previous temperature readings, the current temperature, and the estimated future temperature. The Proportional calculation uses the current difference between actual temperature, measured by thermocouple submersed in the water, and desired temperature. The difference between the desired temperature and the target temperature is called the error. The Integral calculation is the integral of the error up to the current point in time, which assesses the history of the error. Derivative calculation takes the derivative of the error at the current time, and uses the derivative value to predict the future temperature. Using these three calculations, the PID can heat water up to a point quickly, and then lower the heating power just before the target to ensure the water does not exceed the target temperature.

Water in the insulated tank was warmed to $43^{\circ} \mathrm{C}$ using the electric water heater and PID controller. Specimens designated for steam curing were wrapped in plastic, and then submersed in the warm water. 


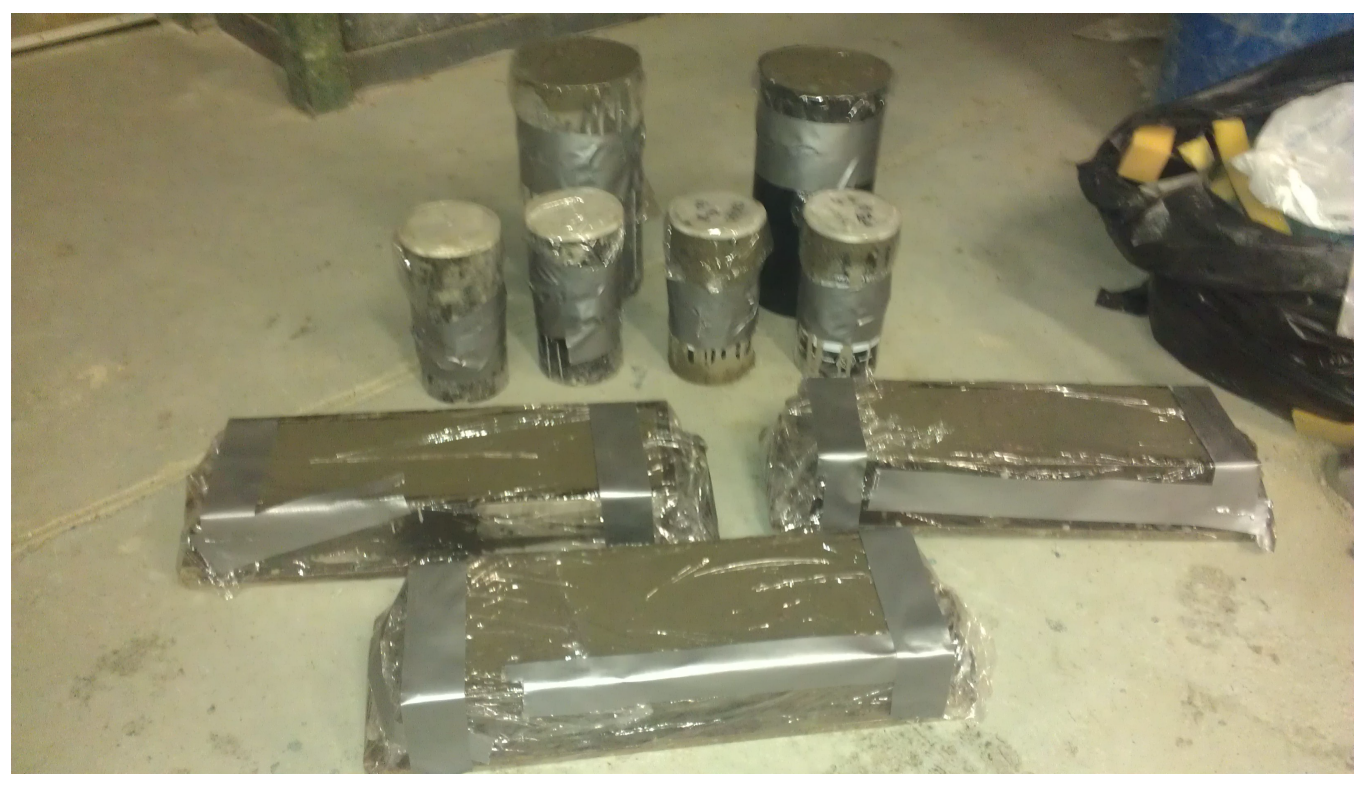

Figure 3.09 - Wrapped Specimens for Steam Curing

In Figure 3.09, the number of specimens prepared for steam curing is shown. Three freeze-thaw prisms, four $4 \times 8$ in. cylinders for compressive strength testing, and two 6x12 in. cylinders for hardened air void analysis. Each of the specimens shown was submersed into the warm water and the water temperature was maintained at $43^{\circ} \mathrm{C}$ for 18 hours. Meanwhile, the specimens not designated for steam curing were left under the burlap and plastic at room temperature.

After 24 hours, both steam cured and traditional cured cylinders were tested for compressive strength. Compressive strength testing is dictated by ASTM C39, the Standard Test Method for Compressive Strength of Cylindrical Concrete Specimens (2012). The compressive machine used has an accuracy of $500 \mathrm{lbs}$. Specimens were removed from the plastic molds and the finished end was trimmed if any protrusions exist to ensure even loading. According to the ASTM standard, the specified rate of loading is 
$28-42 \mathrm{psi} / \mathrm{s}(352-528 \mathrm{lbs} / \mathrm{s}$ for a $4 \times 8$ cylinder). Cylinders were loaded at a rate of approximately $500 \mathrm{lbs} / \mathrm{s}$ until catastrophic failure. The loading was initialized without shock to the cylinder. Two steam cured cylinders and two moist cured cylinders were loaded until failure. Cylinder failures are acceptable if the cylinder's failure pattern matches one of the drawings in Figure 3.10. According to ASTM, if the difference in strength values is greater than $10 \%$, a third cylinder must be tested.

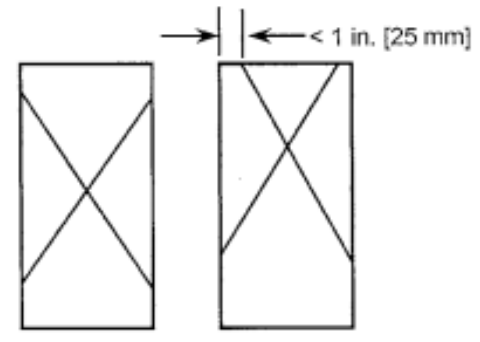

Type 1

Reasonably well-formed cones on both ends, less than 1 in. [ $25 \mathrm{~mm}]$ of cracking through caps

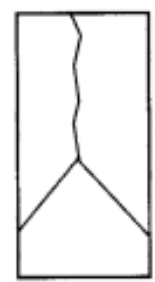

Type 2

Well-formed cone on one end, vertical cracks running through caps, no welldefined cone on other end

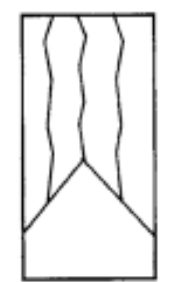

Columnar vertical cracking through both ends, no wellformed cones

Figure 3.10 - Ideal Cylinder Failures (ASTM C39 - 2012)

After the 24 hour curing period, both steam cured and moist cured specimens were removed from the molds and submerged in a lime water bath maintained at room temperature $\left(\sim 23^{\circ} \mathrm{C}\right)$.

\subsection{Freeze-Thaw Testing}

The freeze-thaw resistance of concrete follows ASTM C666, Standard Test Method for Resistance of Concrete to Rapid Freezing and Thawing. According to the standard, the smallest dimension of concrete test specimens must be greater than or equal 
to 3 inches and less than or equal to 5 inches. The length of the concrete prisms must be less than or equal to 16 inches but greater than or equal to 11 inches. In the laboratory, prisms with dimensions of $3 \times 4 \times 16$ were cast for this test.

ASTM C666 states that specimens should be cured for 14 days before being subjected to the test. Concrete specimens cast in the laboratory were kept in the lime water bath until 14 days after casting. When testing the specimens, the standard requires that be between $-1^{\circ} \mathrm{C}$ and $+2^{\circ} \mathrm{C}$ of the target thaw temperature of the freeze thaw cycles. To initially test the freeze-thaw specimens, they must first be brought to the thaw temperature.

Actual testing of freeze-thaw specimens required the use of ASTM C215, Standard Test Method for Fundamental Transverse, Longitudinal, and Torsional Resonant Frequencies of Concrete Specimens. This test is designed to detect changes in dynamic modulus of elasticity of a test specimen exposed to degrading effects. For freeze thaw specimens being tested in the laboratory, both the transverse and longitudinal resonant frequencies were was measured.

Two methods are acceptable for measuring transverse frequency. The first method, called a forced resonance test, places a driver capable of vibrating at a known, adjustable frequency at the center of the prism. A pickup is placed at the end of the prism, and the pickup is connected to an indicator and an oscilloscope. A schematic of the setup for the forced resonance test is given in Figure 3.11. 


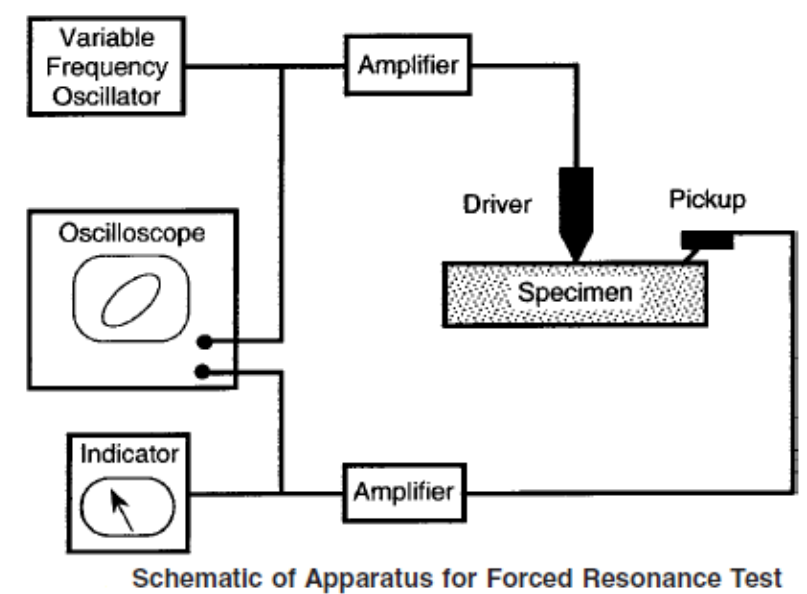

Figure 3.11 - Transverse Frequency Schematic (ASTM)

The value of the frequency of the driver when the indicator reads a maximum value is the resonant frequency of the specimen.

The second method for determining the transverse frequency is the impact resonance test. A light accelerometer is placed at the end of the freeze thaw prism, and the center of the prism is lightly struck by a hard object, such as a steel hammer. The transverse frequency is then determined by using a digital waveform analyzer. The digital analyzer finds the frequency at which the maximum resonance occurs and records it as the resonant frequency. A schematic of this method is given in Figure 3.12.

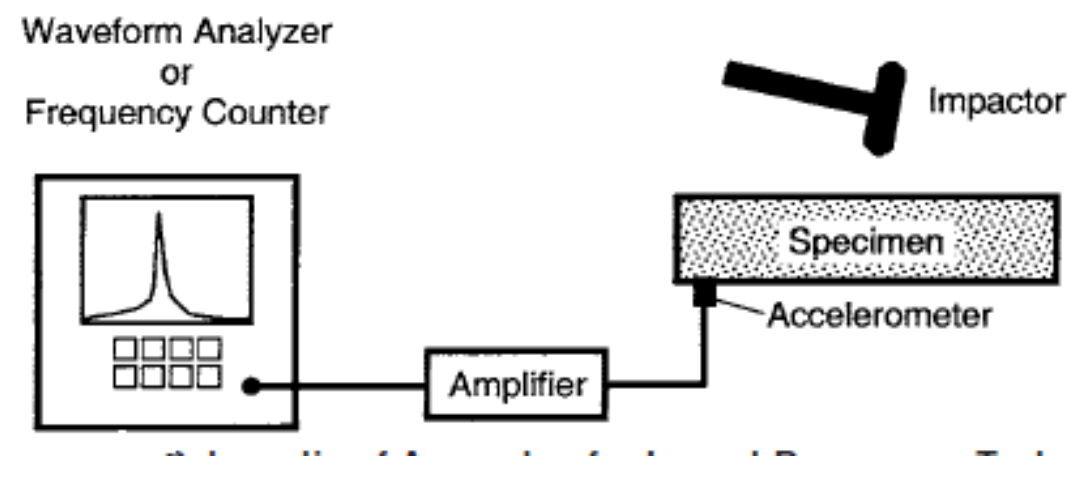

Figure 3.12 - Impact Resonance Schematic (ASTM) 
For the transverse frequency test in the laboratory, Method 2 was used. The accelerometer used was a PCB Piezotronics shear accelerometer with a sensitivity of 9.65 $\mathrm{mV} / \mathrm{g}$. The accelerometer was loosely attached to a small aluminum plate, which was needed to secure the accelerometer with rubber bands. Rubber bands were wrapped around the specimen at the point of contact of the accelerometer to hold the accelerometer tightly on the surface of the specimen. The accelerometer was connected to an amplifier that transferred the analog signal to a digital output for use in a computer. The amplifier was a National Instruments NI 9234 4-Channel IEPE. The amplifier was connected to a National Instruments Hi-Speed USB Carrier NI USB-9162 and the USB was connected to a computer. The actual setup used for the transverse frequency is shown and labeled in Figure 3.13.

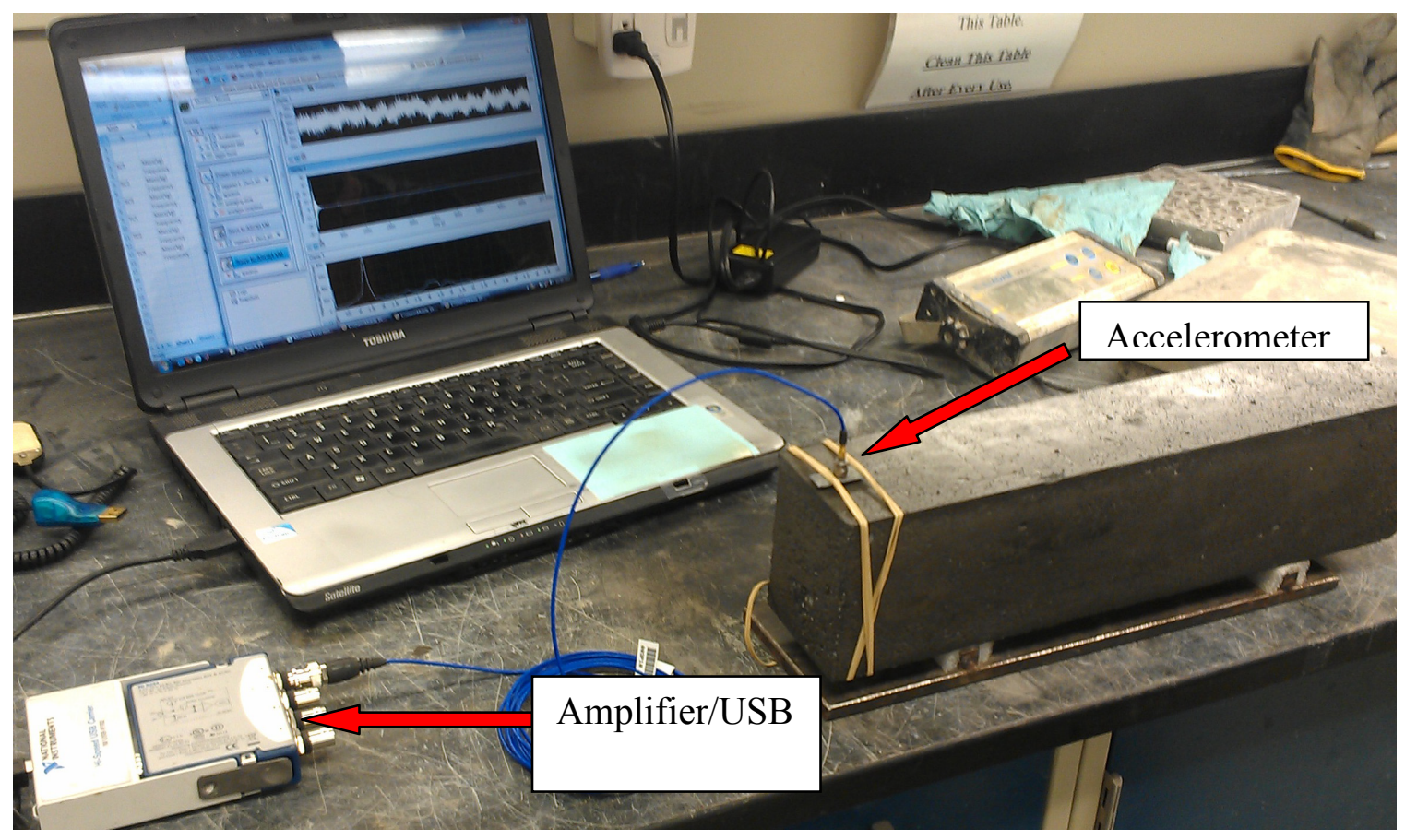

Figure 3.13 - Setup for Transverse Frequency Test 
The computer program LabVIEW SignalExpress 2009 was used to analyze the digital signal from the USB carrier. The LabVIEW program operates on a trigger that begins recording data as soon as the signal from the accelerometer exceeds an acceleration of $5 \mathrm{~g}$. The 100 data points before the trigger were recorded, and then all data points up to $0.5 \mathrm{~s}$ after the trigger were recorded. The actual acceleration data was recorded, and the power spectrum was recorded. The power spectrum is a frequency vs. amplitude curve. The maximum point of the power spectrum curve is located at the specimen's transverse frequency. An example of one test result for transverse frequency is shown in Figure 3.14 .

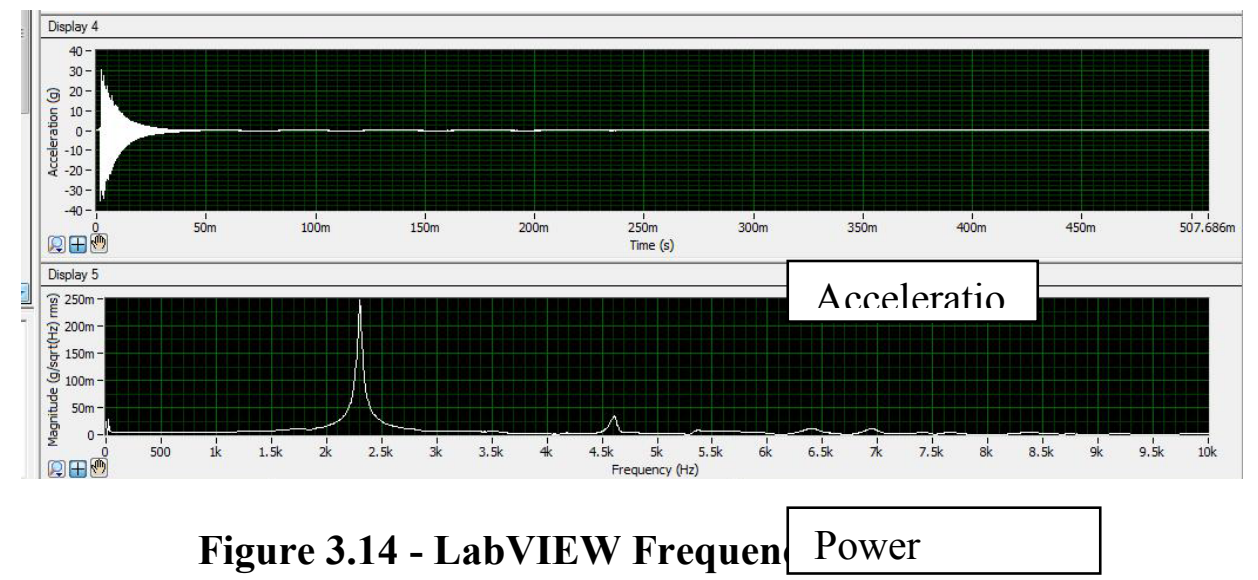

To confirm the accuracy of the transverse frequency test, longitudinal resonant frequency was also tested. This test was conducted similar to Method 1 of the transverse frequency test. A driver capable of vibrating at a known, adjustable frequency is placed at the center of one end of the prism. A pickup is placed at the end of the prism at the 
top, and both the pickup and driver are connected to an oscilloscope and indicator. The frequency of the driver is adjusted by hand. The value of the frequency of the driver where the indicator reads a maximum value is the resonant frequency of the specimen. The setup of the longitudinal frequency test is shown in Figure 3.15.

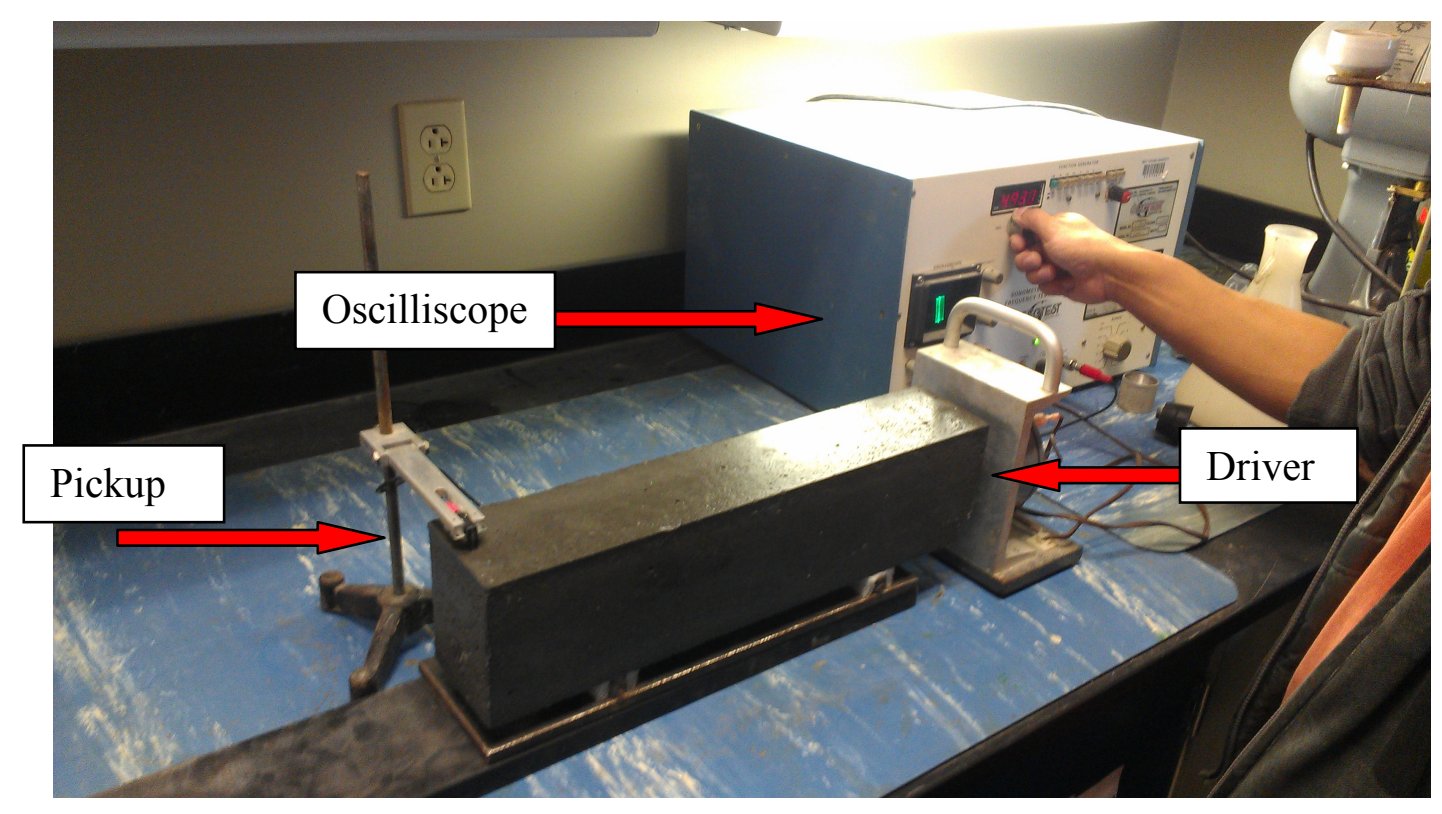

Figure 3.15 - Longitudinal Resonant Frequency Test Setup

For both frequencies, ASTM C666 is dependent on the relative dynamic modulus of elasticity $P$ of the test specimens. ASTM gives the following equation to calculate $P$.

$$
P_{c}=\frac{n_{c}^{2}}{n^{2}} \times 100
$$

Where:

$P_{c}=$ relative dynamic modulus of elasticity as a percent after $c$ cycles $n_{c}=$ transverse frequency after $c$ cycles 
$n=$ transverse frequency at 0 cycles

If the relative dynamic modulus falls below $60 \%$, the test may be stopped.

\subsubsection{Freeze-Thaw Cycles}

The saturated concrete prisms for freeze-thaw testing were subjected to temperature cycling according to ASTM C666, Standard Test Method for Resistance of Concrete to Rapid Freezing and Thawing. The concrete test specimens were subjected to cyclic freezing and thawing temperatures. Specimens must be completely immersed in no more than $1 / 8$ in. and no less than $1 / 32$ in. of water during the freeze thaw cycles. The core temperature of the specimens must reach within $2-6^{\circ} \mathrm{C}$ at the end of the warming cycle. At the end of the cooling period, the core temperature of the specimens must reach within -16 to $-20^{\circ} \mathrm{C}$. Specimens should not be heated or cooled so quickly that the difference between surface temperature and internal temperature exceeds $28^{\circ} \mathrm{C}$. The durability of every specimen must be tested every 36 cycles or less.

Prior to freeze-thaw testing, specimens were tested for longitudinal, transverse

frequency, and mass. Specimens were then placed into thin aluminum trays and the trays were filled with water. A small piece of metal inside each tray allowed water to surround the entire specimen. Trays with concrete specimens were covered with plastic to prevent water evaporation during the cycles. 


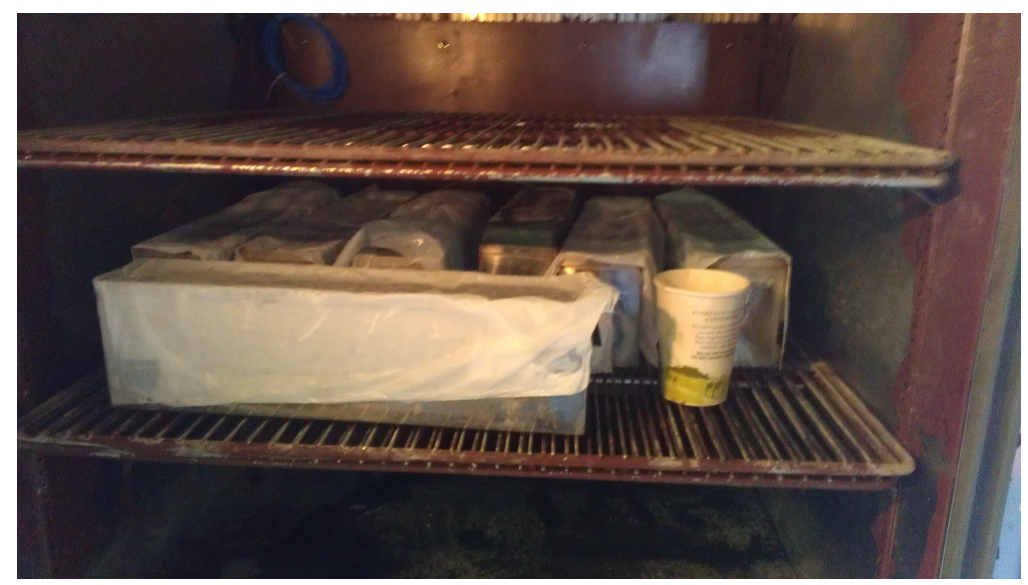

Figure 3.16 - Freeze-Thaw Specimens in Test Chamber

Specimens were placed into a Z60 programmable freeze and thaw chamber. A dummy specimen containing a thermocouple in its core was also in the chamber to ensure the test specimens are reaching the ASTM required core temperatures.

After 30 cycles, the freeze thaw specimens were brought to a core temperature of $3.2^{\circ} \mathrm{C}$. One prism was removed from the freeze-thaw chamber at a time, with the rest in the chamber maintaining the core temperature of $3.2^{\circ} \mathrm{C}$. The specimen was tested was then removed from the metal container and dried with paper towels until it was in the saturated surface dry condition. The specimen was then placed on a scale to measure mass. The specimen was tested for longitudinal and transverse frequency using the method detailed previously. After testing, the specimen was returned to the chamber. After each 30 cycles, the specimens in the chamber were rotated clockwise in their position in the chamber to ensure consistency in the temperature fluctuations. For example, the specimen in front in Figure 3.16 was placed in the left most position after testing, and the specimen on the far right was rotated into the front position. 


\subsection{Hardened Air Void Analysis}

Hardened air void analysis follows ASTM C457, Microscopical Determination of Parameters of the Air-Void System in Hardened Concrete. This analysis is designed to help predict the freeze-thaw durability of a concrete mix. Two methods are acceptable in the standard: the linear traverse method and the modified point count method. In this thesis, the linear traverse method was used.

The specimen used for ASTM C457 must be prepared with extreme care. The minimum finished area is dictated by Figure 3.17 which is given in ASTM C457.

\begin{tabular}{|c|c|c|}
\hline \multirow[t]{2}{*}{$\begin{array}{l}\text { Nominal or Observed } \\
\text { Maximum Size of Aggregate } \\
\text { in the Concrete, } \mathrm{mm} \text { [in.] }\end{array}$} & \multicolumn{2}{|c|}{$\begin{array}{c}\text { Total Area to be Traversed for } \\
\text { Determination of } A, \alpha \text { or } L^{B}, \text { min, } \mathrm{cm}^{2} \\
{\left[\text { in. }^{2}\right]} \\
\text { Based on Direct Measurement of: }\end{array}$} \\
\hline & $\begin{array}{c}\text { Total Air-Void } \\
\text { Content }\end{array}$ & Paste-Air Ratio, $p / A$ \\
\hline $150[6]$ & $1613[250]$ & 645 [100] \\
\hline 75 [3] & 419 [65] & $194[30]$ \\
\hline $37.5\left[1 \frac{1}{2}\right]$ & $155[24]$ & $97[15]$ \\
\hline $25.0[1]$ & 77 [12] & 77 [12] \\
\hline $19.0[3 / 4]$ & $71[11]$ & $71[11]$ \\
\hline $12.5[1 / 2]$ & $65[10]$ & $65[10]$ \\
\hline $9.5[3 / 8]$ & $58[9]$ & $58[9]$ \\
\hline 4.75 (No. 4 ) & $45[7]$ & $45[7]$ \\
\hline \multicolumn{3}{|c|}{$\begin{array}{l}\text { A The indicated values refer to reasonably homogeneous, well-compacted con- } \\
\text { crete. The microscopical measurement should be made on proportionately larger } \\
\text { area of sections if the concrete is markedly heterogeneous in distribution of } \\
\text { aggregate or large air voids. If more than one finished surface is taken from a } \\
\text { single portion of the concrete, the finished surfaces shall be separated by a } \\
\text { distance greater than one half of the nominal or observed maximum size of } \\
\text { aggregate. }\end{array}$} \\
\hline
\end{tabular}

Figure 3.17 - Minimum Finished Surface Size (ASTM C457)

The flat surface of the specimen must be as flat and even as possible due to the visual nature of the test. To create a flat surface, a $6 \times 12$ concrete cylinder was quartered by cutting first lengthwise, and then cutting again to give two flat $6 x 6$ inch surfaces using 
a diamond-edged water saw. The flat surfaces were rinsed off and subjected to polishing. Polishing was done using a Struers TegraPol 31 flat piano polisher. This polisher features water cooling and an air pressurized arm to hold the specimen in place. The bed of the polisher uses diamond polishing surfaces of varying fineness. The mechanical setup shown in Figure 3.18 guarantees that the specimen surface is as flat and level as possible. Each specimen underwent up to an hour each of 120, 200, 600, and 1200 grade polishing surfaces.

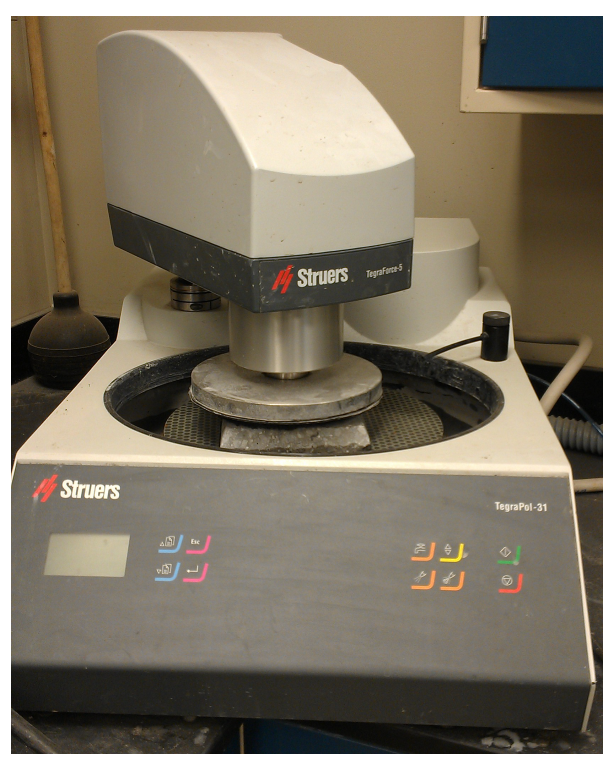

Figure 3.18 - Struers Polisher with Specimen

After each level of fineness, the specimen was rinsed with water and sprayed with compressed air to remove any particles from the air voids. After the final polish, the specimens were dipped into ultrasonic water cleaner for 4 seconds after rinsing and before spraying with compressed air. A satisfactory specimen should easily reflect light and show no relief between the cement paste and aggregates. A satisfactory specimen surface is demonstrated in Figure 3.19. 


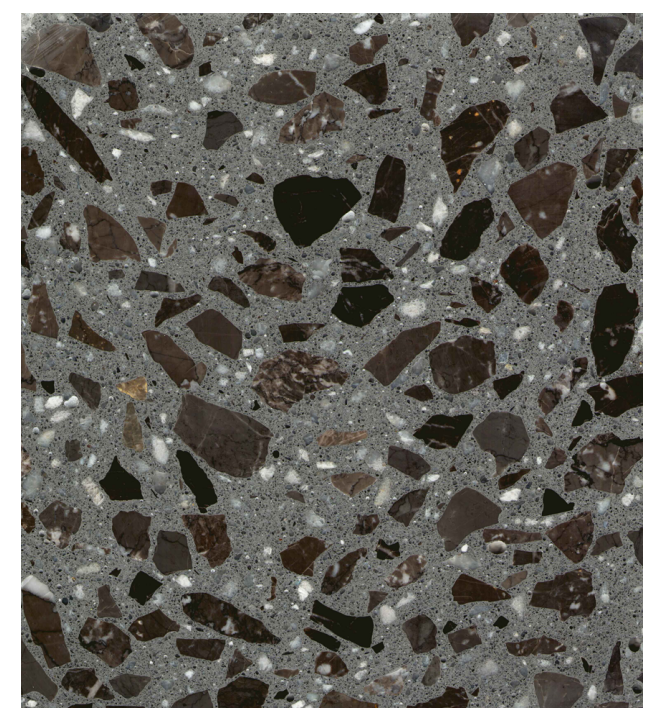

Figure 3.19 - Example of Acceptable Polished Concrete Surface

A digital image of the polished surface was captured using a flatbed scanner at high resolution. This image was used to calculate the percent aggregate content in the sample. Using image analysis software developed by JMicroVision, the percent of aggregate in the specimen can be calculated. The software finds and outlines the large aggregates in the image by outlining regions of large color differences. The software then calculates the area of the image that is encased by the large aggregate outline. The percent of the image that is made up of aggregate is then displayed as a percent of the total image.

The polished surface then was coated with ink by passing a marker over the entire surface in parallel lines. The surface was given additional coats of ink, each coat applied perpendicular to the previous, until no fine aggregate was readily distinguishable. The specimen was left to dry for 24 hours, then Barium Sulfate powder was lightly tamped into the specimen using a rubber stopper. Barium Sulfate was chosen for its ease of use, 
its exceptionally white color, and its high fineness. After tamping, the excess powder was removed by lightly passing a finger over the surface. The Barium Sulfate was applied a minimum of 3 times. After the final time, a 5x magnifying glass was used to observe the specimen. If any unfilled or partially filled voids were observed, the powder was applied to the entire surface until no unfilled voids were present. One prepared specimen ready for air void analysis is shown in Figure 3.20.

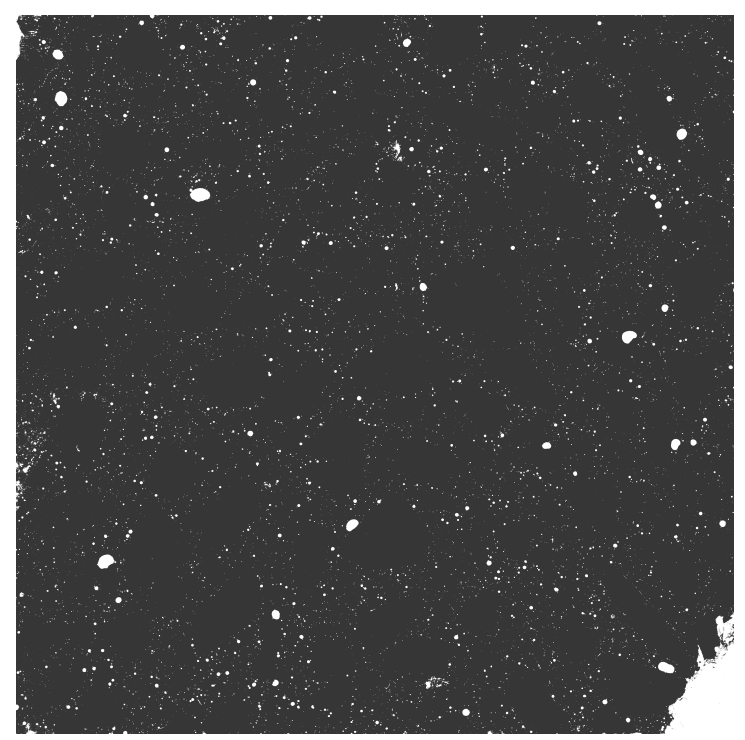

Figure 3.20 - Prepared Specimen for Air Void Analysis

The linear traverse method involves making evenly spaced parallel traverses across the prepared concrete specimen. ASTM specifies a minimum cumulative length of traverses needed to ensure the accuracy of the test. This minimum value is dependent on the maximum size of the coarse aggregates in the concrete. The ASTM specified values for the cumulative traverse length is given in Table 3.03. When an air void is intersected, the length of the air void must be measured and recorded. The total length of all traverses must be recorded as well. Using the length of traverses through air and the total length of all the traverses, several calculations can be made about the air void 
structure. Of all the calculations, three were chosen as the most important to air void structure: percent air content, spacing factor, and specific surface.

Table 3.03 - Minimum Total Length of Traverses (ASTM C457)

\begin{tabular}{|c|c|}
\hline $\begin{array}{l}\text { Nominal or Observed } \\
\text { Maximum Size of Aggregate } \\
\text { in the Concrete, mm [in.] }\end{array}$ & $\begin{array}{l}\text { Length of Traverse for } \\
\text { Determination of } \mathrm{A}, \alpha \text {, or } \\
\bar{L}, \\
\min , \mathrm{mm}[\mathrm{in} .]\end{array}$ \\
\hline $150[6]$ & $4064[160]$ \\
\hline $75[3]$ & $3048[120]$ \\
\hline $37.5\left[1 \frac{11 / 2]}{3}\right.$ & $2540[100]$ \\
\hline $25.0[1]$ & 2413 [95] \\
\hline $19.0[3 / 4]$ & 2286 [90] \\
\hline $12.5[1 / 2]$ & 2032 [80] \\
\hline $9.5[\% / 8]$ & 1905 [75] \\
\hline 4.75 (No. 4 ) & 1397 [55] \\
\hline \multicolumn{2}{|c|}{$\begin{array}{l}{ }^{A} \text { The limits of uncertainty of results obtained for air-void content depend upon the } \\
\text { length of traverse and the air-void content of the concrete. Based on experience } \\
\text { the recommended minimum length of traverse shown in this table should produce } \\
\text { limits of uncertainty such that up to } 3 \% \text { air-void content the standard deviation is } \\
\text { not greater than } 0.5 \% \text {, which at } 3 \% \text { air-void content corresponds to a coefficien } \\
\text { of variation of } 17 \% \text {. For traverse lengths greater than } 1375 \mathrm{~mm} \text { [ } 55 \text { in.] and } \\
\text { air-void contents greater than } 3 \% \text { the coefficient of variation is correspondingl } \\
\text { reduced. The data obtained can be analyzed by statistical methods to determine } \\
\text { the limits of uncertainty to be applied. }\end{array}$} \\
\hline
\end{tabular}

Calculating the percent air content $A$ using the linear traverse method follows the

following formula:

$$
A=\frac{T_{a} * 100}{T_{t}}
$$

Where:

$T_{a}=$ length of traverses through air voids

$T_{t}=$ total length of traverses

For additional calculations, the average chord length must be calculated.

$$
\bar{l}=\frac{T_{a}}{N}
$$

Where: 
$\bar{l}=$ average chord length

$N=$ total number of air voids intersected

Specific surface $\alpha$ is the ratio of the surface area of an air void with the volume of the air void. Generally a greater number of small bubbles is preferred over fewer, larger

bubbles. The higher the specific surface, the smaller and more numerous the bubbles are.

$$
\alpha=\frac{4}{\bar{l}}
$$

The paste-air ratio $(p / A)$ determines the equation needed for use in determining the spacing factor.

$$
\frac{p}{A}=\frac{T_{p}}{T_{a}}
$$

Where:

$T_{p}=$ length of traverse through paste

The spacing factor $(\bar{L})$ is the single most important value when estimating the freeze thaw durability of concrete. The equation to use for spacing factor depends on the pasteair ratio previously calculated. If the paste-air ratio is less than or equal to 4.342 , the following equation is used:

$$
\bar{L}=\frac{T_{p}}{4 N}
$$

If the paste-air ratio is greater than 4.342 , the following equation is used:

$$
\bar{L}=\frac{3}{\alpha}\left[1.4\left(1+\frac{p}{A}\right)^{1 / 3}-1\right]
$$


Bubble Counter developed by Michigan Tech University performs the linear traverse method of ASTM C457 on a digitally scanned image of a prepared specimen surface. Each image was scanned at 3200 dpi. The program runs as a script in Adobe Photoshop. To run the script, a threshold must be applied to the image. Bubble Counter has a built-in script made to calibrate the brightness and contrast of the image. A black and white representative sample of the image is first selected, and then the "Set White Balance" option of the script is selected. After the calibration, the dialog box shown in Figure 3.21 is opened and the inputs are inserted. The user can change the threshold, the number of traverses, the orientation of traverses (horizontal or vertical), and the paste/aggregate volume ratio. Once the Analyze button is pressed, the program then extracts a thin horizontal or vertical image from the whole image. This extracted image is then analyzed for the number of air voids and the length of air voids intersected. The script repeats the process for the user specified number of traverses.

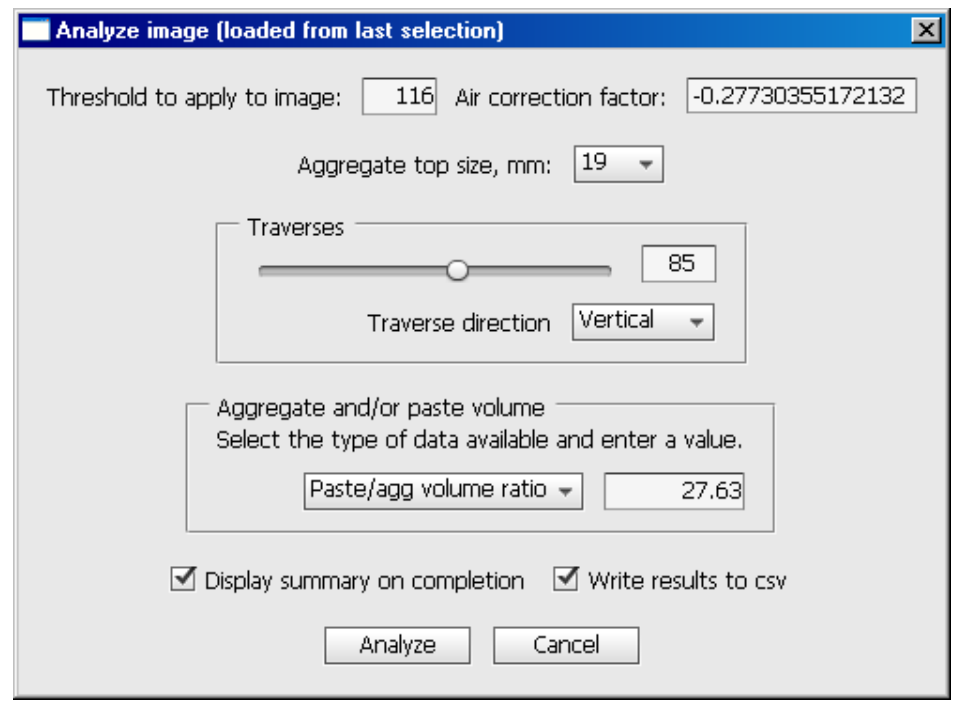

Figure 3.21 - Dialog Box for Bubble Counter 
The program then outputs the percent air content, specific surface, and spacing factor of the sample. The program also counts and sorts every bubble by size, allowing histograms of bubble size distribution to be constructed.

Using the bubble sizes, a MATLAB program was created to import the bubble sizes and counts. This program then generated a semi-log plot of the bubble distribution. The distribution was quantified by plotting the percent of bubbles larger than a value on the $\mathrm{x}$-axis, similar to the grain size distribution done in soil analysis. The slope of a linear line drawn between values $10 \%$ and $90 \%$ as well as the percent of bubbles larger than $1 \mathrm{~mm}$ help provide more clues to the air void structure.

\subsubsection{MATLAB Analysis}

The Bubble Counter program has certain limitations. Regardless of the size of the specimen, the program can only perform a maximum of 150 traverses. Also, the programming does not clearly show the calculations used for the air void analysis. MATLAB is a readily available computer software that is capable of importing images. The author of this thesis attempted to write a MATLAB program capable of conducting ASTM C457 linear traverse method.

The purpose of developing the new program was to have access to the source coding of the program, ensure compliance with ASTM C457, allow the user to specify the number of traverses desired for linear traverse analysis, and give future users the opportunity to add in any additional data collection regarding hardened air void structures. 
MATLAB imports the same image scanned for the Bubble Counter. In MATLAB, a grayscale image is transformed from an image into a matrix in which each pixel is represented by a number in the matrix. The values in the image matrix range from 0 (absolutely black) to 255 (absolutely white). Parameters set at the beginning include threshold and percent aggregate content. Percent aggregate content was previously determined by JMicroVision. The threshold dictates which pixels are considered by the program as air. In Figure 3.20, it is apparent that the edges of the specimen have many flaws that should not be considered when performing the hardened air void analysis. To remove the flaws, the image to be analyzed was offset by 1000 pixels, or approximately $7.94 \mathrm{~mm}$. An example of an offset image is shown in Figure 3.22 where the dotted box outlines the area to be examined by MATLAB. The large piece missing in the lower right corner and the irregularity of the edge in the top left corner are all eliminated from evaluation by the offset, ensuring a more accurate result.

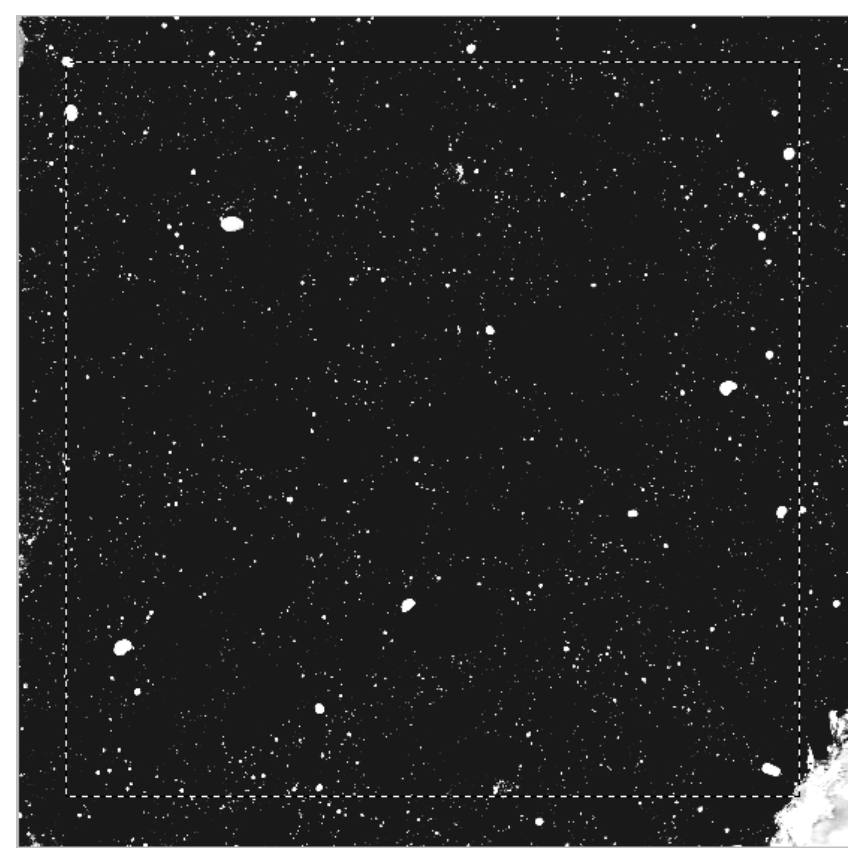

Figure 3.22 - Image Offset Example 
Using two loops, the MATLAB program then selects evenly spaced rows according to the number of traverses requested by the user. The program then analyzes every single value in that row. The program adds the amount of values that are to be considered air and adds the total number of values in the row. The program also adds the number of bubbles. Adding the number of bubbles is done by comparing the previous column value with the current value being analyzed. If the previous value is not air but the current value is air, then a new bubble has been identified and counted. The process is repeated as many times as the user has defined. An example of the traverses visually drawn in red on the image is given by Figure 3.23 and Figure 3.24. The vertical traverses follow the same pattern, except that every value in evenly spaced columns is analyzed.

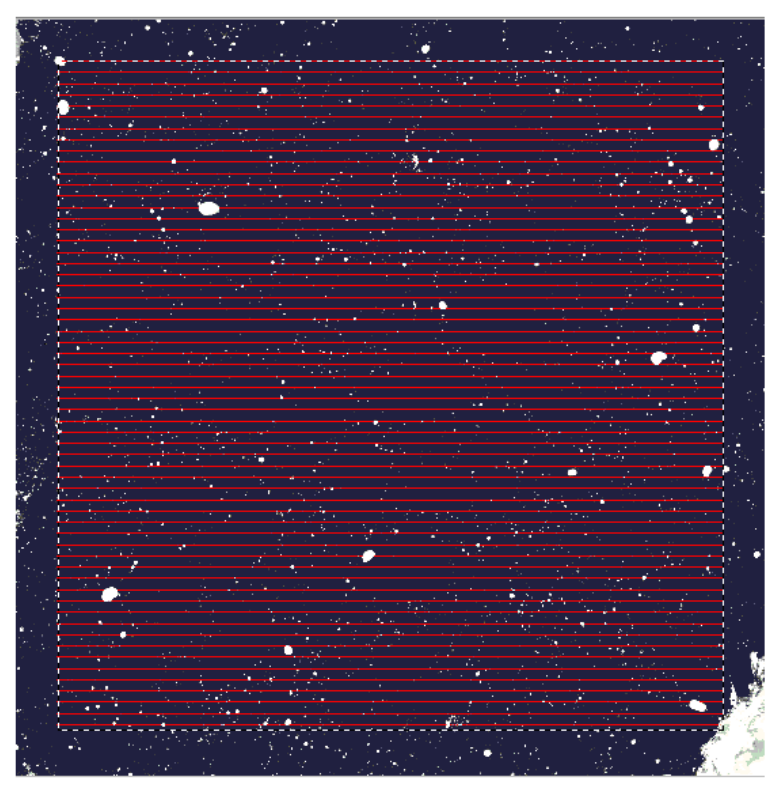

Figure 3.23 - Example of 60 horizontal traverses used in MATLAB 


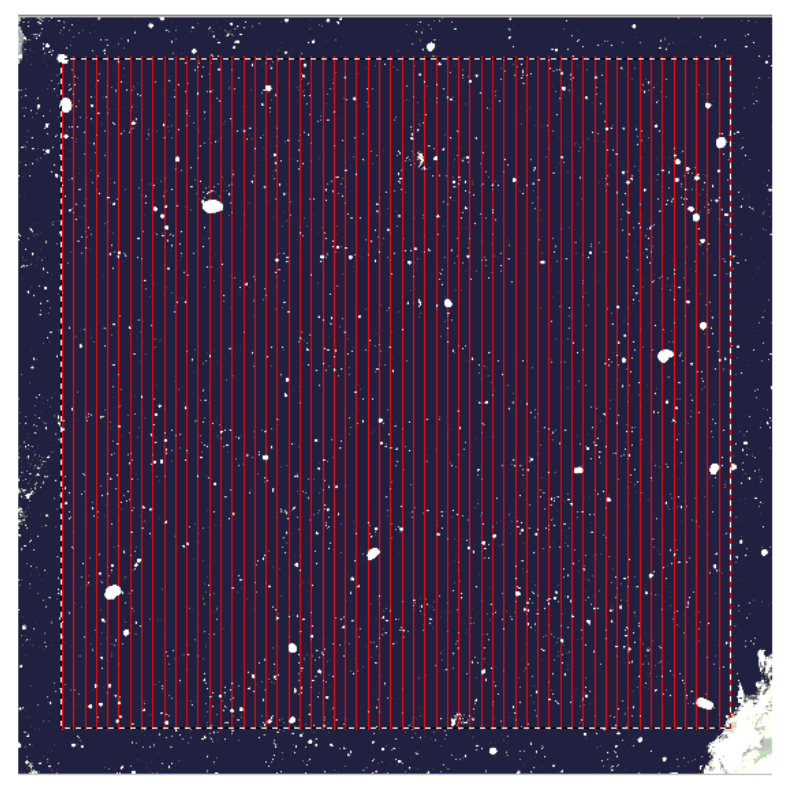

Figure 3.24 - Example of 60 vertical traverses used in MATLAB

\subsubsection{Accuracy and Convergence}

Both the Bubble Counter script and the MATLAB program can perform a wide range of traverses. The number of traverses to be performed should give a consistent result. To test the number of traverses necessary for the Bubble Counter script, a comparison of the linear traverse method in the vertical direction should be compared with a comparison of the linear traverse method in the horizontal direction. This was performed multiple times with traverses numbering $40,60,80,100,120$, and the maximum 150.

The horizontal and vertical percent air contents were then compared. The slopes of the distribution lines were also compared. The number of traverses where both the percent air content and the slope of the distribution line were most similar was the value used for the Bubble Counter script in all other future tests. 
The MATLAB program must be tested for accuracy in the same way, but it must also undergo multiple other accuracy tests. First, the MATLAB program must prove that it is comparable with the Bubble Counter script because the Bubble Counter has already been proven to be comparable with RapidAir system. If the MATLAB program is sufficiently comparable with the Bubble Counter, the vertical vs. horizontal accuracy and the minimum number of traverses necessary must be calculated. Since MATLAB can perform as many traverses as there are pixels, the effect of performing thousands of traverses can be observed as well. Most importantly, a threshold for counting air bubbles must be established. The MATLAB program is capable of running a large range of traverses, ranging from 40 to over 15000 for a 6 in. specimen. The threshold can range from 0 to 255 .

To establish a proper threshold and an appropriate number of traverses, the MATLAB program was run multiple times over a range of traverses from 40-150 with a spacing of 5 (e.g. 40, 45, 50 traverses), and then 250-1950 traverses with a spacing of 100. The maximum possible number of traverses was also run. For every traverse scenario, the values of spacing factor, specific surface, and air content were calculated for every threshold ranging from 100-255 with a spacing of 5. All data derived from this program was written into a matrix that, when charted, enabled the simultaneous establishing of a threshold and an appropriate number of traverses. The threshold was confirmed by comparing the values generated by MATLAB at 150 traverses with the values at 150 traverses using Bubble Counter. The point where the Bubble Counter and MATLAB are most similar should be the threshold used in future testing. 


\section{CHAPTER 4 - Results and Discussion}

\subsection{Stalnaker Run Bridge Specimens}

Concrete cylinders from the Stalnaker Run bridge beam production were taken from both the SCC and traditional concrete batches. Cylinders were placed with the steam cured bridge beams in a steaming chamber so the cylinders would be exposed to the same temperatures as the bridge beams. These $6 \times 12$ cylinders were used for the hardened air void analysis of both SCC and traditional concrete. Freeze thaw prisms were also formed from the same batches. Freeze thaw testing was performed on both the SCC and the traditional concrete prisms.

The $6 \times 12$ cylinders were cut lengthwise and in half. Each quarter was prepared for hardened air void analysis according to the previously detailed procedure. Figure 4.01 and Figure 4.02 show the scanned images of the prepared surfaces of the traditional concrete and the SCC, respectively. 


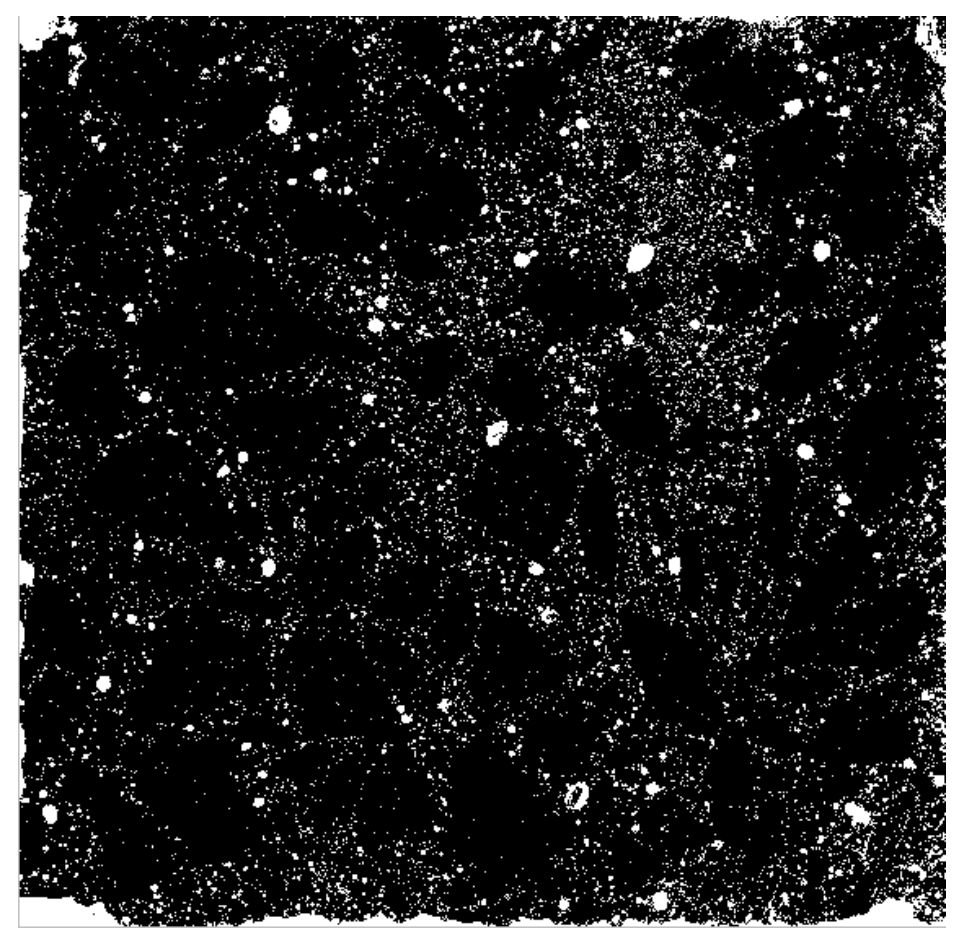

Figure 4.01 - Traditional Concrete Air Void Structure

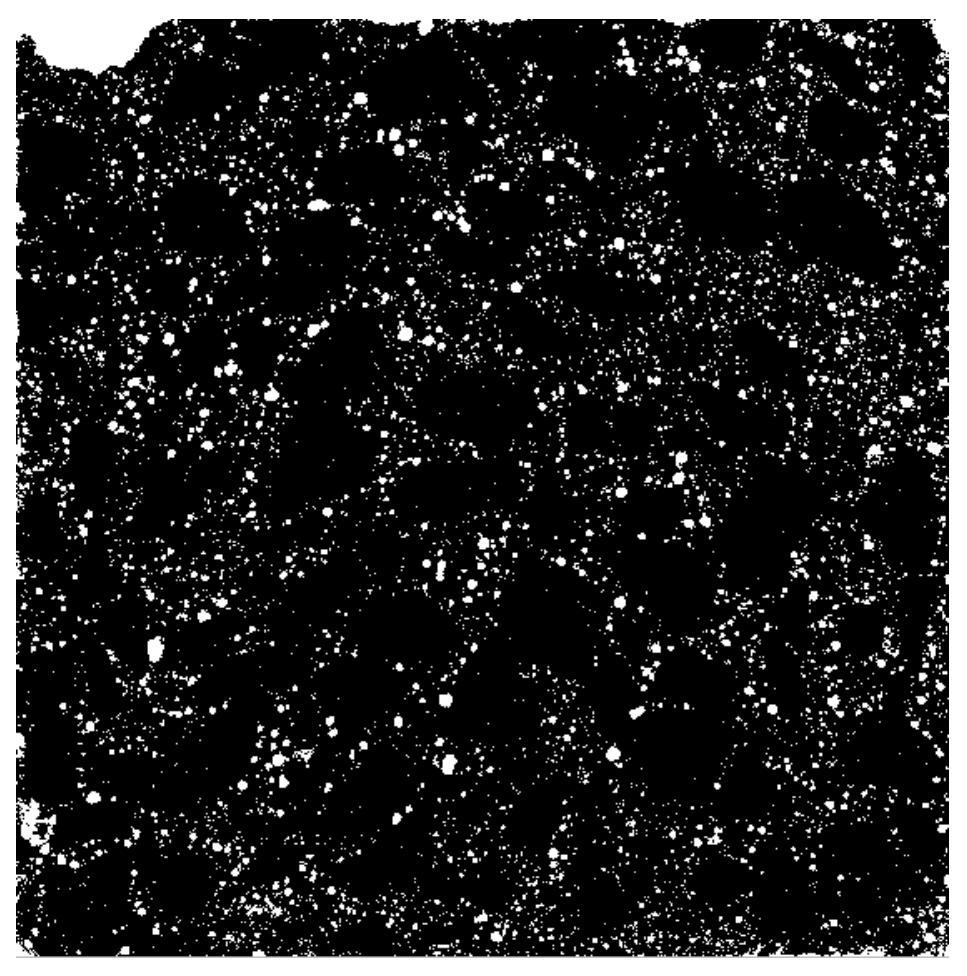

Figure 4.02 - SCC Air Void Scanned Image 
Upon visual inspection, it is apparent that the traditional concrete has a higher quantity of small closely spaced air bubbles, while SCC has a high number of large air bubbles spaced relatively far apart. The following figures further illustrate this observation

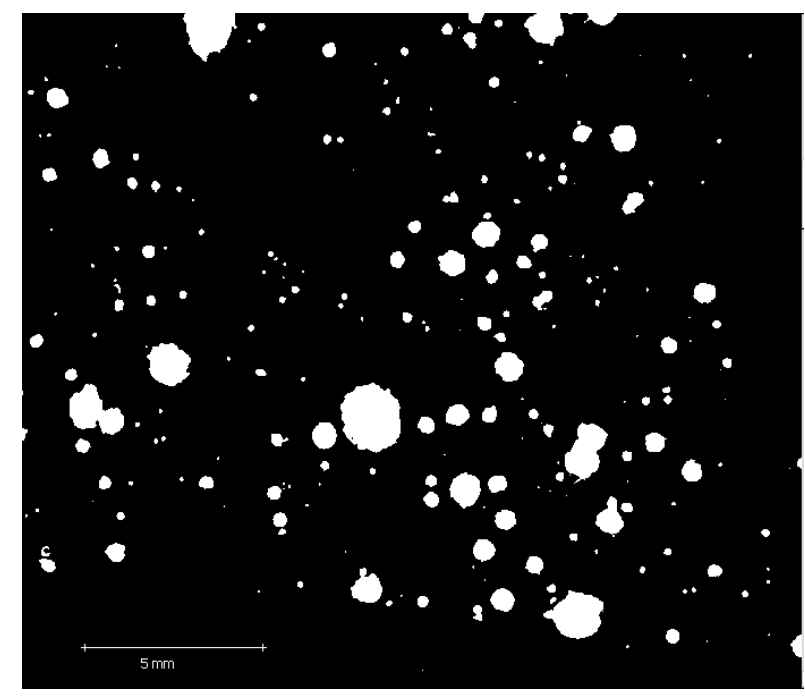

Figure 4.03 - Magnified Sample of SCC Image

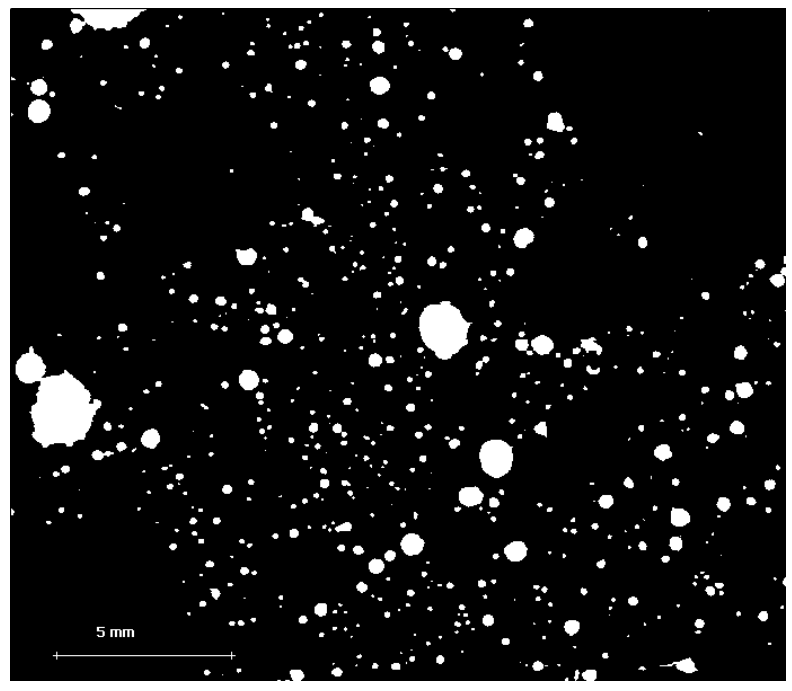

Figure 4.04 - Magnified Sample of Traditional Concrete Image 
The linear traverse method can prove the visual observation of traditional concrete having more small bubbles and SCC having larger spaced bubbles. If the normal concrete truly has more small bubbles, then the spacing factor, the ratio of bubble surface area to bubble volume, should be higher than SCC. Also, more bubbles imply that the bubbles are spaced more closely together. If this assumption is true, then the spacing factor, the average distance between air bubbles, should be smaller for normal concrete.

\subsubsection{Convergence}

Before the prepared samples can be analyzed, the Bubble Counter script must be tested for accuracy at a varying number of traverses. The script was run using three different samples: SCC1_1, SCC1_2, and SCC2_1. The second number denotes a lengthwise half of the specimen. The first number specifies either the top, given by a 1 , or the bottom, given by a 2 of the cylinder. Thus, SCC1_1 is directly above SCC2_1 and opposite SCC1_2. Each sample was run through the Bubble Counter a total of 6 times with traverse numbers ranging from 40 to 150 . Then, the slope of the percent larger curve was taken for each case. The process was done for both horizontal and vertical traverses, and the two were directly compared. Table 4.01 shows the percent differences between the horizontal and vertical traverses with respect to air and slope. 
Table 4.01 - Horizontal vs. Vertical Traverse Comparisions

\begin{tabular}{|l|l|l|l|l|}
\hline SCC 1_1 & $\begin{array}{l}\% \\
\text { Difference }\end{array}$ & & $\begin{array}{l}\text { Air } \\
\text { Content }\end{array}$ & $\begin{array}{l}\text { Average } \\
\text { Slope }\end{array}$ \\
\hline Traverses & Air & Slope & & \\
\hline 40 & $9.01 \%$ & $3.83 \%$ & 5.25 & -0.503 \\
\hline 60 & $0.74 \%$ & $6.07 \%$ & 5.35 & -0.530 \\
\hline 80 & $1.01 \%$ & $1.70 \%$ & 5.28 & -0.535 \\
\hline 100 & $1.38 \%$ & $3.59 \%$ & 5.23 & -0.539 \\
\hline 120 & $1.10 \%$ & $1.14 \%$ & 5.20 & -0.532 \\
\hline 150 & $0.48 \%$ & $1.09 \%$ & 5.25 & -0.536 \\
\hline
\end{tabular}

\begin{tabular}{|l|l|l|l|l|}
\hline SCC 1_2 & $\begin{array}{l}\% \\
\text { Difference }\end{array}$ & & $\begin{array}{l}\text { Air } \\
\text { Content }\end{array}$ & $\begin{array}{l}\text { Average } \\
\text { Slope }\end{array}$ \\
\hline Traverses & Air & Slope & & \\
\hline 40 & $9.01 \%$ & $3.83 \%$ & 4.70 & -0.500 \\
\hline 60 & $1.12 \%$ & $0.84 \%$ & 4.69 & -0.567 \\
\hline 80 & $1.51 \%$ & $0.82 \%$ & 4.69 & -0.579 \\
\hline 100 & $1.02 \%$ & $1.20 \%$ & 4.67 & -0.573 \\
\hline 120 & $1.23 \%$ & $1.05 \%$ & 4.70 & -0.565 \\
\hline 150 & $1.87 \%$ & $0.96 \%$ & 4.68 & -0.569 \\
\hline
\end{tabular}

\begin{tabular}{|l|l|l|l|l|}
\hline SCC 2_1 & $\begin{array}{l}\% \\
\text { Difference }\end{array}$ & & $\begin{array}{l}\text { Air } \\
\text { Content }\end{array}$ & $\begin{array}{l}\text { Average } \\
\text { Slope }\end{array}$ \\
\hline Traverses & Air & Slope & & \\
\hline 40 & $4.32 \%$ & $0.18 \%$ & 5.22 & -0.438 \\
\hline 60 & $4.96 \%$ & $0.86 \%$ & 5.10 & -0.468 \\
\hline 80 & $2.21 \%$ & $1.60 \%$ & 5.13 & -0.469 \\
\hline 100 & $1.84 \%$ & $0.06 \%$ & 5.16 & -0.464 \\
\hline 120 & $1.82 \%$ & $2.06 \%$ & 5.20 & -0.461 \\
\hline 150 & $1.19 \%$ & $2.18 \%$ & 5.10 & -0.465 \\
\hline
\end{tabular}




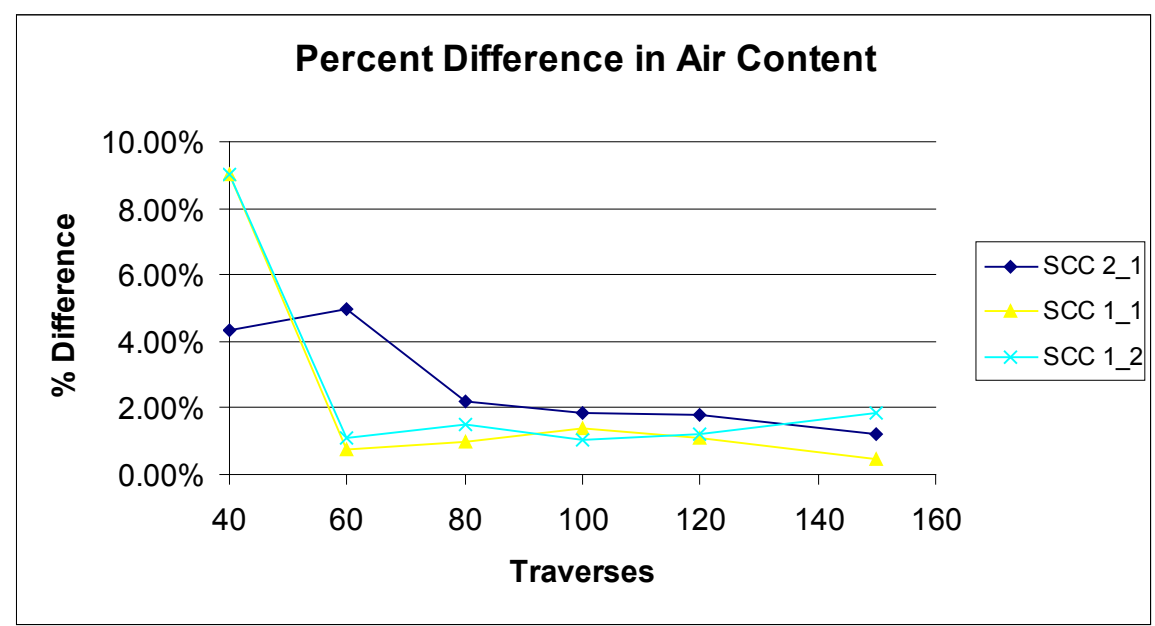

Figure 4.05 - Percent Difference in Air Content

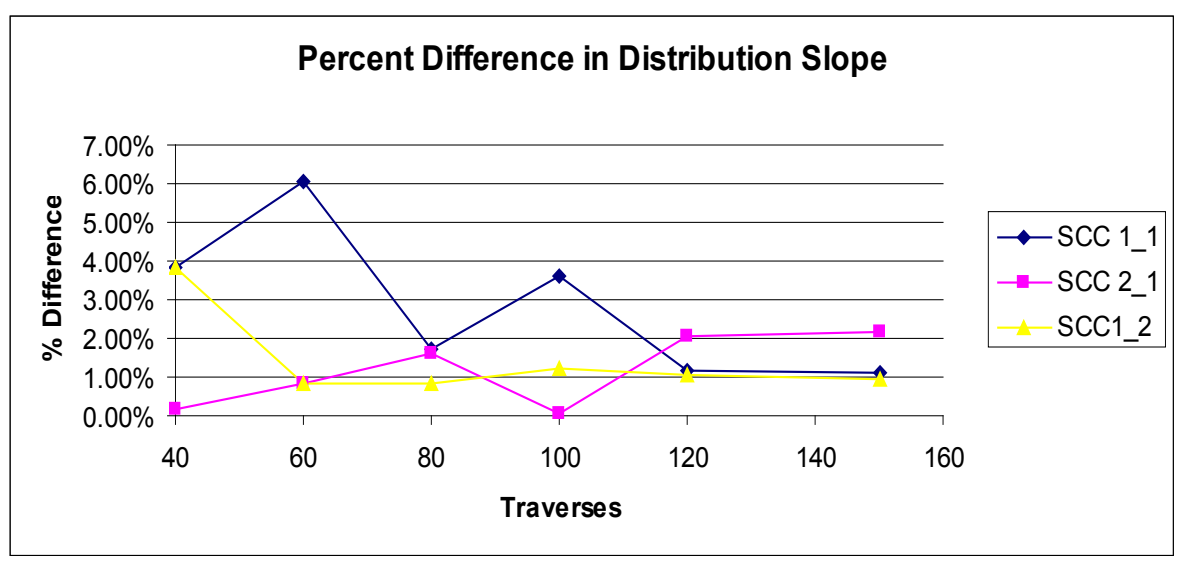

Figure 4.06 - Percent Difference in Bubble Distribution Slope

As is evident in the graphs, fluctuations in the percent difference of both properties are seen until the 120 traverse mark. The maximum 150 traverses is also shown to be acceptable. In conclusion, a minimum of 120 traverses was used for all future 6 inch square sample surfaces. 


\subsubsection{Analyzing the Air Voids of the Stalnaker Run Specimens}

The specimens for both traditional concrete and SCC were both tested using the linear traverse method using the Bubble Counter script. For each surface, 150 traverses were used. The top half of Table 4.02 contains the results from the SCC samples. The bottom half contains the results from the traditional concrete samples. Results from the other half of specimens are in the Appendix.

Table 4.02 - Air Void Properties of Stalnaker Run Concrete

\begin{tabular}{|l|l|l|}
\multicolumn{1}{c}{} & Top & \multicolumn{1}{l}{ Bottom } \\
\hline & SCC1_2 & SCC2_2 \\
\hline Air Content & 5.29 & 4.2 \\
\hline Spacing Factor $(\mathrm{mm})$ & 0.2284 & 0.3221 \\
\hline Specific Surface $\left(\mathrm{mm}^{-1}\right)$ & 22.346 & 17.857 \\
\hline
\end{tabular}

\begin{tabular}{|l|l|l|}
\hline & TC1_2 & TC2__2 \\
\hline Air Content & 4.45 & 4.22 \\
\hline Spacing Factor(mm) & 0.2308 & 0.2205 \\
\hline Specific Surface $\left(\mathrm{mm}^{-1}\right)$ & 23.529 & 25.316 \\
\hline
\end{tabular}

Though the SCC has higher air content than the traditional concrete, the average spacing factor is higher. The higher value means that the bubbles are spaced farther apart than the traditional concrete's bubbles. The specific surface of the SCC is also lower than the traditional concrete. A lower specific surface means that the air voids are larger. Concretes with larger air voids have fewer voids than those of equivalent air content with small air voids. A higher number of air voids can reduce the spacing factor. Spacing factor and specific surface are related in this way. 
ASTM C457 recommends that the spacing factor should be less than $0.2 \mathrm{~mm}$ and the specific surface be in the range of 25 to $45 \mathrm{~mm}^{-1}$. Both of the traditional concrete's spacing factors are very near the recommended value, but the bottom half of the SCC is $0.1 \mathrm{~mm}$ above the limit. The traditional concrete specific surface is very near the ASTM value, but the bottom SCC specific surface is significantly below the ASTM value. The superior air void structure of the traditional concrete is the most likely reason for the traditional concrete's better freeze thaw durability and the SCC's early freeze-thaw failure.

The difference between the top and the bottom of the SCC should be noted. The difference between the top and bottom halves of the traditional concrete showed very minor differences in each of the three properties measured. The SCC top half contained significantly more air than the bottom half. The major difference in air content gives the top half a significantly better air void structure than the bottom half. If an SCC mix displays a very low viscosity, air bubbles entrained in the concrete can float up through the paste and leave the bottom half of the concrete susceptible to damage from freeze thaw cycling.

\subsection{Laboratory Replication}

The SCC used in the Stalnaker Run bridge beams was replicated in the laboratory using the theoretical mix design. The same Type III cement used for the Stalnaker Run bridge beams was acquired for the mix. The coarse aggregate used was a \#67 limestone. The natural sand was natural silica sand stored in sealed buckets to prevent moisture loss. 
Moisture tests were performed on the silica sand and the limestone. After oven drying, the limestone was found to have $0 \%$ moisture content. The sand was found to have $0.1 \%$ moisture. Both the limestone and sand have an absorption percent of $0.3 \%$ as provided by the suppliers. As a result, the water added and the amount of sand in the mix had to be adjusted slightly to account for the lack of water present in the aggregate. The design used for mixing the SCC in the laboratory is shown in Table 4.03. A volume of $2.5 \mathrm{ft}^{3}$ of SCC was mixed.

Table 4.03 - Mix Design for Batch 1 of Lab SCC

\begin{tabular}{|l|l|}
\hline Material & $\mathrm{lb} / \mathrm{yd}^{3}$ \\
\hline Type III Cement & 735 \\
\hline Silica Fume & 75 \\
\hline Coarse Aggregate & 1443 \\
\hline Natural Sand & 1326.5 \\
\hline Water & 284 \\
\hline HRWRA* & 14.2 \\
\hline VMA* $^{*}$ & 1.85 \\
\hline AEA* & 2.84 \\
\hline
\end{tabular}

Values are in oz/CWT

Tests for slump flow, J-ring flow, fresh air content, and unit weight were performed. The values for the fresh properties tested are given in Table 4.04. The VSI was determined to be 1 because of the lack of a mortar halo but a slightly uneven distribution of aggregates as shown in Figure 3.06. 


\section{Table 4.04 - Fresh Properties of SCC Lab Batch 1}

\begin{tabular}{|l|l|}
\hline Slump Flow (in) & 29.5 \\
\hline Air content (\%) & 2.9 \\
\hline J-ring (in.) & 27 \\
\hline $\begin{array}{l}\text { Unit Weight } \\
\left(\mathrm{lb} / \mathrm{ft}^{3}\right)\end{array}$ & 179.25 \\
\hline VSI & 1 \\
\hline
\end{tabular}

The target air content was 5\%, so the fresh air content reading was much lower than expected. The slump flow was also very high, indicating very low viscosity. This very low viscosity could be a factor in the low air content.

A total of $4-6 \times 12$ cylinders, $8-4 \times 8$ cylinders, and $6-3 \times 4 \times 16$ rectangular freeze thaw prisms were cast. An additional prism was cast using waste concrete from the fresh air content test and a thermocouple was inserted in the center.

After curing for 6 hours at room temperature, half of the cast specimens were placed in a warm water bath at $48^{\circ} \mathrm{C}$. The other half of specimens were placed in a lime water bath at room temperature. At 24 hours after mixing, the specimens in the warm water bath were removed and placed in a lime water bath at room temperature. Two 4x8 cylinders from the warm water cured specimens and two from the room temperature cured specimens were tested for strength. The 24 hour and 28 day compressive strength of both are given in Table 4.05. Moist cured signifies the lime water bath at room temperature and steam signifies the specimens placed in the warm water bath. Both moist and steam cured specimens had very high strength after 28 days. 


\section{Table 4.05 - Strength Values for SCC Batch 1}

\begin{tabular}{|l|l|l|}
\hline (psi) & Moist & Steam \\
\hline \multirow{3}{*}{-Day } & 5016 & 6608 \\
\cline { 2 - 3 } & 5334 & 6529 \\
\hline \multirow{2}{*}{ 28-Day } & 9554 & 10350 \\
\cline { 2 - 3 } & 10271 & 10669 \\
\hline
\end{tabular}

All freeze thaw prisms were placed in water filled containers and placed in the freeze thaw chamber. The chamber reached a maximum air temperature of $16.16^{\circ} \mathrm{C}$ and a minimum of $-28.6^{\circ} \mathrm{C}$. An example of 30 cycles of freezing and thawing is shown in Figure 4.07. A complication with the machine was noted after the first 60 cycles. The machine was programmed to reach a temperature of $-30^{\circ} \mathrm{C}$ but did not reach the value. A probable reason for the inadequate temperature is that the test was performed during summer in the concrete laboratory. The ambient temperature outside the freeze thaw chamber reached $27^{\circ} \mathrm{C}$. The machine was incapable of reaching the low target temperature in this very high room temperature. The lowest core temperature recorded in the freeze-thaw chamber was $-14^{\circ} \mathrm{C}$ and the highest was $5^{\circ} \mathrm{C}$. The later freeze-thaw cycles were even more drastic, some reaching a low of only $-20^{\circ} \mathrm{C}$. The core thaw temperature was acceptable but the core freezing temperature was not. 


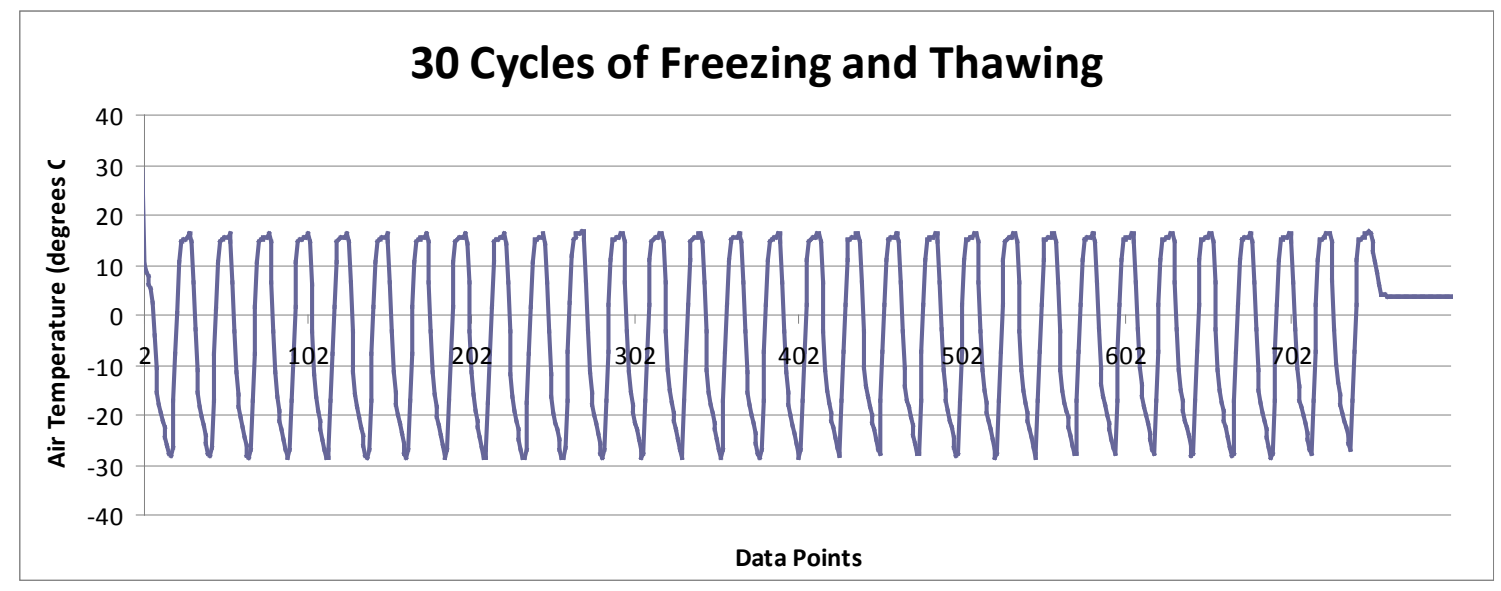

Figure 4.07 - Air Temperature Readings for 30 Cycles of Freeze-Thaw

Every 30 cycles, specimens were tested for relative dynamic modulus using transverse and longitudinal frequency tests. The results for the relative dynamic modulus are shown.

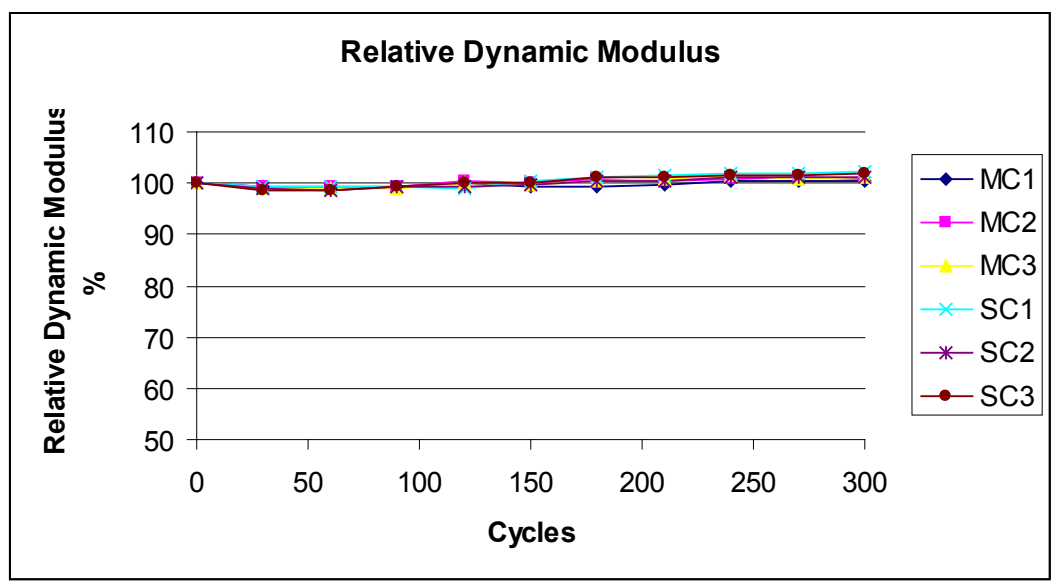

Figure 4.08 - Dynamic Modulus Using Longitudinal Frequency 


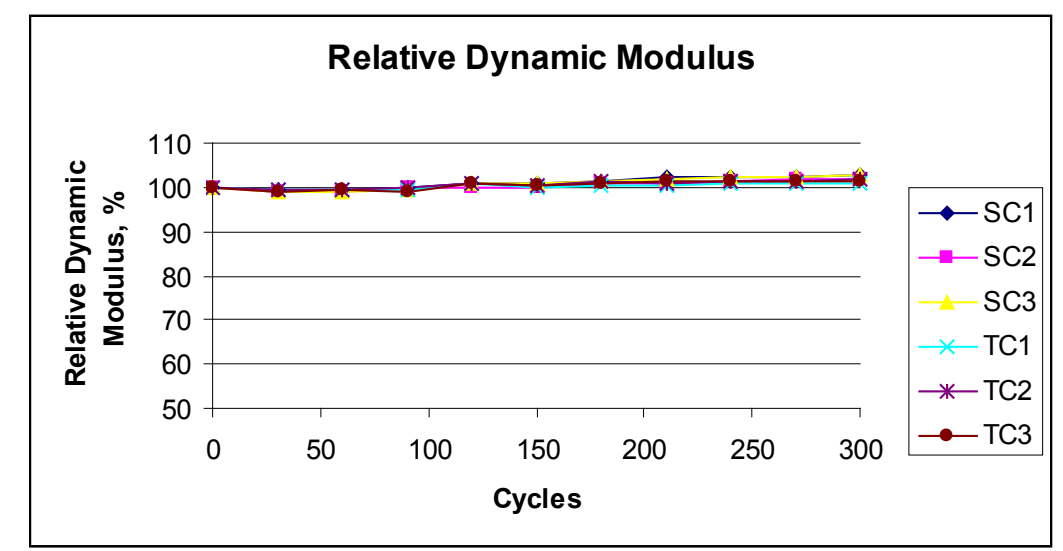

Figure 4.09 - Dynamic Modulus Using Transverse Frequency

Both graphs agree that every specimen passed the freeze thaw test after 300 cycles. The relative dynamic modulus actually slightly increased. However, these results can be disputed because of the core temperature of the specimens did not always reach the required low temperature.

\subsection{Air Void Analysis}

\subsubsection{Calibration}

To calibrate the MATLAB program, the program was run over an image multiple times using different threshold values ranging from 170-255. The Bubble Counter was run on the same script, and the MATLAB values were compared with the Bubble Counter results. The percent difference in the Bubble Counter results and the MATLAB results is shown for two concrete samples in Figure 4.10 and Figure 4.11. The figures show that the specific surface for a sample does not greatly depend on the threshold. However, the air content and spacing factor are greatly affected by the threshold value. 
For both of the trials, the threshold that gives the highest correlation is approximately 200.

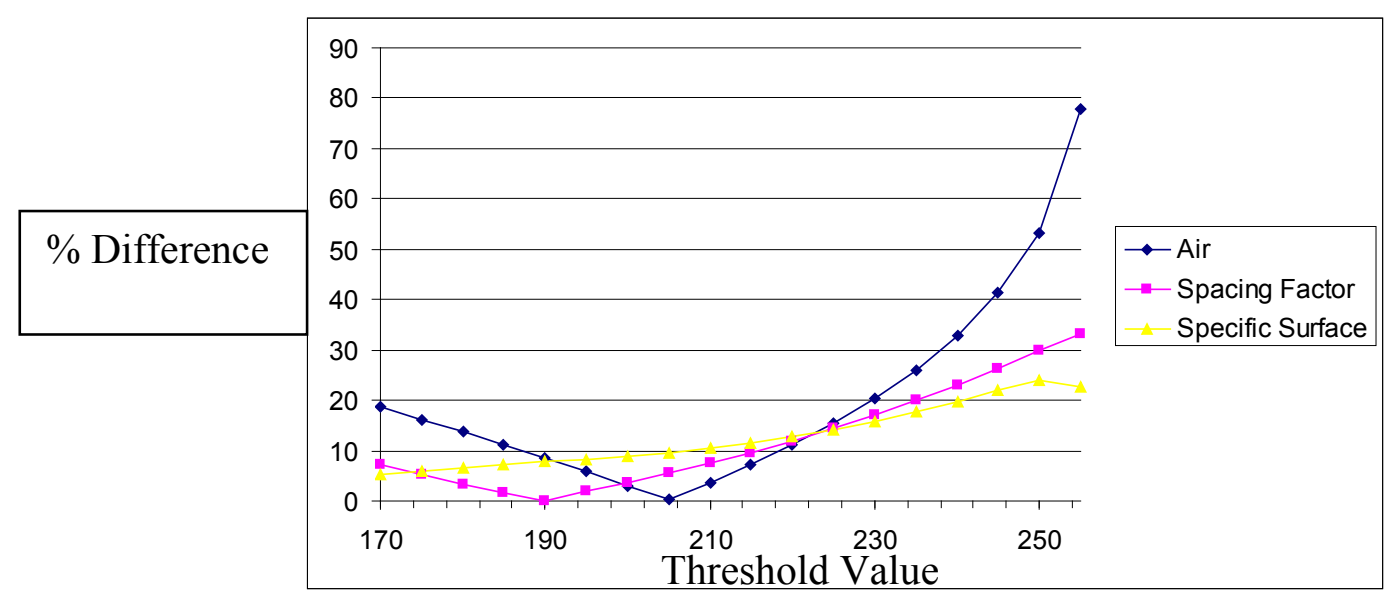

Figure 4.10 - Difference in MATLAB and Bubble Counter with Varying Thresholds Trial 1

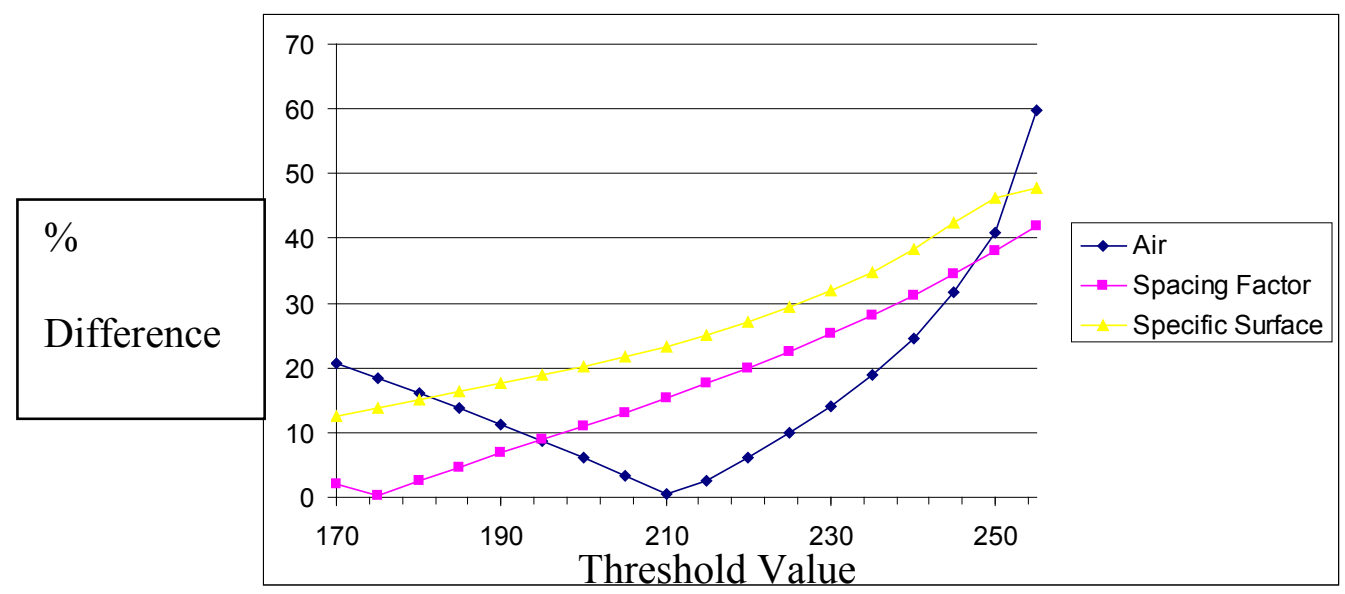

Figure 4.11 - Difference in MATLAB and Bubble Counter with Varying Thresholds

Trial 2 
Now that the proper threshold has been determined, the number of traverses necessary to ensure accuracy must be determined. The MATLAB program was run for many traverses in both the horizontal and vertical direction. The minimum needed number of traverses was found at the location where the vertical and horizontal results were closest. The MATLAB program was run multiple times using differing numbers of traverses ranging from 150 to 1950 as well as different threshold values ranging from 100-255. The percent difference between the vertical and horizontal results of the spacing factor and specific surface are shown below.

\section{\% Difference - Spacing Factor}

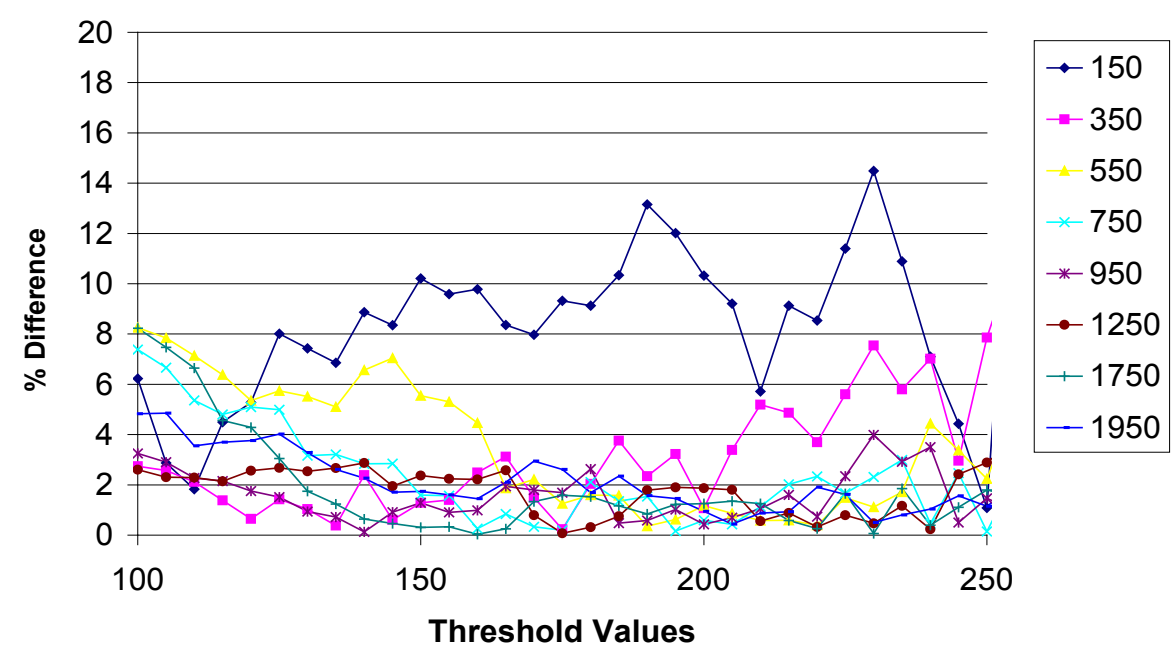

Figure 4.12 - Difference in Spacing Factor of Vertical vs. Horizontal in MATLAB 


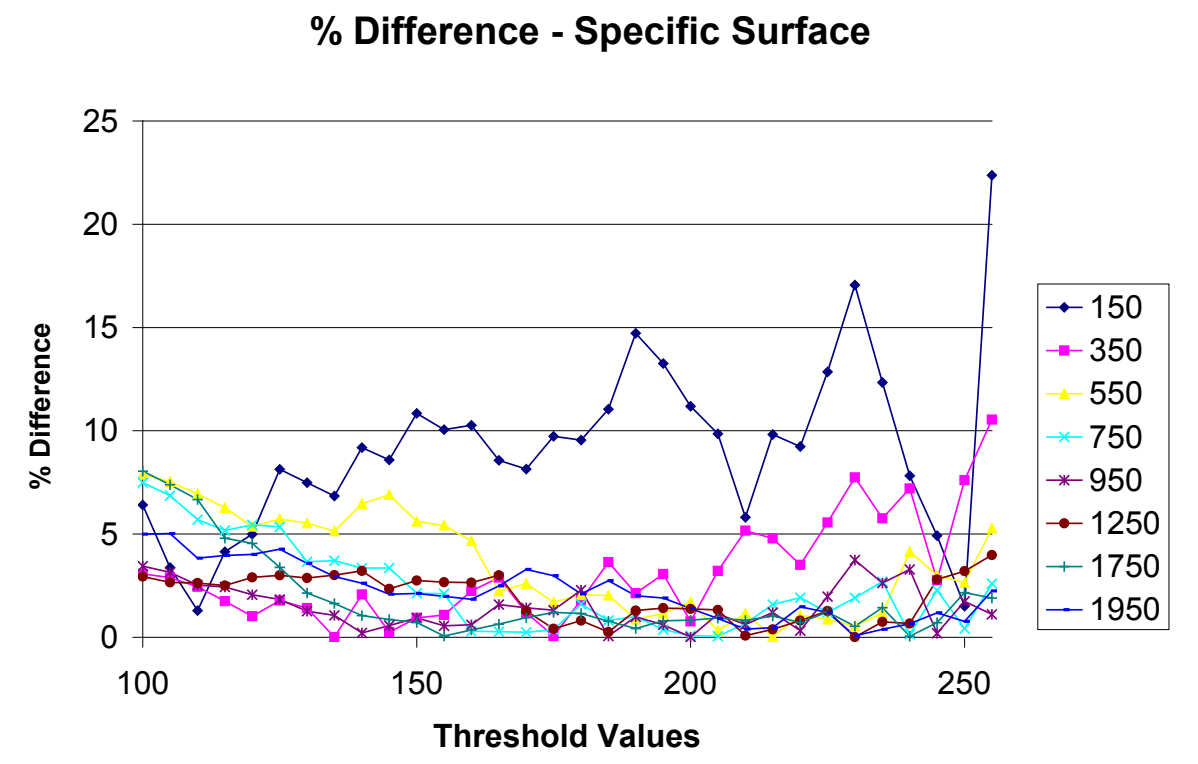

Figure 4.13 - Difference in Specific Surface of Vertical vs. Horizontal in MATLAB

The graph shows a clear correlation between the number of traverses used and the difference between horizontal and vertical results. The higher the number of traverses, the lower the percent difference between horizontal and vertical. This data combined with MATLAB's capabilities means that the maximum number of traverses, that is the number of pixels in the image, can be safely used for the linear traverse method.

\subsubsection{Hardened Air Properties of Batch 1}

The linear traverse method was performed on 6x12 cylinders cast from batch 1.

One cylinder analyzed was from the steam cured set, and the other from the room temperature moist cured set. The top and bottom halves of each cylinder were polished, prepared, and analyzed using Bubble Counter and MATLAB. In addition to air content, 
spacing factor, and specific surface, the slope of the distribution line in a semi-log graph and the percent of bubbles larger than $1 \mathrm{~mm}$ were calculated.

Table 4.06 - Hardened Air Results for Steam Cured Specimen

\begin{tabular}{|c|c|c|c|c|}
\hline \multicolumn{3}{|c|}{ Vertical } & \multicolumn{2}{|l|}{ Horizontal } \\
\hline SC1 - T1 & $\begin{array}{l}\text { Bubble } \\
\text { Counter }\end{array}$ & MATLAB & $\begin{array}{l}\text { Bubble } \\
\text { Counter }\end{array}$ & MATLAB \\
\hline Air Content & 1.44 & 1.5 & 1.45 & 1.508 \\
\hline Spacing Factor & 0.4746 & 0.472 & 0.4978 & 0.474 \\
\hline $\begin{array}{l}\text { Specific } \\
\text { Surface }\end{array}$ & 29.63 & 25.748 & 28.169 & 25.642 \\
\hline Slope & & -34.81 & & -34.35 \\
\hline Percent $>1 \mathrm{~mm}$ & & 1.4 & & 1.2 \\
\hline & \multicolumn{2}{|l|}{ Vertical } & \multicolumn{2}{|c|}{ Horizontal } \\
\hline $\mathrm{SC} 1$ - B1 & $\begin{array}{l}\text { Bubble } \\
\text { Counter }\end{array}$ & MATLAB & $\begin{array}{l}\text { Bubble } \\
\text { Counter }\end{array}$ & MATLAB \\
\hline Air Content & 1.09 & 1.319 & 1.15 & 1.274 \\
\hline Spacing Factor & 0.54 & 0.54 & 0.4742 & 0.556 \\
\hline $\begin{array}{l}\text { Specific } \\
\text { Surface }\end{array}$ & 25.641 & 23.767 & 28.571 & 23.419 \\
\hline Slope & & -36.2 & & -32.8 \\
\hline Percent $>1 \mathrm{~mm}$ & & 2.1 & & 1 \\
\hline
\end{tabular}

Table 4.07 - Hardened Air Void Properties for Most-Cured Specimen

\begin{tabular}{|c|c|c|c|c|}
\hline \multicolumn{3}{|c|}{ Vertical } & \multicolumn{2}{|c|}{ Horizontal } \\
\hline MC1 - T1 & $\begin{array}{l}\text { Bubble } \\
\text { Counter }\end{array}$ & MATLAB & $\begin{array}{l}\text { Bubble } \\
\text { Counter }\end{array}$ & MATLAB \\
\hline Air Content & 1.61 & 1.734 & 1.61 & 1.74 \\
\hline Spacing Factor & 0.4002 & 0.441 & 0.4004 & 0.45 \\
\hline $\begin{array}{l}\text { Specific } \\
\text { Surface }\end{array}$ & 30.769 & 25.967 & 30.769 & 25.438 \\
\hline Slope & & -35.35 & & -35.31 \\
\hline Percent $>1 \mathrm{~mm}$ & & 1.1 & & 1.1 \\
\hline
\end{tabular}




\begin{tabular}{|l|l|l|l|l|}
\multicolumn{3}{|c}{ Vertical } & \multicolumn{3}{c|}{ Horizontal } \\
\hline MC1 - B1 & $\begin{array}{l}\text { Bubble } \\
\text { Counter }\end{array}$ & MATLAB & $\begin{array}{l}\text { Bubble } \\
\text { Counter }\end{array}$ & MATLAB \\
\hline Air Content & 1.71 & 1.787 & 1.64 & 1.742 \\
\hline Spacing Factor & 0.3825 & 0.402 & 0.3649 & 0.404 \\
\hline $\begin{array}{l}\text { Specific } \\
\text { Surface }\end{array}$ & 31.25 & 28.143 & 33.333 & 28.296 \\
\hline Slope & & -35.47 & & -39.37 \\
\hline Percent $>1 \mathrm{~mm}$ & & 0.6 & & 0.6 \\
\hline
\end{tabular}

The specific surface of both moist cured and steam cured specimens were shown to be comfortably within the recommended range given by ASTM. The moist cured specimen displayed higher air content and a lower spacing factor than the steam cured specimen. Regardless, both the steam cured and moist cured specimens have spacing factors that are almost double the maximum requirement provided by ASTM. The large spacing factors imply that the concrete from both curing methods should not withstand the 300 freeze thaw cycles. The acceptable specific surface and the poor spacing factor mean that the concrete has small bubbles, but not enough small bubbles to grant freeze thaw protection.

The size distribution of the bubbles in the sample was plotted in a histogram. From the histograms in Figure 4.14, the relationships between the top and bottom of the samples can be seen. For the steam cured specimen, the top had higher air content but a comparable spacing factor and specific surface. The histogram reflects these findings in that the shapes of the histograms are very similar, but the top half has a greater quantity of bubbles. For the moist cured specimens, every property is nearly equal for both top 
and bottom. The histograms for the top and bottom of the moist cured specimen are very similar in shape and quantity.
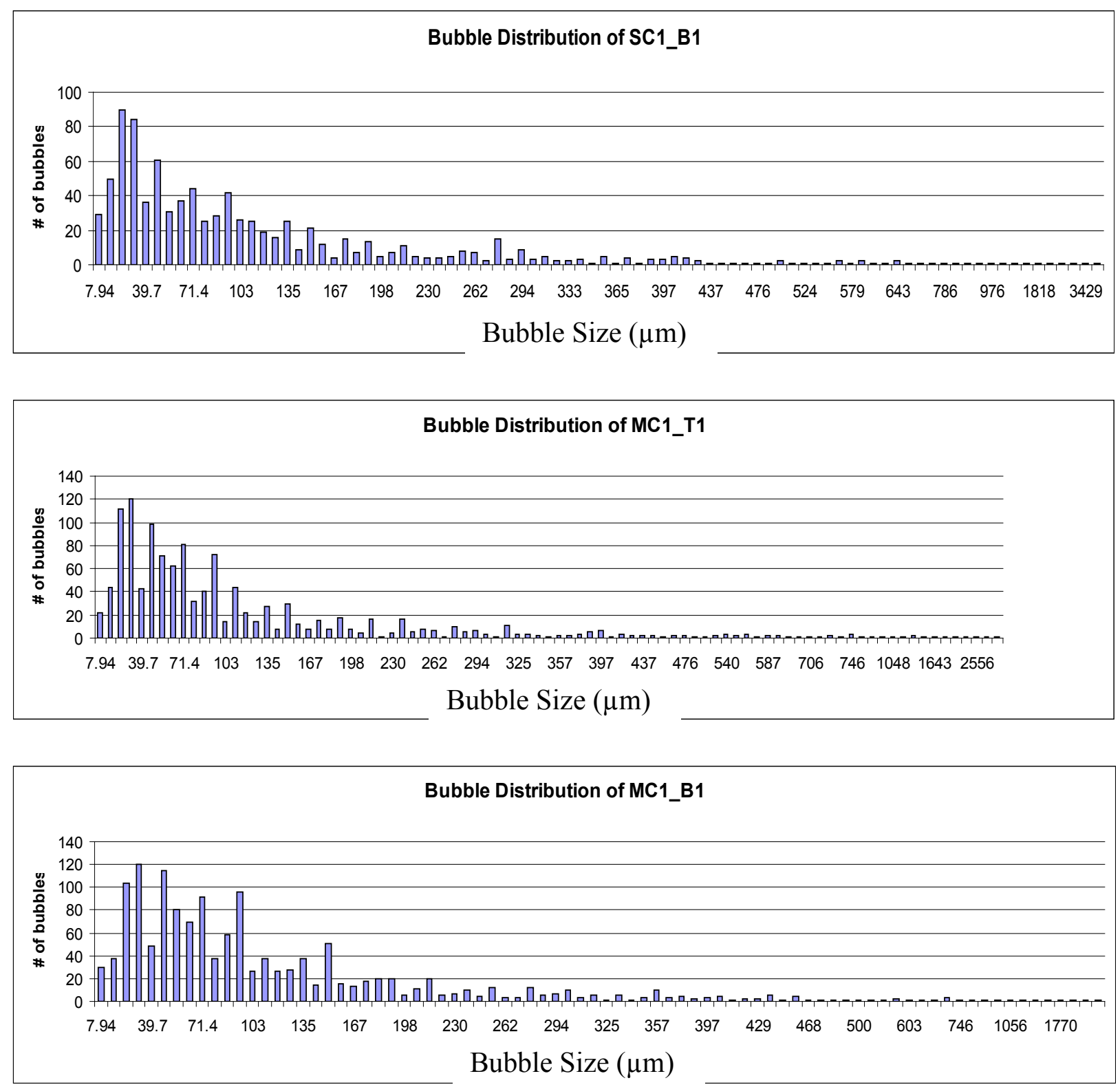

Figure 4.14 - Bubble Size Distributions Batch 1

In conclusion, the fresh air content was much lower than the target air content of

$5 \%$. The concrete from batch 1 had very high strength regardless of curing procedure. 
The low air content lead to poor air void structure, which should cause failure in freeze thaw testing. Based on these results, a second batch of concrete was cast.

\subsection{Laboratory Replication Batch 2}

A second batch was cast using the same materials as the first batch. One problem with the first batch is that the slump flow was too high, potentially allowing segregation to occur. Also, the fresh air content was well below the target of 5\%. The mix design was also changed to reflect the mix design actually used in the field instead of the theoretical mix. Air entraining admixture dosage was increased as well as viscosity modifying admixture VMA. The moisture content of the sand was measured by taking a representative sample after mixing all of the sand and oven drying the sample. The sand had an absorption of $8 \%$ which means the sand was well above the SSD condition. The entire batch of sand was then placed in pans and allowed to air dry for days. After air drying, the absorption was measured again by oven drying and the absorption was $4 \%$.

Table 4.08 - Mix Design Used for Batch 2

\begin{tabular}{|l|l|}
\hline Material & $\mathrm{lb} / \mathrm{yd} 3$ \\
\hline $\begin{array}{l}\text { Type III } \\
\text { Cement }\end{array}$ & 735 \\
\hline Silica Fume & 58 \\
\hline \#67 Limestone & 1446 \\
\hline Natural Sand & 1331 \\
\hline Water & 289 \\
\hline HRWRA* & 14.97 \\
\hline VMA* $^{*}$ & 2.09 \\
\hline AEA* & 3.14 \\
\hline
\end{tabular}

$*_{\text {in }} \mathrm{oz} / \mathrm{CWT}$ 
Tests for slump flow, J-ring flow, fresh air content, and unit weight were conducted. The results are shown in Table 4.09.

\section{Table 4.09 - Fresh Concrete Properties of Batch 2}

\begin{tabular}{|l|l|}
\hline Air Content \% & 3 \\
\hline Slump Flow (in) & 29 \\
\hline J-ring (in) & 24.5 \\
\hline $\begin{array}{l}\text { Unit Weight } \\
(\mathrm{lb} / \mathrm{ft} 3)\end{array}$ & 186.05 \\
\hline VSI & 1 \\
\hline
\end{tabular}

The concrete in batch 2 showed very similar results to batch 1 . The slump flow was very high, and the air content was very low. Six $3 \times 4 \times 16$ prisms, eight $4 \times 8$ cylinders, and two $6 \times 12$ cylinders were cast for freeze thaw testing, compression strength testing, and hardened air void analysis, respectively.

Similar to batch 2 , half of the specimens were steam cured in a warm water bath and the other half were moist cured under wet burlap and a plastic tarp. The steam curing more closely followed the temperature curve of the steam cured Stalnaker Run bridge beams. The steam curing reached a temperature of $71^{\circ} \mathrm{C}$ and maintained this temperature for 5 hours. The temperature was then reduced to $49^{\circ} \mathrm{C}$ until 24 hours. The water heaters were then turned off and the water was allowed to reach room temperature. The temperature time curve to which steam cured specimens were subjected is shown in Figure 4.15. 


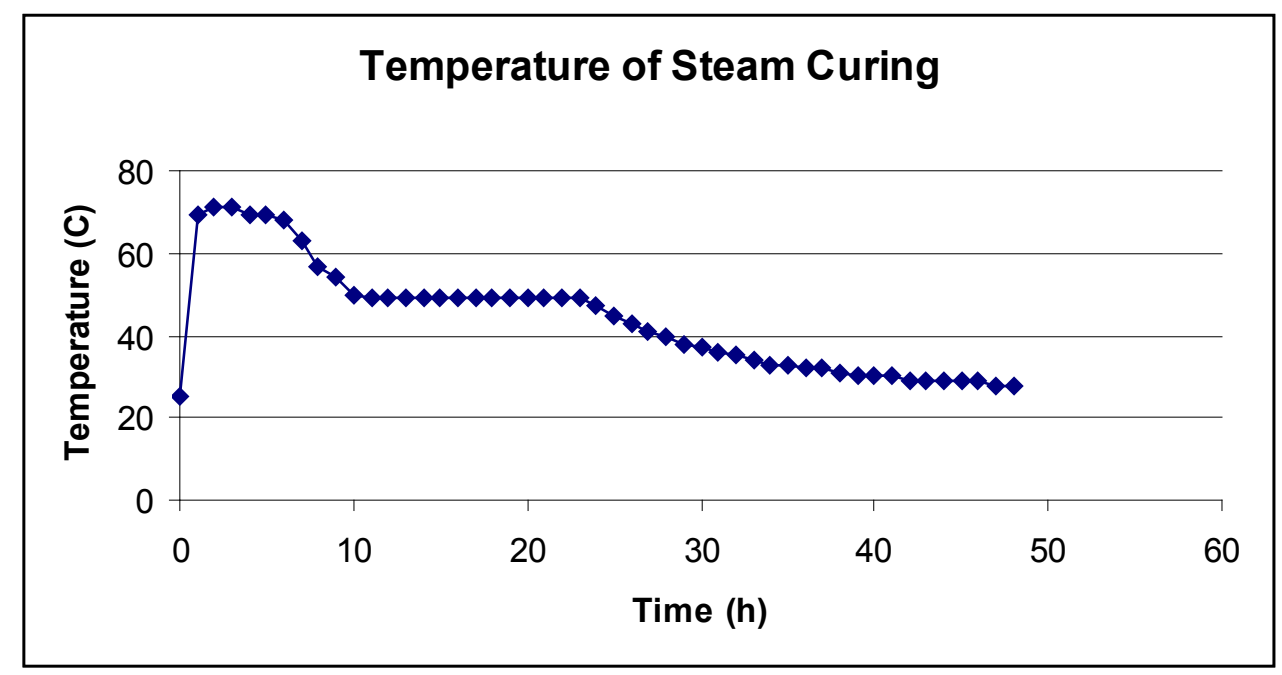

Figure 4.15 - Temperature of Steam Curing Water

The compressive strength test after 24 hours was performed on two cylinders from the steam cured and the moist cured batches. The test was done incorrectly and yielded artificially low results and the results were omitted. Rubber pads of incorrect size were used, and cracked the compressive specimens. The 28 day compressive strength was successfully measured.

Table 4.10 - Compressive Strength of Batch 2

\begin{tabular}{|l|l|l|}
\hline (psi) & Moist & Steam \\
\hline \multirow{2}{*}{ 28-Day } & 11,615 & 12,212 \\
\cline { 2 - 3 } & 11,575 & 11,734 \\
\hline
\end{tabular}

The compressive strength of both moist and steam cured specimens was very high. Batch 2 was even stronger than batch 1, which was stronger than the Stalnaker Run bridge batch.

After 14 days, the freeze thaw prisms from steam curing and moist curing were subjected to the freeze thaw test according to ASTM C666. Due to the inadequate 
temperature cycling of batch 1 , the freeze thaw machine values for maximum and minimum temperatures were adjusted. The freezing cycle was extended by 10 minutes to ensure the machine reaches the target value. The maximum temperature was reduced to $15^{\circ} \mathrm{C}$ and the lowest temperature was reduced to $-34^{\circ} \mathrm{C}$. Each data point in Figure 4.16 indicates 10 minutes.

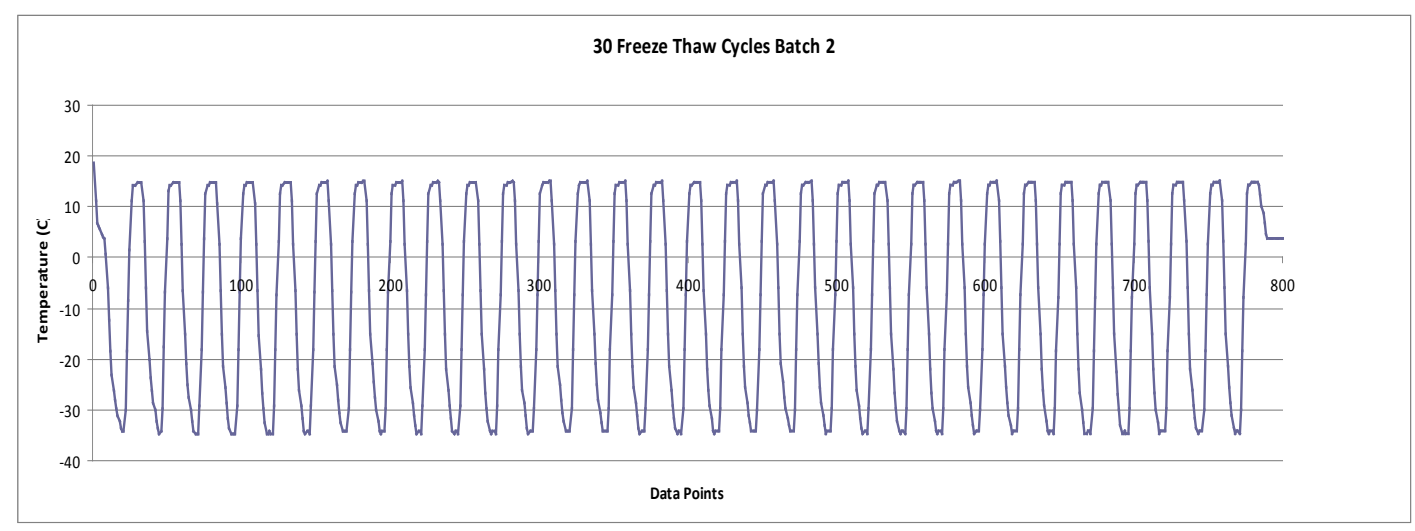

Figure 4.16 - Air Temperature of Freeze-Thaw Cycles

For this batch, the freeze thaw machine successfully reached the target temperatures. The core of the thermocouple prism also reached the ASTM required values for freezing and thawing. The thermocouple read a maximum core temperature of $3.5^{\circ} \mathrm{C}$ and a minimum core temperature of $-19.8^{\circ} \mathrm{C}$. Both the maximum and minimum core temperatures are within the limits of ASTM values, so this freeze thaw testing is acceptable.

After 30 cycles, the longitudinal frequency, transverse frequency, and mass were measured. The pattern of 30 cycles and testing continued until 300 cycles had elapsed. The results of freeze-thaw testing are shown in Figure 4.17. 


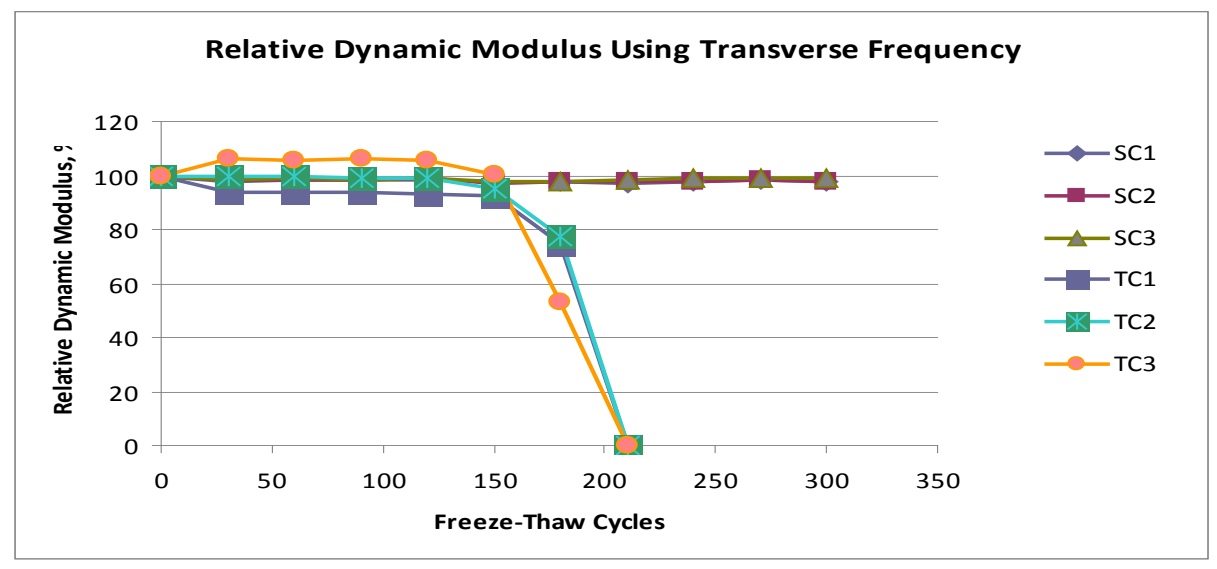

Figure 4.17 - Dynamic Modulus Using Transverse Frequency

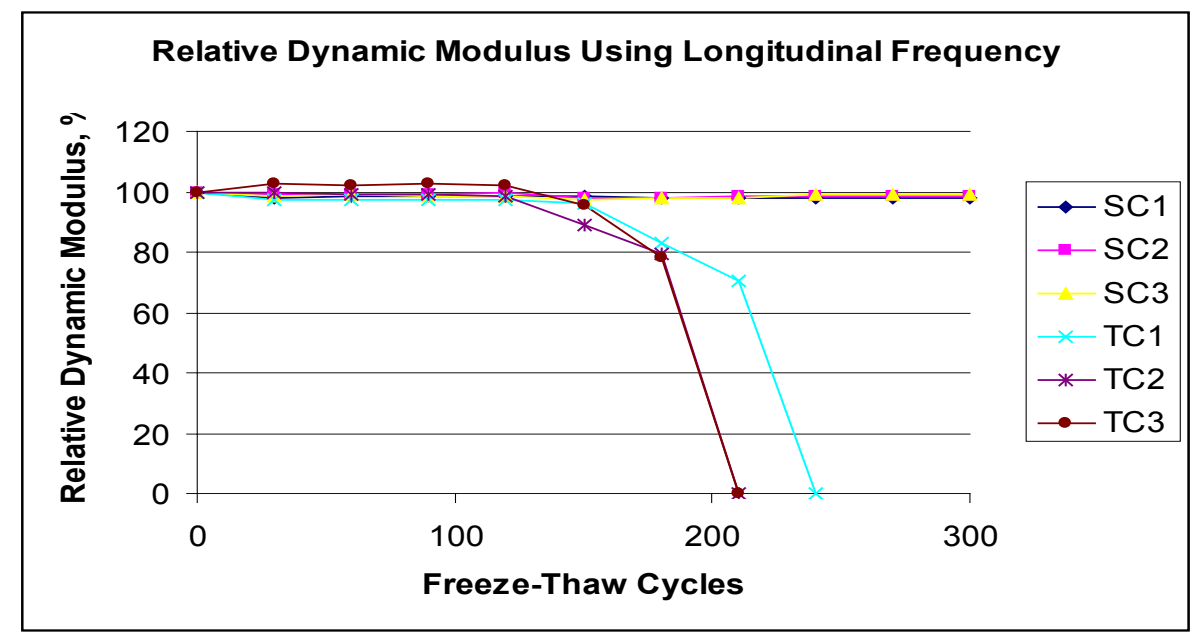

Figure 4.18 - Dynamic Modulus Using Longitudinal Frequency

ASTM states that if the relative dynamic modulus passes below $60 \%$, the test may be halted. After 180 cycles, TC3, a traditionally cured specimen, failed the test and the other traditional cured specimens exhibited decreasing dynamic moduli. Also, damages to every traditional cured specimen were observed after 180 cycles and are illustrated by Figure 4.19, Figure 4.20, and Figure 4.21. 


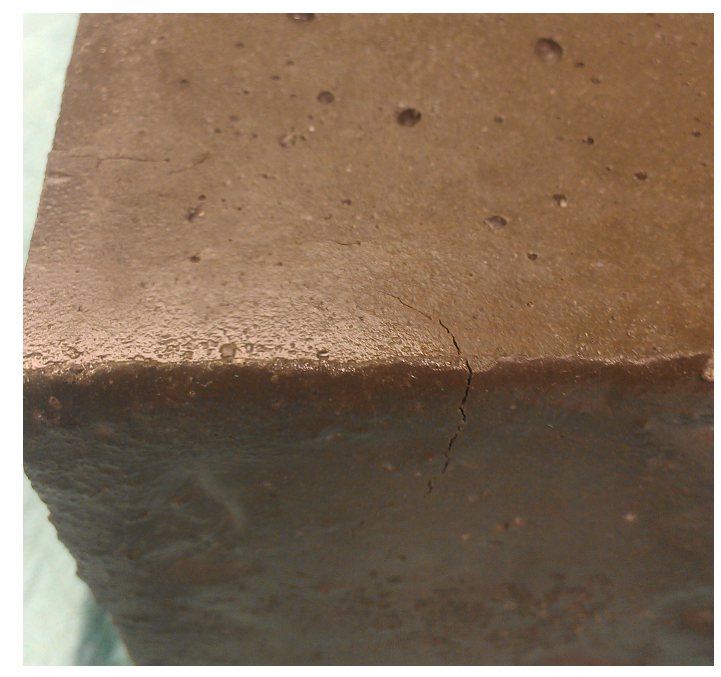

Figure 4.19 - Cracking after 180 cycles on TC1

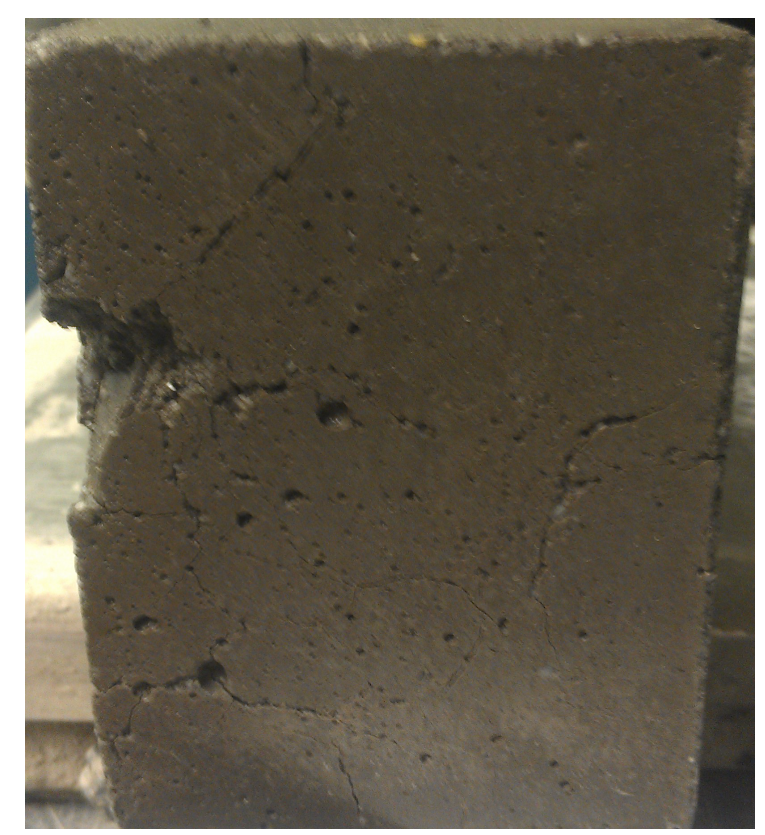

Figure 4.20 - Mass Loss and Cracking after 180 Cycles on TC2 


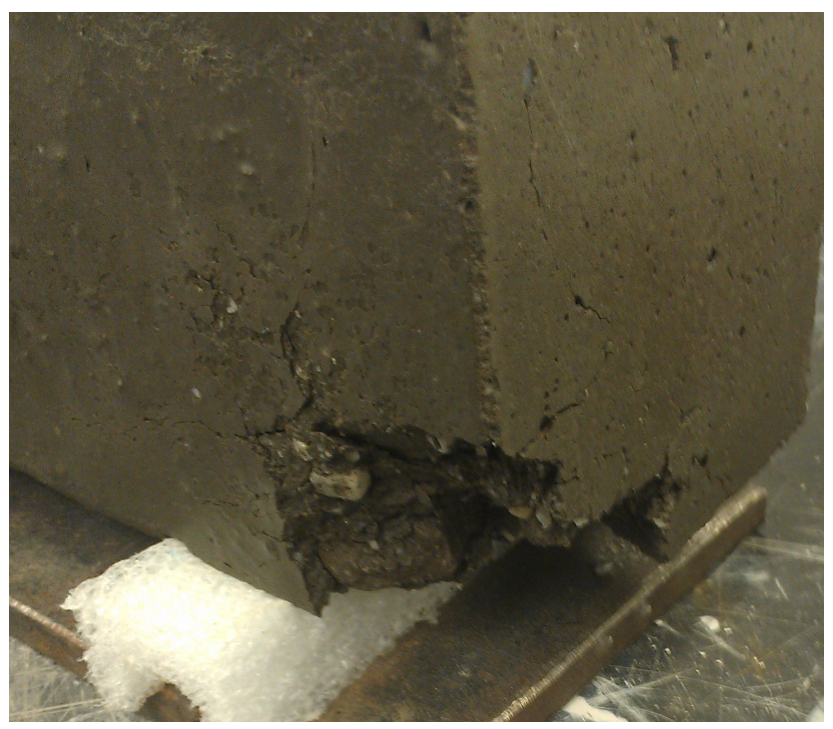

Figure 4.21 - Major Mass Loss and Cracking after 180 Cycles on TC3

After 220 cycles, the damage to every traditionally cured specimen was so catastrophic that the frequencies could not be measured. Both graphs show catastrophic failure in every single moist cured specimen, but excellent durability in every steam cured specimen. For testing the steam cured specimens up to 300 cycles, the failed specimens were placed inside the temperature to maintain a consistent thermal mass throughout the testing. This result gives credibility to the temperature cycling used in the freeze thaw test and also calls into question the temperature cycling used for the first batch. 


\subsection{Air Void Analysis Batch 2}

\subsubsection{Calibration}

Even though a recommended threshold value for batch 1 was generated, the recommended threshold to be used in batch 2 was generated to check the applicability of the threshold value. Because batch 2 images were scanned at a different time than batch 1, the threshold value may need to be different. Two surfaces, SC1_B1 and SC1_T1, were used to compare to the Bubble Counter script. The results shown in Figure 4.22 and Figure 4.23 show that the ideal threshold is between 230 and 240 .

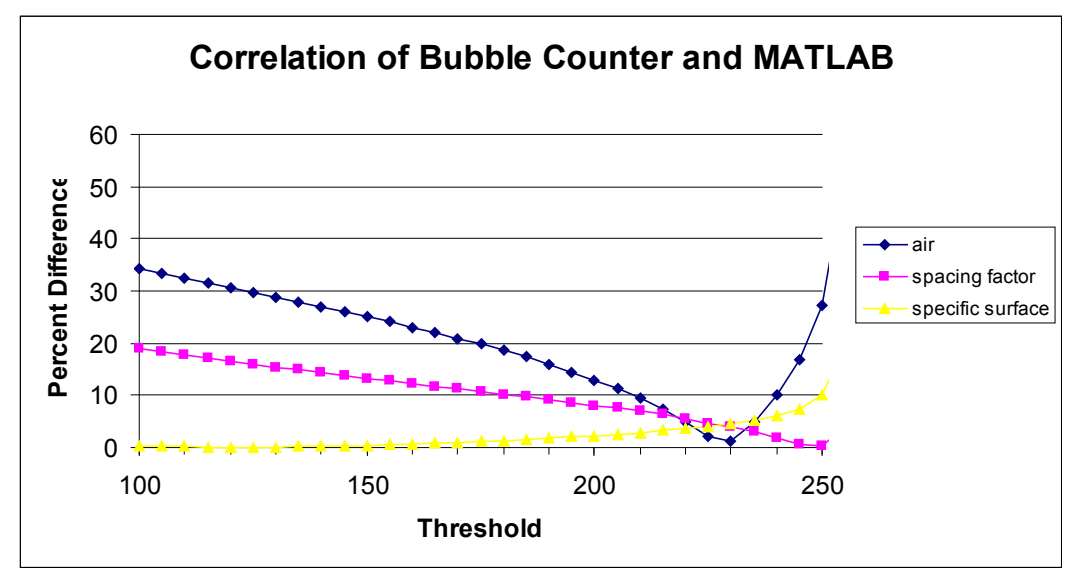

Figure 4.22 - Effect of Threshold on MATLAB Accuracy Trial 1 


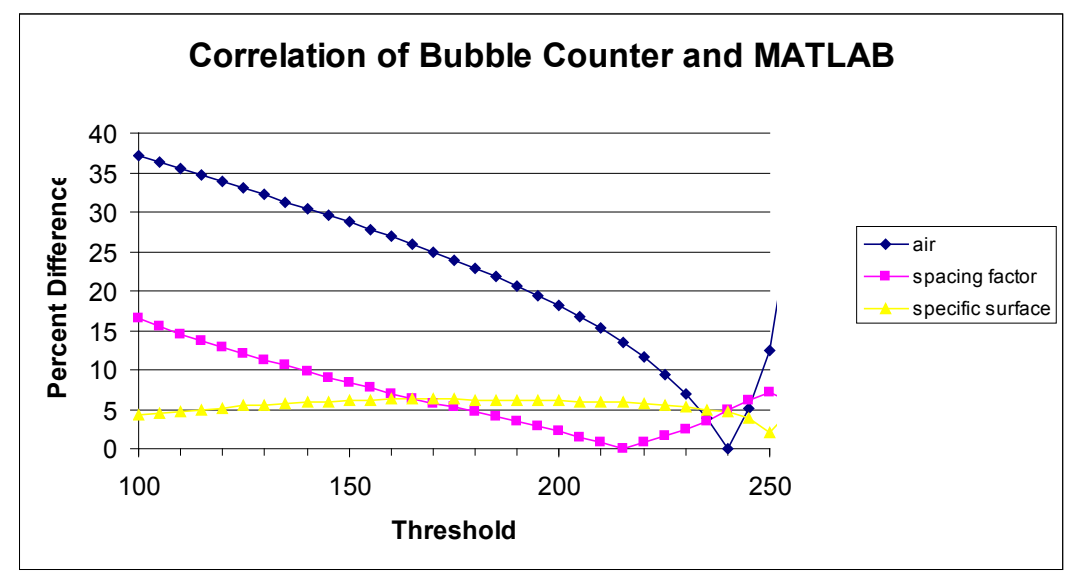

Figure 4.23 - Effect of Threshold on MATLAB Accuracy Trial 2

Using a threshold of 230 , the hardened air void properties for steam cured and traditional cured are shown.

Table 4.11 - Hardened Air Void Properties for Traditionally Cured Specimen

\begin{tabular}{|l|l|l|l|l|}
\hline & \multicolumn{2}{|l|}{ Vertical } & Horizontal \\
\hline TC1 - T1 & BC & MATLAB & BC & MATLAB \\
\hline Air Content & 1.68 & 1.838 & 1.68 & 1.838 \\
\hline Spacing Factor & 0.5955 & 0.623 & 0.6044 & 0.599 \\
\hline Specific Surface & 20 & 17.944 & 19.704 & 18.663 \\
\hline
\end{tabular}

\begin{tabular}{|l|l|l|l|l|}
\hline & \multicolumn{2}{|l|}{ Vertical } & Horizontal \\
\hline TC1 - B1 & BC & MATLAB & BC & MATLAB \\
\hline Air Content & 1.79 & 1.855 & 1.85 & 1.855 \\
\hline Spacing Factor & 0.5792 & 0.602 & 0.591 & 0.595 \\
\hline Specific Surface & 19.802 & 18.499 & 19.139 & 18.725 \\
\hline
\end{tabular}

Table 4.12 - Hardened Air Void Properties for Steam Cured Specimen

\begin{tabular}{|l|l|l|l|l|}
\hline \multicolumn{3}{|l|}{ Vertical } & Horizontal \\
\hline SC1 - T1 & BC & MATLAB & BC & MATLAB \\
\hline Air Content & 1.81 & 1.927 & 1.73 & 1.927 \\
\hline Spacing Factor & 0.5941 & 0.62 & 0.6027 & 0.602 \\
\hline Specific Surface & 18.868 & 18.679 & 18.957 & 18.217 \\
\hline
\end{tabular}




\begin{tabular}{|l|l|l|l|l|}
\hline & \multicolumn{3}{|l|}{ Vertical } & \multicolumn{2}{l|}{ Horizontal } \\
\hline SC1 - B1 & BC & MATLAB & BC & MATLAB \\
\hline Air Content & 1.89 & 1.937 & 1.87 & 1.937 \\
\hline Spacing Factor & 0.5454 & 0.542 & 0.5423 & 0.538 \\
\hline Specific Surface & 20.202 & 20.185 & 20.408 & 20.352 \\
\hline
\end{tabular}

The bubble size distributions for the 4 specimens are given in Appendix 1. The spacing factor, specific surface, and percent air content are all very similar. The spacing factor is almost equal for every specimen tested regardless of steam curing or traditional curing. The differences between the top and bottom of the $6 \times 12$ cylinder are negligible, indicating that segregation did not occur and the concrete was of desirable quality.

For every specimen, the spacing factor was significantly above the ASTM limit of $0.2 \mathrm{~mm}$. The specific surface of every specimen was below the minimum specific surface of 24 . In conclusion, the air void structure of the concrete batch 2 was found to be insufficient to resist freeze-thaw testing.

\subsection{Additional Testing}

Because the freeze thaw cycling of batch 1 did not reach the required maximum and minimum temperatures, the specimens from batch 1 were returned to the freeze thaw chamber to undergo 60 cycles with the corrected temperature cycles. The steam cured specimens from batch 2 were also tested to 360 cycles to demonstrate the effect that the additional cycles have on durable concrete specimens. 


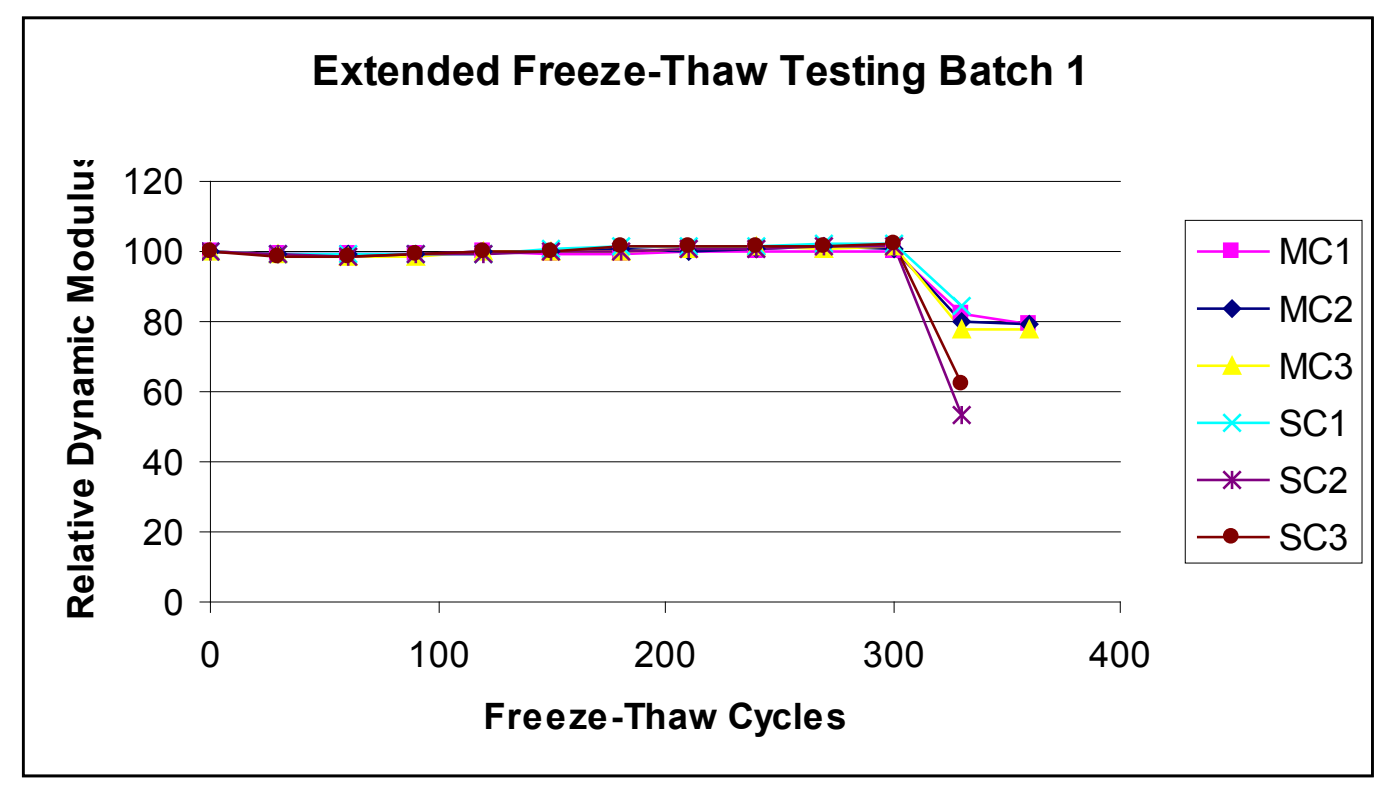

Figure 4.24 - Extended Freeze-Thaw Testing for Batch 1

The results shown in Figure 4.24 show an immediate drop in durability of every specimen after only 30 cycles of proper freezing and thawing. The steam cured specimens could not be accurately tested because of internal damage after 360 cycles and were deemed failed. The moist cured specimens declined sharply after 30 cycles and survived with $80 \%$ dynamic modulus after 360 total cycles. While the specimens survived, the immediate drop indicates that the specimens would not have survived 300 cycles of appropriate core temperature cycling. The steam cured specimens in batch 2 survived the additional 60 freeze thaw cycles with very minor, if any, loss in dynamic modulus. 


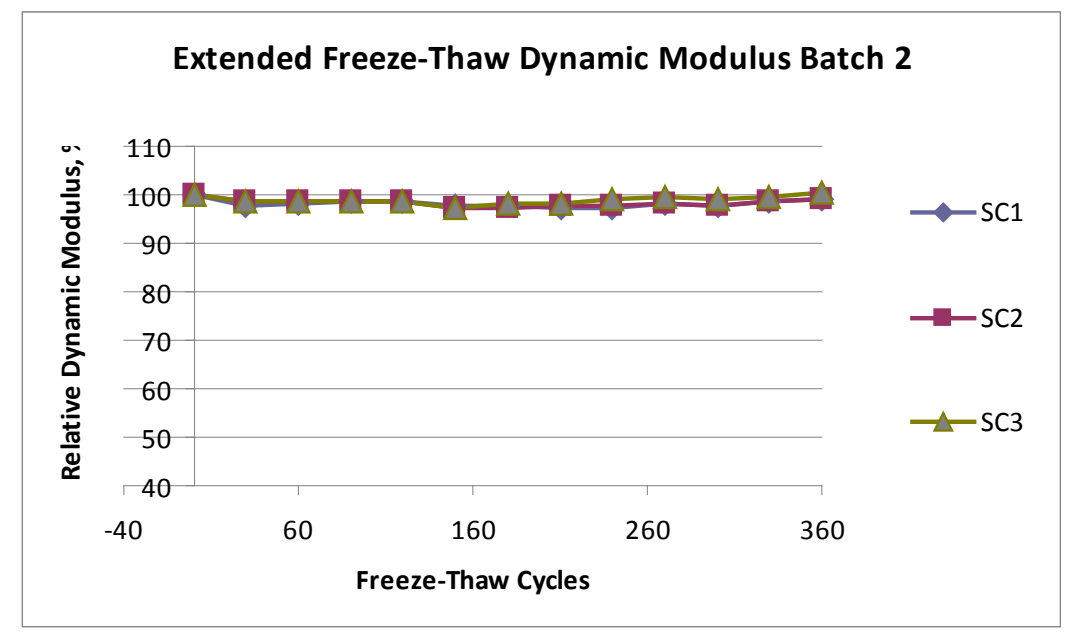

Figure 4.25 - Extended Freeze-Thaw Testing for Batch 2 


\section{CHAPTER 5 - CONCLUSIONS AND RECOMMENDATIONS}

\subsection{Conclusions}

Two batches of SCC were cast in the laboratory using the same materials as the concrete used in the Stalnaker Run bridge. Both batches exhibited lower air content $(1.09 \%-1.71 \%)$ than the bridge, which had an air content of 5.5\%, even though the amount of air entraining admixture (AEA) was as close as possible to the mix design. One possible explanation is that the AEA used was almost 2 years old when used in the laboratory. According to the admixture producer, the AEA has a shelf life of 18 months. The AEA's age could have rendered the admixture much less effective. Also, the mix showed signs of segregation while in the mixer. Air bubbles were observed escaping the surface of the concrete, which contributed to total air loss.

All of the specimens tested for freeze thaw with the exception of steam cured specimens in batch 2 failed freeze thaw testing when subjected to acceptable temperature variations. The spacing factor $(0.22-0.32 \mathrm{~mm})$ shown in Table 4.02, which is the most important property in relation to freeze thaw durability, correctly predicted that the specimens would fail under freeze thaw testing.

The steam cured specimens for batch 2 passed the freeze thaw test even though the air void structure present in those specimens was very similar to the traditionally cured specimens. This indicates that even if the air void spacing factor is too large, the 
concrete can still have good freeze thaw durability. One possible explanation is that because the concrete had such high strength (11-12.2 ksi), it could resist the freeze-thaw internal loading. Another possibility is that the concrete could have very low permeability.

A MATLAB program was successfully created to quickly perform the linear traverse analysis that conforms to ASTM C457. The accuracy of the MATLAB program can be as accurate as 5\% different from the Bubble Counter script. However, for future use, a means of calibrating the program to conform to every image is necessary. This necessity is shown in the varying thresholds needed for accuracy; for batch 1, the threshold needed was 200 but for batch 2 the threshold needed was 230. The program will need to be given a means of automatically determining the ideal threshold using the image.

The contribution of this research to the engineering and scientific community includes the following: the production of a digital air void analysis program using widely available software, freeze-thaw testing of SCC used in the field and developed in the laboratory, and the comparison of steam-cured concrete with ambient moist-cured concrete regarding freeze-thaw durability.

\subsection{Future Research Recommendations}

Future studies on the effects of steam curing SCC should be conducted to discover the cause of its survival after the freeze thaw cycles. The air void structure of the steam cured specimens indicated that they should fail in freeze thaw testing, but that 
was not the case. An automatic threshold calculator for the MATLAB program needs to be developed to enable the program to act independently without the need for verification from the Bubble Counter software. Future experimentation using multiple scanners and varying background lighting is necessary to achieve this threshold calculator. 


\section{REFERENCES}

ASTM Standard C39, 1999 (2012), "Standard Test Method for Compressive Strength of Cylindrical Concrete Specimens," ASTM International, West Conshohocken, PA, 1999, DOI: 10.1520/C0039_C0039M-12A, www.astm.org.

ASTM Standard C192, 2000 (2012), "Standard Practice for Making and Curing Concrete Test Specimens in the Laboratory," ASTM International, West Conshohocken, PA, 2000, DOI: 10.1520/C0192_C0192M-12A, www.astm.org.

ASTM Standard C215, 1997 (2002), "Standard Test Method for Fundamental Transverse, Longitudinal, and Torsional Resonant Frequencies of Concrete Specimens," ASTM International, West Conshohocken, PA, 1997, DOI: 10.1520/C0215-08, www.astm.org.

ASTM Standard C231, 1997 (2009b), "Standard Test Method for Air Content of Freshly Mixed Concrete by the Pressure Method," ASTM International, West Conshohocken, PA, 1997, DOI: 10.1520/C0231_C0231M-10, www.astm.org.

ASTM Standard C457, 1998 (2011), "Microscopical Determination of Parameters of the Air-Void System in Hardened Concrete," ASTM International, West Conshohocken, PA, 1998, DOI: 10.1520/C0457_C0457M-12, www.astm.org.

ASTM Standard C556, 1997 (2004), "Standard Test Method for Total Evaporable Moisture Content of Aggregate by Drying " ASTM International, West Conshohocken, PA, 1997, DOI: 10.1520/C0566-13, www.astm.org.

ASTM Standard C556, 1997 (2004), "Standard Test Method for Total Evaporable Moisture Content of Aggregate by Drying " ASTM International, West Conshohocken, PA, 1997, DOI: 10.1520/C0566-13, www.astm.org.

ASTM Standard C666, 1997 (2003), "Standard Test Method for Resistance of Concrete to Rapid Freezing and Thawing" ASTM International, West Conshohocken, PA, 1997, DOI: 10.1520/C0666_C0666M-03R08, www.astm.org.

ASTM Standard C1611, 2005 (2009b), "Standard Test Method for Slump Flow of SelfConsolidating Concrete" ASTM International, West Conshohocken, PA, 2005, DOI: 10.1520/C1611_C1611M-09BE01, www.astm.org. 
ASTM Standard C1621, 2006 (2009a), "Standard Test Method for Passing Ability of Self-Consolidating Concrete by J-Ring" ASTM International, West Conshohocken, PA, 2006, DOI: 10.1520/C1621_C1621M-09B, www.astm.org.

ASTM Standard C1758, 2011, "Standard Practice for Fabricating Test Specimens with Self-Consolidating Concrete " ASTM International, West Conshohocken, PA, 2011, DOI: 10.1520/C1758_C1758-11, www.astm.org.

Araki, M. (n.d.). PID control. In Control Systems, Robotics, and Automation (Vol. 2). Kyoto University.

Boel, A. (2003). Behaviour of self-compacting concrete concerning frosting action with de-icing salts. International rilem symposium on self-compacting concrete, Reykjavi'k, Iceland.

Carlson, J. (2005). Advancement on the application of a flat-bed scanner for hardened portland cement concrete air void analysis. (Master's thesis).

Carlson, J. (2005). Comparison of a flat-bed scanner and the rapidair 457 system for determining air-void system parameters of hardened concrete. Department of Civil and Environmental Engineering, Michigan Tech University.

Du, L., \& Folliard, K. J. (2004). Mechanisms of air entrainment in concrete. Cement and Concrete Research, 35, 1463-1471.

Ghafoori, N., \& Barfield, M. (2009). Effects of admixture type on air-entrained self consolidated concrete. In M. Grantham, V. Salomoni \& C. Majorana (Eds.), Concrete Solutions (pp. 97-100). London, England: Taylor \& Francis Group.

Hameed, M. A. (2005). A study of mix design and durability of self compacting concrete. (Master's thesis).

Hover, K. C. (2006). Air content and density of hardened concrete. Significance of Tests and Properties of Concrete and Concrete-Making Materials, (ASTM STP169D), 288-308.

Jana, D. (2001, May 20-24). A round robin test on measurements of air void parameters in hardened concrete by various automated image analyses and astm c 457 methods. Twenty-ninth conference on cement microscopy, Quebec City, PQ, Canada. 
Nawy, Edward G. (2008). Reinforced Concrete: A Fundamental Approach. Prentice Hall. 6th edition.

Naito, C., Brunn et al. (2005). Comparative performance of high early strength and self consolidating concrete for use in precast bridge beam construction. Final Report, Lehigh University,

Nmai, C. K. (1994). Freezing and thawing. Significance of Tests and Properties of Concrete and Concrete-Making Materials, (ASTM STP169D), 155-163.

Ouchi, M. (2003). Applications of self-compacting concrete in Japan, Europe and the United States ISHPC.

Ozyildirim, C. (2004). Air-void characteristics of concretes in different applications. Transportation Research Record, (1893), 70-74.

Powers, T.C. and Willis, T.F. The Air Requirement of Frost Resistant Concrete. Highway Research Board Proceedings. Highway Research Board. (1994) Vol 29, pp 184-211 .

Skarendahl, A. and Billberg, Peter. Final Report of RILEM Technical Committee 188CSC: Casting of Self Consolidating Concrete. "Requirements of Fresh SCC". Rilem Publications S.A.R.I. (2006)

U.H. Jakobsen, et al. Automated air void analysis of hardened concrete - a Round Robin study, Cement and Concrete Research, Volume 36, Issue 8, August 2006, Pages 14441452, ISSN 0008-8846, 10.1016/j.cemconres.2006.03.005.

Wang, Kejin. "Investigation into Freezing-Thawing Durability of Low-Permeability Concrete with and without Air Entraining Agent." Investigation into Freezing-Thawing Durability of Low-Permeability Concrete with and without Air Entraining Agent. (2009) 


\section{APPENDIX 1}
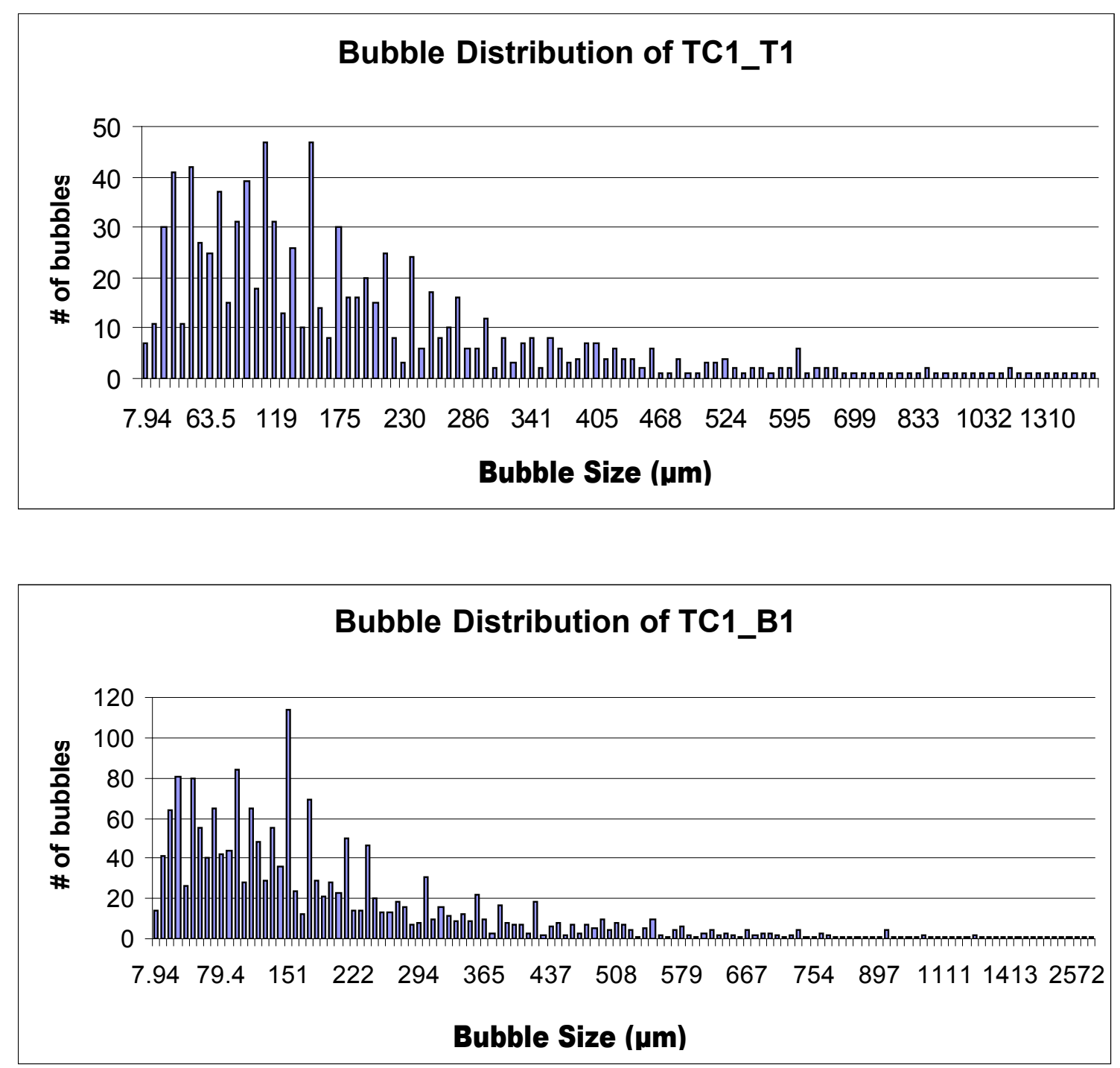

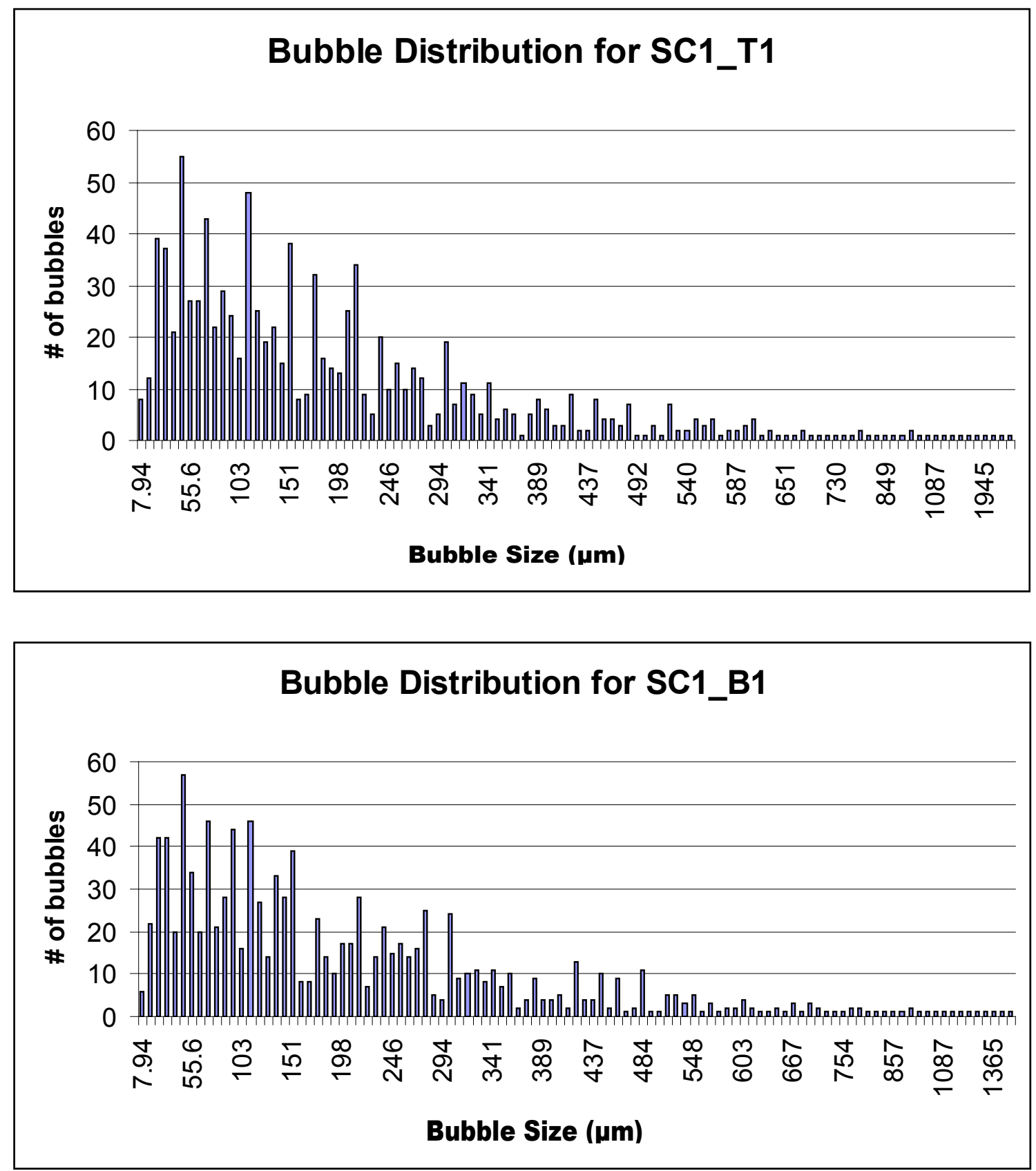


\section{APPENDIX 2}

\begin{tabular}{|l|l|l|}
\multicolumn{1}{c}{ Top } & Bottom \\
\hline & SCC1_1 & SCC2_1 \\
\hline Air Content & 5.31 & 4 \\
\hline $\begin{array}{l}\text { Spacing Factor } \\
(\mathrm{mm})\end{array}$ & 0.3127 & 0.5088 \\
\hline $\begin{array}{l}\text { Specific } \\
\text { Surface }(1 / \mathrm{mm})\end{array}$ & 22.727 & 45.936 \\
\hline
\end{tabular}




\section{APPENDIX 3}

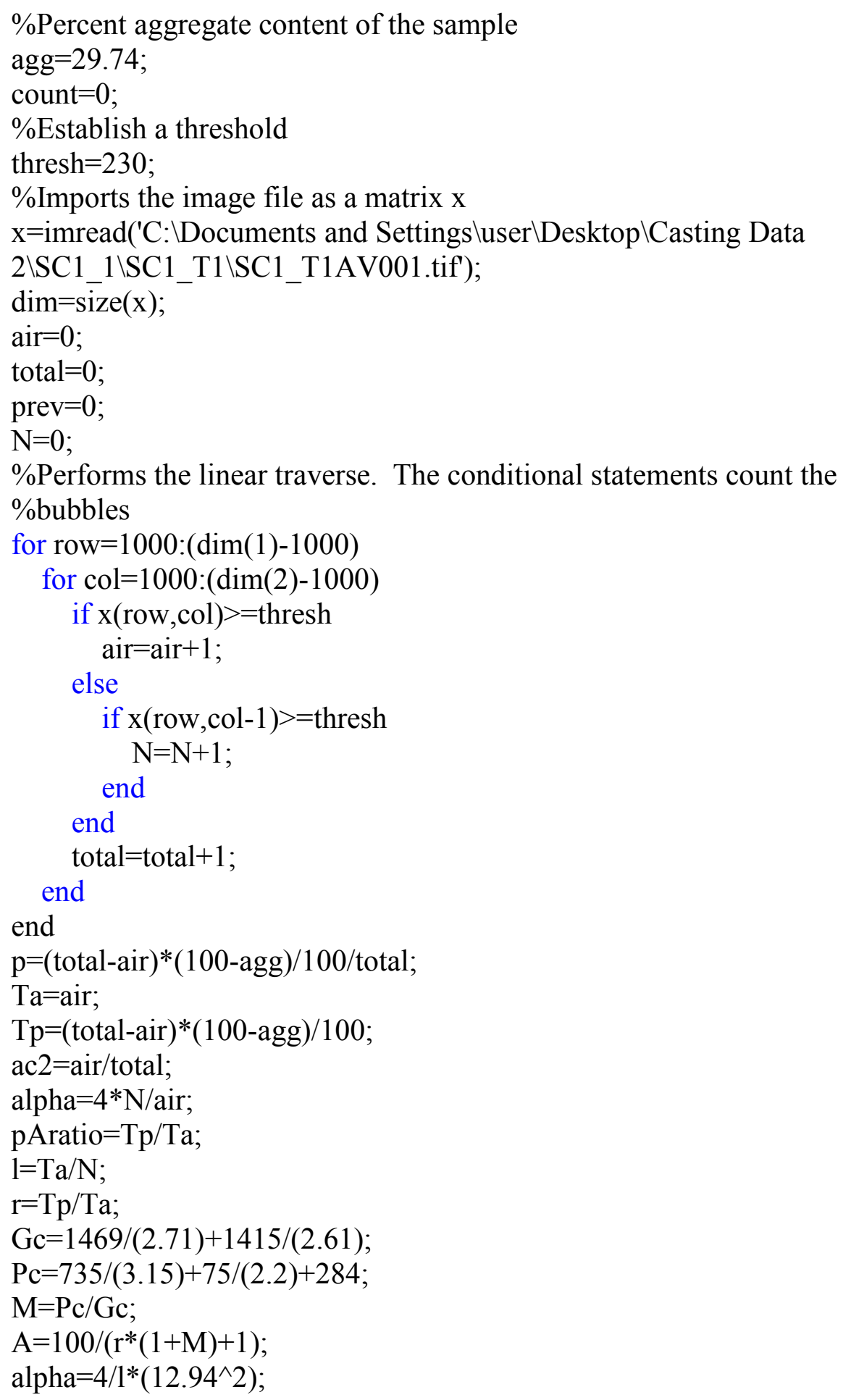


$\mathrm{L}=(3 / \mathrm{alpha}) *\left(1.4^{*}(1+\text { pAratio })^{\wedge}(1 / 3)-1\right)$

if pAratio $<=4.342$

disp('less than 4.342')

$\mathrm{sp} \_$factor $=\mathrm{p} /\left(4^{*} \mathrm{~N}\right)$;

else

sp_factor $=(3 /$ alpha $) *\left(1.4 *(1+\text { pAratio })^{\wedge}(1 / 3)-1\right)$;

end

fprintf('For Linear Traverse, air content is \%3.3f $\mathrm{fn} \backslash \mathrm{n}$ ',ac $2 * 100$ )

fprintf('For Linear Traverse, specific surface is \%3.3f $\mathrm{fn} \backslash \mathrm{n}$ ',alpha)

fprintf('For Linear Traverse, spacing factor is \%3.3f $\backslash n \backslash n$ ',sp_factor) 